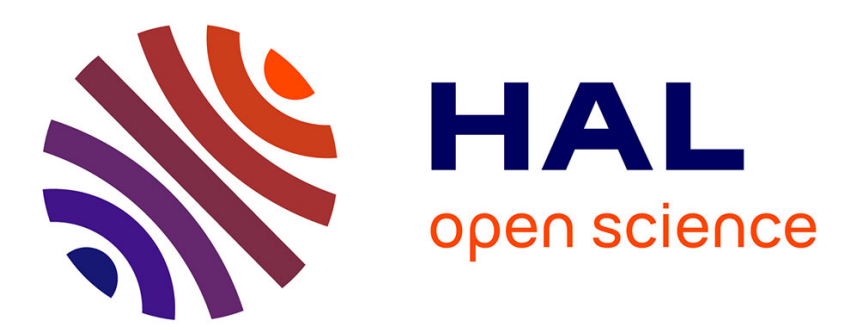

\title{
An Empirical Model of Bargaining with Equilibrium of Fear: Application to Retail Mergers in the French Soft Drink Industry
}

Céline Bonnet, Zohra Bouamra-Mechemache, Hugo Molina

\section{To cite this version:}

Céline Bonnet, Zohra Bouamra-Mechemache, Hugo Molina. An Empirical Model of Bargaining with Equilibrium of Fear: Application to Retail Mergers in the French Soft Drink Industry. 2021. hal03375907

\section{HAL Id: hal-03375907 https: / hal.inrae.fr/hal-03375907}

Preprint submitted on 13 Oct 2021

HAL is a multi-disciplinary open access archive for the deposit and dissemination of scientific research documents, whether they are published or not. The documents may come from teaching and research institutions in France or abroad, or from public or private research centers.
L'archive ouverte pluridisciplinaire HAL, est destinée au dépôt et à la diffusion de documents scientifiques de niveau recherche, publiés ou non, émanant des établissements d'enseignement et de recherche français ou étrangers, des laboratoires publics ou privés. 


\title{
An Empirical Model of Bargaining with Equilibrium of Fear: Application to Retail Mergers in the French Soft Drink Industry*
}

\author{
Céline Bonnet $^{\dagger}$ Zohra Bouamra-Mechemache Hugo Molina $^{\S}$
}

October 8, 2021

\begin{abstract}
We develop a framework of bilateral oligopoly with a sequential two-stage game in which manufacturers engage in bilateral bargains with retailers competing on a downstream market. We show that bargaining outcomes depend on three different bargaining forces and can be interpreted in terms of "equilibrium of fear". We estimate our framework using data on soft drink purchases in France and find that retailers have a higher bargaining power than manufacturers. Using counterfactual simulations, we highlight that retail mergers always increase retailers' fear of disagreement which weakens their bargaining power vis-à-vis manufacturers and leads to higher wholesale and retail prices.
\end{abstract}

Keywords: Bilateral oligopoly, Bargaining, Retail mergers, Soft drink industry.

JEL classification: C78, D43, L11, L13, L14, L41, L81.

*We would like to thank Stéphane Caprice, Claire Chambolle, Philippe Choné, Xavier D’Haultfœuille, Olivier de Mouzon, Alon Eizenberg, Sebastian Fleitas, Germain Gaudin, Gautam Gowrisankaran, Alessandro Iaria, Alessandro Ispano, Yassine Lefouili, Laurent Linnemer, Julien Monardo, Patrick Rey, Howard Smith, Frank Verboven, Thibaud Vergé, and Ao Wang for helpful discussion as well as seminar and workshop participants at CREST, Toulouse School of Economics, and Düsseldorf Institute for Competition Economics for their comments. We acknowledge funding from ANR under grant ANR-17-EURE-0010 (Investissements d'Avenir program). All remaining errors are ours.

†Toulouse School of Economics, INRAE, 1, Esplanade de l’Université 31000 Toulouse, France; celine.bonnet@tse-fr.eu; https://www.tse-fr.eu/people/celine-bonnet

†Toulouse School of Economics, INRAE, 1, Esplanade de l’Université 31000 Toulouse, France; zohra.bouamra@tse-fr.eu; https://www.tse-fr.eu/people/zohra-bouamra-mechemache

§Université Paris-Saclay, INRAE, UR ALISS, 94205, Ivry-sur-Seine, France; hugo.molina@inrae.fr; https://sites.google.com/site/hugomolinaresearch/ 


\section{Introduction}

In a large number of industries, manufacturers deal with intermediaries to distribute their products to consumers. ${ }^{1}$ Such vertical structures often exhibit "interlocking relationships" where competing manufacturers sell their products through the same competing retailers. Terms of trade are also determined via bilateral bargains rather than set solely by either manufacturers or retailers. Despite the complexity of such market environments, understanding how firms interact with each other at different levels of the supply chain is critical for policymakers and antitrust agencies.

Of particular interest is the rise of large retailers and intermediaries which has generated debates of whether buyer power is a cause of concern. For instance, the food retail sector has undergone profound changes with the emergence of private labels (store brands) and the formation of retail mergers and buyer alliances in many European countries (Colen et al., 2020). Hospital markets in the U.S. have also become increasingly concentrated over the last 25 years (Gaynor, Ho and Town, 2015). According to the conventional wisdom, buyer power confers an ability for retailers to counteract the market power of manufacturers and pass on this benefit to consumers (Galbraith, 1952). Mechanisms underlying buyer power are, however, ambiguous and empirical evidence sparse, implying that the proper antitrust treatment of buyer power remains to date an unsettled question (Carlton and Israel, 2011). ${ }^{2}$

This article provides a general framework for analyzing bilateral oligopolies with product differentiation. Our framework includes a two-stage game in which multiple manufacturers engage in simultaneous and secret bilateral negotiations with multiple retailers to determine wholesale prices and where the latter subsequently compete in retail prices for consumers. Using the "Nash-in-Nash" bargaining solution (Horn and Wolinsky, 1988) as a surplus sharing rule in the vertical chain, we show that bargaining outcomes directly relate to the concept of "equilibrium of fear" introduced by Aumann and Kurz (1977) and Svejnar (1986). In particular, our framework embeds three different sources of bargaining power. First, a firm's bargaining power increases when its gains from trade decrease (i.e., its losses from not reaching an agreement are smaller) or when the gains of its trading partner increase. Second, a firm's bargaining power is greater the higher its cost of making price concessions (that is, agreeing to concede more favorable trading terms to its partner)

\footnotetext{
${ }^{1}$ Prominent examples include the food retail sector, the pharmaceutical industry, the cable television market, the smartphone industry, the car market, or the health care sector.

${ }^{2}$ For instance, the Federal Trade Commission and the U.S. Department of Justice have adopted conflicting views on the treatment of buyer power in recent merger reviews (Hemphill and Rose, 2018).
} 
relative to that of its trading partner. ${ }^{3}$ Third, we allow for asymmetric bargaining weights in each bilateral negotiation to capture the ability of firms to get more favorable trading terms. ${ }^{4}$ Despite the richness of our framework, we are able to derive closed-form expressions for the price-cost margins of manufacturers determined through bilateral bargains, which is particularly convenient for applied work.

To illustrate how our bilateral oligopoly framework can be taken to data, we use consumerlevel scanner data on soft drink purchases in France. Besides our illustrative purposes, the soft drink industry constitutes an interesting laboratory for studying manufacturer-retailer relationships. First, its upstream market is one of the most concentrated of the French agri-food sector. ${ }^{5}$ Second, upstream firms supply brands which are often deemed as having "must-have" status for retailers due to consumer brand loyalty. ${ }^{6}$ These particular features of the soft drink industry imply that upstream firms may be able to keep exerting market power despite the presence of large retailers. To estimate the distribution of bargaining power between retailers and soft drink manufacturers, we use a structural model of demand and supply. The demand-side includes a random coefficient logit model which allows for unobserved heterogeneity in consumer preferences. The supply-side is directly based on our bilateral oligopoly framework.

Absent data on wholesale contracts negotiated between manufacturers and retailers, our empirical strategy relies on demand estimates as well as on the set of first-order conditions characterizing the pricing behavior of retailers on the downstream market to back out retail marginal costs for each soft drink product (e.g., Villas-Boas, 2007). Using these (inferred) marginal costs, we then specify the marginal cost function of retailers in terms of two components. The first component corresponds to the marginal cost of production and distribution for soft drink products (operational costs). Following Gowrisankaran, Nevo and Town (2015), we assume that such costs are constant in quantity and incorporate a structural error term capturing unobserved cost factors. The second component of this marginal cost function is the price-cost margins of manufacturers determined through bilateral negotiations with retailers and derived from the "Nash-in-Nash" solution. We thus build an econometric framework to explain the variation in (inferred) marginal costs of retailers by

\footnotetext{
${ }^{3}$ In other words, a firm's concession cost reflects how its profit decreases when it agrees to grant a better price to its trading partner.

${ }^{4}$ Following Grennan's (2013) terminology, we refer to this source of bargaining power as the bargaining ability of firms.

${ }^{5}$ See European Commission (2014, page 306).

${ }^{6}$ As pointed out by the European Commission (2007, page 34): "Just a small number of food products have a recognised brand value. Coca Cola, the number 1 global brand, is a frequently mentioned and well recognised example. The top 50 global brands include 7 food products, mainly beverages."
} 
heterogeneity in operational costs of products as well as differences in the ability of manufacturers to exert market power and charge wholesale unit prices above their marginal production costs. Based on (plausibly) exogenous variation that shifts price-cost margins of manufacturers but not marginal costs, we form moment conditions to estimate bargaining and cost parameters and recover the surplus division between manufacturers and retailers in the vertical chain.

Our results indicate that more than 65 percent of the surplus generated by bilateral contracts is captured by retailers, suggesting that they have more bargaining power than soft drink manufacturers. We mainly explain this distribution of bargaining power by the fact that retailers have larger costs from making price concessions during negotiations than manufacturers. Using estimates of our structural model, we simulate (hypothetical) retail mergers generating multi-store retailers and analyze their impact on buyer power and retail prices paid by consumers. To explore the buyer power effect of these operations, we leverage the concept of "equilibrium of fear" and find that retail mergers always increase the fear of disagreement of the merged retailer relative to that of manufacturers, suggesting that the former should systematically pay higher wholesale prices after the merger. We show that this bargaining effect stems from the decrease in the concession costs of the merging retailers, which reduces their bargaining power vis-à-vis manufacturers. This result is supported by counterfactual simulations in which we recalculate a new bargaining and downstream price equilibrium following a retail merger. Despite this loss of bargaining power vis-à-vis manufacturers, our simulations further show that retail mergers remain profitable due to a lessening of downstream competition. As a result, our analysis do not provide any support for the use of buyer power as a defense for retail mergers which, instead, raise substantial antitrust concerns due to the increase of market power at both the upstream and the downstream level of the supply chain.

Our article provides a methodological contribution to the recent empirical literature on buyer-seller bargaining in bilateral oligopolies. Since Draganska, Klapper and Villas-Boas (2010), a large number of articles have adopted the timing assumption that wholesale and retail prices are determined simultaneously to simplify the estimation and computation of the "Nash-in-Nash" bargaining model (see, e.g., Ho and Lee, 2017; Crawford et al., 2018; Noton and Elberg, 2018; Sheu and Taragin, 2021). While reasonable in the presence of retail price stickiness, it does not reflect well the functioning of vertical markets in which retailers can easily change retail prices of products. Our article highlights that this simultaneous timing assumption imposes strong restrictions on the concession costs of firms in 
bilateral negotiations which, in turn, have important consequences for merger analysis. A notable exception is the bilateral oligopoly framework of Crawford and Yurukoglu (2012) which, like ours, includes a sequential timing where retailers are able to observe wholesale prices and optimally adjust their pricing behavior accordingly. ${ }^{7}$ We differ from Crawford and Yurukoglu (2012) in two important aspects. First, we allow for the presence of marginal cost of production and distribution, which contrasts with their approach assuming no marginal costs. Second, we derive analytical expressions for the price-cost margins of manufacturers which considerably ease the estimation of our model as well as the computational burden of counterfactual simulations involving a new bargaining and downstream price equilibrium.

Our article also contributes to the extensive literature on buyer power (see Snyder, 2008 and Smith, 2016 for recent surveys). Since Galbraith (1952, 1954) and his concept of countervailing buyer power, a large number of articles have analyzed circumstances under which mergers between retailers mitigate upstream market power and may generate pro-competitive effects. Our article is more specifically related to the stream of research that studies mergers among competing retailers. ${ }^{8}$ Theoretical work has highlighted that the emergence of countervailing buyer power depends on particular market conditions such as the degree of product differentiation (Dobson and Waterson, 1997), the nature of downstream competition and the observability of bargaining breakdowns (Iozzi and Valletti, 2014), or the pass-through rate of wholesale to retail prices (Gaudin, 2018). Despite the lack of clear theoretical predictions, empirical works on this topic remain fairly limited. Our empirical analysis is closely related to two recent articles which examine the impact of downstream concentration using structural models of bilateral oligopoly with "Nash-inNash" bargaining. ${ }^{9}$ Ho and Lee (2017) simulate the effects of the removal of a downstream firm on market outcomes and find evidence that countervailing buyer power effects depend on the competitiveness of the firm being removed. ${ }^{10}$ Focusing on the effects of horizon-

\footnotetext{
7 Yang (2020) develops an empirical dynamic model of innovation that embeds a static framework of vertical relations which also considers a sequential timing. We differ from his approach in many dimensions. First, we allow for upstream competition. Second, our estimation method does not involve a calibration routine requiring information on upstream price-cost margins and marginal costs. Third, we assume that bargaining breakdowns between manufacturers and retailers entail product removals.

${ }^{8}$ Another strand of the literature focuses instead on settings where retailers operate in separate markets. Among others, it has been shown that countervailing buyer power may arise when marginal production costs are convex (Chipty and Snyder, 1999; Inderst and Wey, 2003) or when the merging retailers adopt a singlesourcing policy forcing manufacturers to compete for exclusivity (Inderst and Shaffer, 2007; Dana, 2012).

${ }^{9}$ Along the structural approach, reduced-form analysis have also been used to study the impact of downstream concentration on market outcomes (see, e.g., Chorniy, Miller and Tang, 2020; Craig, Grennan and Swanson, 2021). These articles document mixed evidence on countervailing buyer power effects.

${ }^{10}$ More precisely, countervailing buyer power effects arise only upon the removal of a weak downstream firm which generates limited upward pressure on downstream prices, implying that the gains from trade
} 
tal and vertical mergers in bilateral oligopolies, Sheu and Taragin (2021) find that retail mergers improve the bargaining power of retailers by decreasing their relative gains from trade. We show, however, that this result hinges on their simultaneous timing assumption which precludes the concession costs of firms to play a role in the post-merger bargaining outcome. ${ }^{11}$ By offering an empirical framework which explicitly accounts for this source of bargaining power in a tractable way, our article highlights that changes in the concession costs of firms can rule out the countervailing buyer power effect of retail mergers identified in Sheu and Taragin (2021). We thus complement prior antitrust work on buyer power in showing that it is very unlikely to offset the standard upward pressure on retail prices caused by a reduction of competition, an argument often debated in merger litigation both in Europe and in the United States. ${ }^{12}$

The remainder of this article is organized as follows. Section 2 introduces our bilateral oligopoly framework. Section 3 describes our empirical application to the French soft drink industry, discusses identification and estimation of model parameters, and presents the empirical results. Section 4 is devoted to the analysis of retail mergers and Section 5 concludes. Technical proofs and other materials are deferred to the Appendix of the article.

\section{A model of bilateral oligopoly}

To analyze bilateral oligopolistic markets, we develop a flexible framework involving "interlocking relationships" in which multi-product manufacturers engage in bilateral negotiations with multi-product retailers competing in retail prices for consumers. Our framework embeds three sources of bargaining power, accounts for the effects of negotiated wholesale prices on downstream competition, and does not impose any restriction on the (constant) marginal costs of production and distribution. We further show that it admits a bargaining

of the remaining downstream firms are less likely to increase relative to that of the upstream firms. Ho and Lee (2017) further show that this countervailing force decreases downstream prices only when they are determined via bilateral bargains.

${ }^{11}$ Note also that Sheu and Taragin (2021) use a calibration routine to estimate model parameters which requires the observation of one upstream and downstream margin. As emphasized in footnote 7, our approach only requires data on market shares and retail prices as in Berry, Levinsohn and Pakes (1995) and the ensuing literature.

${ }^{12}$ The buyer power defense is incorporated in the horizontal merger guidelines of the U.S. Department of Justice and the Federal Trade Commission (Sections 8 and 12) and the European Commission (Sections IV.4 and V). It has also been discussed in a number of merger cases including Kesko/Tuko (1996) - Case No IV/M.784; Rewe/Meinl (1999) - Case No IV/M.1221; Anthem/Cigna (2017) - United States v. Anthem, Inc., 236 F. Supp. 3d 171 (D.D.C. 2017); Tesco Plc/Booker Group Plc, Competition and Markets Authority (CMA) decision of 20 December 2017; J Sainsbury Plc/Asda Group Ltd., CMA decision of 25 April 2019. 
equilibrium outcome with an analytically tractable form and an intuitive interpretation.

Formally, we consider a market, indexed by $t$, in which $F$ multi-product manufacturers, indexed by $f=1, \ldots, F$, sell their brands to $R$ multi-product retailers, indexed by $r=1 \ldots, R$, which resell to consumers. Assuming that a product consists of a brand-retailer combination, each consumer on the market chooses among a set $\mathscr{J}_{t} \equiv\left\{0,1, \ldots, J_{t}\right\}$ of differentiated products. ${ }^{13}$ Let $\mathscr{J}_{f t}$ denotes the set of products owned by manufacturer $f$ and $\mathscr{J}_{r t}$ the set of products distributed by retailer $r$ such that $\bigcup_{f=1}^{F} \mathscr{J}_{f t}=\bigcup_{r=1}^{R} \mathscr{J}_{r t}=\mathscr{J}_{t} \backslash\{0\}$.

Timing, information, and solution concept. Interactions between manufacturers and retailers are described by the following two-stage game:

- Stage 1: Manufacturers and retailers engage simultaneously and secretly in bilateral bargains to determine wholesale prices of products.

- Stage 2: Retailers compete in retail prices on the downstream market.

To determine wholesale prices in the vertical chain, we leverage the "Nash-in-Nash" bargaining solution pioneered by Horn and Wolinsky (1988) which has been extensively used in applied work to deal with the presence of contracting externalities (see, e.g., Crawford and Yurukoglu, 2012; Grennan, 2013; Gowrisankaran, Nevo and Town, 2015; Ho and Lee, 2017). ${ }^{14,15}$ This bargaining concept can be seen as the solution of a delegated agent model in which firms assign distinct delegates to each bilateral negotiation and where each pair of delegates negotiates according to the Nash's axiomatic theory of bargaining (Nash, 1950) taking as given the outcome of other bilateral negotiations. It thus implies that firms behave "schizophrenically" (that is, delegates coming from the same firm are unable to communicate with one another during the course of negotiations) and contracts are binding. ${ }^{16}$ In the downstream market, we consider a retail price competition with "interim unobservability", which refers to an information structure in which the outcome of each retailer's negotiations

\footnotetext{
${ }^{13}$ We define product 0 as the outside option to the $J_{t}$ products in the choice set of consumers.

${ }^{14}$ The terminology "Nash-in-Nash" has been introduced by Collard-Wexler, Gowrisankaran and Lee (2019) because this solution concept can be interpreted as a Nash equilibrium in wholesale prices negotiated by pairs of firms according to the Nash's axiomatic theory of bargaining. It is similar in spirit to the concept of "contract equilibrium" pioneered by Crémer and Riordan (1987) (see also O’Brien and Shaffer, 1992).

${ }^{15}$ Contracting externalities arise because the upstream and downstream competition imply that the bargaining outcome for a given manufacturer-retailer pair affects the surplus division in other negotiations.

${ }^{16}$ In the spirit of the "passive beliefs" introduced in McAfee and Schwartz (1994), this delegation game implies that agents never revise their beliefs about other secret deals even when an unexpected outcome arises from their bilateral negotiation (e.g., bargaining breakdown).
} 
remains unobserved to other retailers (Rey and Vergé, 2004, 2020; Gaudin, 2019). ${ }^{17}$ Hence, any (unexpected) change in wholesale prices paid by one retailer does not affect the pricing behavior of other retailers. However, absent retail price inertia, we consider that each retailer sets retail prices conditional on the outcomes of its negotiations with manufacturers. We refer to Rey and Vergé (2020) for a microfoundation of this bargaining game using a random-proposer procotol. Assuming complete information about (constant) marginal costs of production and distribution, we solve this two-stage game by working backwards.

Contractual form. We restrict the contractual form between manufacturers and retailers to linear wholesale prices. Even though such a simple payment scheme generates double marginalization, a body of empirical work has provided evidence of its use in numerous vertical markets. ${ }^{18,19}$ We however acknowledge that extending our empirical framework to nonlinear wholesale contracts raise important identification issues that are beyond the scope of this article. ${ }^{20}$

\footnotetext{
${ }^{17}$ Alternative information structures have been proposed in the literature such as "observable breakdowns" in which bargaining breakdowns are observed before retail price competition takes place (Iozzi and Valletti, 2014) and "interim observability" where all bargaining outcomes are revealed (Rey and Vergé, 2004). Following Iozzi and Valletti (2014), the "interim unobservability" assumption is more in line with the retail grocery industry that we consider in our application (Section 3) as negotiation failures will probably not be immediatly observed by competing retailers.

${ }^{18}$ Luco and Marshall (2020) provide (indirect) evidence of the presence of linear wholesale prices in the U.S. carbonated-beverage industry. Noton and Elberg (2018) observe wholesale unit prices negotiated between manufacturers and retailers in the Chilean coffee market. Smith and Thanassoulis (2015) provide interviewbased evidence of the use of linear tariffs in the UK liquid milk industry. Outside the food industry, simple linear prices have also been either observed or considered as a good approximation of the contractual form used in the U.S. healthcare sector (Grennan, 2013; Gowrisankaran, Nevo and Town, 2015; Ho and Lee, 2017), the U.S. television multichannel industry (Crawford and Yurukoglu, 2012; Crawford et al., 2018), or the U.S. video rental industry (Mortimer, 2008).

${ }^{19}$ Several rationales have also been advanced to justify the use of such simple contracts in bilateral oligopolies. For instance, Crawford and Yurukoglu (2012) argue that committing to linear wholesale prices can be a means to avoid the dissipation of profits when the downstream competition is fierce. In the presence of demand uncertainty and risk averse retailers, double marginalization may also arise to reduce the sensitivity of retailers' profits to demand variations (Rey and Tirole, 1986).

${ }^{20}$ In particular, Rey and Vergé (2020) have shown that nonlinear tariffs are always cost-based in bilateral oligopolies with secret contracting (i.e., marginal wholesale prices reflect marginal costs of production). This implies that the distribution of bargaining power in the vertical chain never affects the marginal costs of retailers and, in turn, retail prices which are the primary source of variation that we exploit to identify parameters in our "Nash-in-Nash" bargaining model (see Section 3).
} 
Profit functions. We define respectively the (per-market) profit function of manufacturer $f$ and retailer $r$ as follows:

$$
\begin{aligned}
\pi_{f t} & \equiv \sum_{j \in \mathscr{I}_{f t}}\left(w_{j t}-\mu_{j t}\right) q_{j t}\left(\mathbf{p}_{t}\right) \\
\pi_{r t} & \equiv \sum_{j \in \mathscr{I}_{r t}}\left(p_{j t}-w_{j t}-c_{j t}\right) q_{j t}\left(\mathbf{p}_{t}\right)
\end{aligned}
$$

where $w_{j t}$ is the wholesale price of product $j$ in market $t, \mu_{j t}$ and $c_{j t}$ are respectively the (constant) marginal cost of production and distribution for product $j$ in market $t$, and $q_{j t}$ is the corresponding demand written as a function of retail prices denoted by the $J_{t^{-}}$ dimensional vector $\mathbf{p}_{t}$. For expositional purpose, we take demand as a primitive of our bilateral oligopoly model and defer to Section 3.2.1 for an application to the French soft drink industry.

\subsection{Stage 2: Downstream price competition}

We assume that retail prices are determined in a pure-strategy Nash equilibrium where retailers hold consistent beliefs about wholesale contracts of their rivals. ${ }^{21,22}$ From the maximization problem of each retailer's profit function (1b), we can derive the set of first-order conditions characterizing equilibrium retail prices in market $t$ as follows:

$$
q_{k t}\left(\mathbf{p}_{t}\right)+\sum_{j \in \mathscr{g}_{r}(k) t}\left(p_{j t}-w_{j t}-c_{j t}\right) \frac{\partial q_{j t}}{\partial p_{k t}}=0 \quad \forall k \in \mathscr{J}_{t} \backslash\{0\}
$$

where $r(k)$ indexes the retailer distributing product $k$. Following Berry and Haile (2014), price-cost margins and marginal costs of retailers can be directly recovered from (2) when demand is continuously differentiable with respect to retail prices and products are "connected substitutes". ${ }^{23}$ Importantly, they stress that such conditions for invertibility of (2) do not place any restriction on the structure of retailers' marginal costs which are fundamental ingredients for the determination of the surplus division in our empirical framework.

\footnotetext{
${ }^{21}$ We follow the empirical literature on oligopoly pricing with differentiated products and assume existence of a Nash equilibrium in pure strategies (e.g., Berry, Levinsohn and Pakes, 1995; Nevo, 2001).

${ }^{22}$ Following Rey and Vergé (2020), belief consistency implies that a retailer always conjectures that its rivals have negotiated the equilibrium wholesale prices (even if some of its negotiations with manufacturers have failed).

${ }^{23}$ The notion of "connected substitutes" implies weak substitution between all products and some strict substitution as well. These conditions are shown to hold under a wide range of demand models including the random coefficient logit considered in our application (see Section 3).
} 
Hence, using matrix algebra, we invert (2) and recover the $J_{t}$-dimensional vector of pricecost margins of retailers (computational details are deferred to Appendix A.1). The retail price-cost margin of product $j \in \mathscr{J}_{t} \backslash\{0\}$ is given by:

$$
p_{j t}-w_{j t}-c_{j t}=\gamma_{j t}\left(\mathbf{q}_{\mathbf{t}}, \mathbf{Q}_{\mathbf{p}_{t}}\right)
$$

where $\mathbf{Q}_{\mathbf{p}_{t}}$ denotes the $J_{t} \times J_{t}$ matrix of partial derivatives $\frac{\partial q_{j t}}{\partial p_{k t}}$ and $\mathbf{q}_{t}$ is the $J_{t}$-dimensional vector of demand for products in market $t$. We then obtain the marginal cost of retailers for each product $j \in \mathscr{J}_{t} \backslash\{0\}$ as follows:

$$
w_{j t}+c_{j t}=p_{j t}-\gamma_{j t}
$$

\subsection{Stage 1: Manufacturer-retailer bargaining}

Bargaining between manufacturer $f$ and retailer $r$ over $w_{j t}$. As previously described, the allocation of surplus in the vertical chain is determined according to the "Nash-in-Nash" bargaining solution (Horn and Wolinsky, 1988). Therefore, the equilibrium wholesale price of product $j$ owned by manufacturer $f$ and distributed by retailer $r$ solves the following Nash bargaining problem conditioning on all other wholesale prices:

$$
w_{j t}^{*} \equiv \underset{w_{j t}}{\operatorname{argmax}}\left(\pi_{f t}-d_{f t}^{-j}\right)^{1-\lambda_{f r}}\left(\pi_{r t}-d_{r t}^{-j}\right)^{\lambda_{f r}}
$$

where $\lambda_{f r} \in[0,1]$ denotes the bargaining weight of retailer $r$ when negotiating with manufacturer $f, \pi_{f t}$ and $\pi_{r t}$ are profits of firms respectively defined in (1a) and (1b), and $d_{f t}^{-j}$ and $d_{r t}^{-j}$ are respectively the status quo payoffs of manufacturer $f$ and retailer $r$ in the event of bilateral disagreement. Following our bargaining protocol which assumes that wholesale prices of other products remain unchanged to an out-of-equilibrium event and that retailers compete downstream with "interim unobservability", we specify the status quo payoffs of firms as follows:

$$
\begin{aligned}
& d_{f t}^{-j}=\sum_{k \in \mathscr{F}_{f t} \backslash\{j\}}\left(w_{k t}^{*}-\mu_{k t}\right) \tilde{q}_{k t}^{-j}\left(\tilde{\mathbf{p}}_{t}^{-j}\right) \\
& d_{r t}^{-j}=\sum_{k \in \mathscr{I}_{r t} \backslash\{j\}}\left(\tilde{p}_{k, t}^{-j}-w_{k t}^{*}-c_{k t}\right) \tilde{q}_{k t}^{-j}\left(\tilde{\mathbf{p}}_{t}^{-j}\right)
\end{aligned}
$$


where $w_{k t}^{*}$ corresponds to the (anticipated) equilibrium wholesale price of product $k \neq j$, $\tilde{\mathbf{p}}_{t}^{-j}$ denotes the $J_{t}$-dimensional vector of out-of-equilibrium retail prices when product $j$ is no longer offered on market $t$ (we refer to Appendix C for computational details):

$$
\tilde{\mathbf{p}}_{t}^{-j}[k, 1]= \begin{cases}+\infty & \text { if } j=k \\ \tilde{p}_{k, t}^{-j} & \text { if } j \neq k \text { and } j, k \in \mathscr{J}_{r t} \\ p_{k, t} & \text { otherwise }\end{cases}
$$

and $\tilde{q}_{k t}^{-j}$ is the demand for each product $k$ remaining on the market. Status quo payoffs are thus determined by removing product $j$ from market $t$, holding fixed wholesale prices of other products and retail prices chosen by retailer $r$ 's rivals, but allowing retailer $r$ to adjust retail prices of its remaining products and consumers to purchase other products in the choice set. ${ }^{24}$

Surplus division and determinants of bargaining power. From (4), we can obtain the set of first-order conditions that characterizes the division of surplus in every bilateral negotiation taking place in market $t$ as follows:

$$
\underbrace{\lambda_{f(j) r(j)}\left(\pi_{f(j) t}-d_{f(j) t}^{-j}\right) \frac{\partial \pi_{r(j) t}}{\partial w_{j t}}}_{\text {retailer } r(j) \text { 's bargaining power }}+\underbrace{\left(1-\lambda_{f(j) r(j)}\right)\left(\pi_{r(j) t}-d_{r(j) t}^{-j}\right) \frac{\partial \pi_{f(j) t}}{\partial w_{j t}}}_{\text {manufacturer } f(j) \text { 's bargaining power }}=0 \quad \forall j \in \mathscr{J}_{t} \backslash\{0\}
$$

where $f(j)$ indexes the manufacturer of product $j$. For a given bilateral negotiation, the first (resp. second) term on the left-hand side of (6) embeds every factor determining the retailer's (resp. manufacturer's) bargaining power. More precisely, we can identify three sources of bargaining power.

The first source of bargaining power is captured by the terms $\pi_{f(j) t}-d_{f(j) t}^{-j}$ and $\pi_{r(j) t}-d_{r(j) t}^{-j}$, which represent respectively the incremental gains from trade obtained by manufacturer $f(j)$ and retailer $r(j)$ given that all other bilateral contracts are formed. The higher a firm's incremental gains from trade the larger its losses from not reaching an agreement, which

\footnotetext{
${ }^{24}$ This sharing rule thus implies that each bilateral contract is a best-response from one another on the equilibrium path and that trading terms of every agreement remain unchanged in case of an out-of-equilibrium event. An alternative specification allowing for non-binding contracts and immediate renegotiation ("from scratch") following a bargaining breakdown has been considered in the theoretical literature on vertical contracting (Stole and Zwiebel, 1996; de Fontenay and Gans, 2014). Under this framework, the bargaining game is a function of the buyer-seller network and status quo payoffs of firms in their negotiations are equilibrium objects themselves. However, the recursive structure of this bargaining protocol remains dramatically complex and computationally burdensome to solve in bilateral oligopolies with multi-product firms.
} 
reinforces the bargaining power of its trading partner. In our bilateral oligopoly framework, these terms are given by:

$$
\begin{aligned}
\pi_{f(j) t}-d_{f(j) t}^{-j}= & \left(w_{j t}-\mu_{j t}\right) q_{j t}\left(\mathbf{p}_{t}\right)-\sum_{k \in \mathscr{I}_{f(j) t} \backslash\{j\}}\left(w_{k t}^{*}-\mu_{k t}\right)\left(\tilde{q}_{k t}^{-j}\left(\tilde{\mathbf{p}}_{t}^{-j}\right)-q_{k t}\left(\mathbf{p}_{t}\right)\right) \\
\pi_{r(j) t}-d_{r(j) t}^{-j}= & \left(p_{j t}-w_{j t}-c_{j t}\right) q_{j t}\left(\mathbf{p}_{t}\right) \\
& -\sum_{k \in \mathscr{F}_{r(j) t} \backslash\{j\}}\left(\tilde{p}_{k t}^{-j}-w_{k t}^{*}-c_{k t}\right) \tilde{q}_{k t}^{-j}\left(\tilde{\mathbf{p}}_{t}^{-j}\right)-\left(p_{k t}-w_{k t}^{*}-c_{k t}\right) q_{k t}\left(\mathbf{p}_{t}\right)
\end{aligned}
$$

They correspond to the difference between the profit generated by the sale of product $j$ for each trading partner and the additional profit that each trading partner would obtain from removing product $j .{ }^{25}$

The second source of bargaining power relates to the concession costs of firms. They are embedded in $\frac{\partial \pi_{f(j) t}}{\partial w_{j t}}$ and $\frac{\partial \pi_{r(j) t}}{\partial w_{j t}}$ which respectively refer to the cost incurred by manufacturer $f(j)$ and retailer $r(j)$ from making a price concession to its trading partner during the course of negotiations. ${ }^{26}$ Hence, a bargainer with a high concession cost is less willing to provide more favorable trading terms to his trading partner which, in turn, increases his bargaining power in the bilateral negotiation. In our setting, concessions costs of firms are given by:

$$
\begin{aligned}
& \frac{\partial \pi_{f(j) t}}{\partial w_{j t}}=q_{j t}\left(\mathbf{p}_{t}\right)+\sum_{k \in \mathscr{I}_{f(j) t}}\left(w_{k t}-\mu_{k t}\right) \sum_{l \in \mathscr{J}_{r(j) t}} \frac{\partial q_{k t}}{\partial p_{l t}} \frac{\partial p_{l t}}{\partial w_{j t}} \\
& \frac{\partial \pi_{r(j) t}}{\partial w_{j t}}=-q_{j t}\left(\mathbf{p}_{t}\right)+\sum_{k \in \mathscr{I}_{r(j) t}} \frac{\partial p_{k t}}{\partial w_{j t}} q_{k t}\left(\mathbf{p}_{t}\right)+\sum_{k \in \mathscr{I}_{r(j) t}}\left(p_{k t}-w_{k t}-c_{k t}\right) \sum_{l \in \mathscr{F}_{r(j) t}} \frac{\partial q_{k t}}{\partial p_{l t}} \frac{\partial p_{l t}}{\partial w_{j t}}
\end{aligned}
$$

In words, the first term in (8a) and (8b) shows that a marginal increase in the wholesale price $w_{j t}$ raises (resp. lessens) manufacturer $f(j)$ 's profit (resp. retailer $r(j)$ 's profit) proportionally to the demand $q_{j t}$. The second term in (8b) describes a retail price effect following the increase in $w_{j t}$ which affects retailer $r(j)$ 's profit proportionally to the demand of each product $k \in \mathscr{J}_{r(j) t}{ }^{27}$ This retail price effect, in turn, generates two effects on consumer

\footnotetext{
${ }^{25}$ The additional profit that retailer $r(j)$ would obtain upon dropping product $j$ is strictly positive whenever products are gross substitutes. However, the additional profit that manufacturer $f(j)$ would obtain is not necessarily positive (due to the change in retail prices) and can be related to the "recapture effect" in Ho and Lee (2017) which describes the ability of consumers to switch to a different retailer to purchase the same brand or to purchase another brand belonging to manufacturer $f(j)$.

${ }^{26}$ In other words, this can be defined as the marginal effect of agreeing upon a lower (resp. higher) wholesale price on manufacturer $f(j)$ 's profit (resp. retailer $r(j)$ 's profit).

${ }^{27}$ Our two-stage game with "interim unobservability" implies that only retailer $r(j)$ is able to observe any
} 
demand that are grasped by the last terms in (8a) and (8b). First, the retail price change of each product $k \in \mathscr{J}_{r(j) t}$ affects their own demand $q_{k t}$, which impacts manufacturer $f(j)$ 's profit (resp. retailer $r(j)$ 's profit) proportionally to the price-cost margins $w_{k t}-\mu_{k t}$ (resp. $\left.p_{k t}-w_{k t}-c_{k t}\right)$. This own effect on demand is, however, mitigated by a portfolio effect reflecting that any change in $p_{k t}$ affects the demand of other products sold by manufacturer $f(j)$ and retailer $r(j) .^{28}$

The last source of bargaining power comes from the bargaining weight $\lambda_{f r}$, which captures asymmetries in the bargaining ability of firms. ${ }^{29}$

To gain further insights on the bargaining outcome obtained in our framework, we rearrange (6) as follows:

$$
\frac{1}{\lambda_{f(j) r(j)}} \frac{\pi_{r(j) t}-d_{r(j) t}^{-j}}{-\partial \pi_{r(j) t} / \partial w_{j t}}=\frac{1}{\left(1-\lambda_{f(j) r(j)}\right)} \frac{\pi_{f(j) t}-d_{f(j) t}^{-j}}{\partial \pi_{f(j) t} / \partial w_{j t}} \quad \forall j \in \mathscr{J}_{t} \backslash\{0\}
$$

where the ratios $\frac{\pi_{r(j) t}-d_{r(j) t}^{-j}}{-\partial \pi_{r(j) t} / \partial w_{j t}}$ and $\frac{\pi_{f(j) t}-d_{f(j) t}^{-j}}{\partial \pi_{f(j) t} / \partial w_{j t}}$ can be related to the concept of "fear of ruin" introduced in Aumann and Kurz (1977). More specifically, firms' gains from trade in the numerator of each ratio can be interpreted as the cost incurred by retailer $r(j)$ (reps. manufacturer $f(j)$ ) in the event of a bargaining breakdown. Therefore, each ratio provides a measure of a firm's fear of risking a bargaining breakdown compared to accepting a concession to its trading partner. Based on this appealing concept, Svejnar (1986) develops a bargaining model in which, at any given stage, the firm with a greater fear of bargaining breakdown relative to its bargaining ability must make a price concession to its trading partner: e.g., retailer $r(j)$ makes a price concession to manufacturer $f(j)$ whenever $\frac{1}{\lambda_{f(j) r(j)}} \frac{\pi_{r(j) t}-d_{r(j) t}^{-j}}{-\partial \pi_{r(j) t} / \partial w_{j t}}>\frac{1}{\left(1-\lambda_{f(j) r(j)}\right)} \frac{\pi_{f(j) t}-d_{f(j) t}^{-j}}{\partial \pi_{f(j) t} / \partial w_{j t}}$, and conversely. It is shown that the unique solution to this bargaining process is obtained when firms perceive the same fear of bargaining breakdown relative to their bargaining ability, which is precisely what the equality of ratios in (9) describes. ${ }^{30}$ Hence, our bargaining outcome has intuitive appeal in that it can be interpreted

(marginal) change in $w_{j t}$ and react accordingly on the downstream market.

${ }^{28}$ For instance, whenever products are imperfect substitutes and $\frac{\partial p_{k t}}{\partial w_{j t}}>0 \forall k \in \mathscr{J}_{r(j) t} \backslash\{j\}$, the portfolio effect alleviates the manufacturer $f(j)$ 's and retailer $r(j)$ 's losses from a decrease in demand due to the retail price effect of an increase in $w_{j t}$.

${ }^{29}$ These weights are often deemed to reflect some imprecisely defined asymmetries in the bargaining power of firms. As stated by Roth (1979), they may attempt to capture some factors "outside" the model that affect the bargaining outcome. Using strategic models of bargaining, Binmore, Rubinstein and Wolinsky (1986) provide ground for the presence of such parameters in showing that they may capture differences in bargainers' beliefs or asymmetries in the bargaining procedure.

${ }^{30}$ It is noteworthy that the bargaining process postulated by Svejnar (1986) is similar in spirit to the behavioural approach of Zeuthen-Harsanyi (Harsanyi, 1956, 1977). In particular, it leads to the Zeuthen- 
in terms of "equilibrium of fear". In Section 4, we further show that the left- and right-hand side of (9) provide insightful measures to predict the directional wholesale price effects of changes in market conditions.

Price-cost margins of manufacturers. As for the vector of retail price-cost margins derived from (2), we show in Appendix A.2 that a closed-form expression for the $J_{t}$-dimensional vector of price-cost margins of manufacturers can be obtained by inverting the system (6). The price-cost margins of manufacturer $f(j)$ for product $j$ is given by: ${ }^{31}$

$$
w_{j t}-\mu_{j t}=\Gamma_{j t}\left(\mathbf{q}_{t}, \mathbf{Q}_{\mathbf{p}_{t}}, \mathbf{Q}_{\mathbf{p}_{t} \mathbf{p}_{t}}, \tilde{\mathbf{Q}}_{\Delta t} ; \lambda\right)
$$

where $\lambda$ denotes the $J_{t}$-dimensional vector of bargaining weights, $\mathbf{Q}_{\mathbf{p}_{t} \mathbf{p}_{t}}$ is an array of $J_{t}$ matrices of second partial derivatives $\frac{\partial^{2} q_{j t}}{\partial p_{k t} \partial p_{l t}}$ denoted by $\mathbf{Q}_{\mathbf{p}_{k t} \mathbf{p}_{t}}$ (each matrix $\mathbf{Q}_{\mathbf{p}_{k t} \mathbf{p}_{t}}$ being of $J_{t} \times J_{t}$ dimension), and $\tilde{\mathbf{Q}}_{\Delta t}$ is the $J_{t} \times J_{t}$ matrix of differences in quantities upon a bargaining breakdown (that is, $q_{k t}\left(\mathbf{p}_{t}\right)-\tilde{q}_{k t}^{-j}\left(\tilde{\mathbf{p}}_{t}^{-j}\right)$ ). This result makes our model of bilateral oligopoly particularly attractive for empirical works. In what follows, we show how to take the model to data and estimate the surplus division between manufacturers and retailers in the French soft drink industry.

\section{Application to the French soft drink industry}

We apply our framework to the French soft drink industry which features a classic example of bilateral oligopoly in which large firms operate at both the upstream and the downstream level of the market. Six large retail groups dominate the downstream level of the French food retail sector: Groupe Carrefour, Groupe Leclerc, ITM Entreprises, Groupe Casino, Groupe Auchan, and Groupe Système U. These retailers deal with four large soft drink manufacturers operating upstream: The Coca-Cola Company, PepsiCo, Orangina-Schweppes, and Unilever. To determine the distribution of bargaining power in the vertical chain of the French soft drink industry, we proceed as follows. First, we present the data used to conduct our empirical analysis. Second, we introduce our econometric methodology including the specification of consumers' utility and firms' marginal cost functions. We also describe our

\footnotetext{
Harsanyi solution when the bargaining ability of firms are equal (i.e., $\lambda_{f(j) r(j)}=0.5 \forall j$ ).

${ }^{31}$ As shown in Appendix A.2, the closed-form expression also includes every $J_{t}$-dimensional vector of out-ofequilibrium demand for products and $J_{t} \times J_{t}$ matrix of out-of-equilibrium first partial derivatives upon removing product $k \in \mathscr{J}_{t}$ from market $t$ : that is, $\left(\tilde{\mathbf{q}}_{t}^{-1}, \ldots, \tilde{\mathbf{q}}_{t}^{-J_{t}}\right)$ and $\left(\tilde{\mathbf{Q}}_{\tilde{\mathbf{p}}_{t}^{-1}}, \ldots, \tilde{\mathbf{Q}}_{\tilde{\mathbf{p}}_{t}^{-J_{t}}}\right)$. For the sake of conciseness, we omit to express this dependence in our notations.
} 
strategy to identify and estimate model parameters. Third, we discuss the empirical results by paying particular attention to the determinants of bargaining power in the vertical chain.

\subsection{Data}

We use data from a panel of households representative of the French population who scan the bar code of their grocery purchases for home consumption from April 2005 to September 2005. The data are collected by Kantar WorldPanel and include a total of 265, 998 soft drink purchases. For each purchased soft drink, we observe the date of the purchase, the quantity bought in liter, the retail price in euro, the brand name (e.g., Coca-Cola), and the packaged type (e.g., can, plastic bottle). The data also provide information on the store at which each purchase was made including its name, its size area, and its type (e.g., supermarket, hypermarket).

Following Bonnet and Réquillart (2013b), we consider purchases in all retailers. Among the five largest retailers, three are characterized by large outlets while the two others have intermediate-sized outlets. We also define two aggregates: an aggregate of discounters which are outlets of small to intermediate size offering basic services, and an aggregate of the remaining retailers. In addition to the purchases of private labels, we focus on the purchases of the 21 top selling national brands according to our sample. All remaining soft drink purchases are aggregated under the label "outside good" which also includes purchases of flavored water. To analyze the interaction between manufacturers and retailers, we define a product as a brand-retailer combination. ${ }^{32}$ Consequently, we have 157 differentiated products representing $72.51 \%$ of the total soft drink purchases (the remaining $27.49 \%$ being the outside good).

While we observe the retail price of each purchased product, our data do not provide information on the alternatives available to consumers during their shopping trips. To reconstitute the choice set of each consumer, we proceed as follows. First, we define the market $t$ as all soft drink purchases for home consumption in France within a month (implying that $t=1, \ldots, 6)$. Second, we assume that each consumer has access to all retailers. This is a plausible assumption given that we consider soft drink purchases at national retail chains with outlets located in every region in France. Third, we assume that the set of brands distributed by a retailer in a particular month consists of all brands of soft drink for which we observe a purchase at this retailer during the same month. This is a realistic assumption as

\footnotetext{
${ }^{32}$ In other words, we consider that a national brand (e.g., Coca-Cola) sold by two retailers correspond to two different products.
} 
Table 1: Descriptive statistics for manufacturers and product categories

\begin{tabular}{|c|c|c|c|c|c|c|c|c|c|c|}
\hline & \multicolumn{5}{|c|}{ Market share } & \multicolumn{5}{|c|}{ Retail price } \\
\hline & colas & sodas & juices & iced tea & total & colas & sodas & juices & iced tea & total \\
\hline M1 & $\begin{array}{l}12.00 \\
(0.53)\end{array}$ & $\begin{array}{c}1.58 \\
(0.11)\end{array}$ & $\begin{array}{c}0.57 \\
(0.14)\end{array}$ & $\begin{array}{c}0.22 \\
(0.06)\end{array}$ & $\begin{array}{l}14.37 \\
(0.42)\end{array}$ & $\begin{array}{c}0.92 \\
(0.02)\end{array}$ & $\begin{array}{c}0.91 \\
(0.03)\end{array}$ & $\begin{array}{c}1.61 \\
(0.08)\end{array}$ & $\begin{array}{c}0.93 \\
(0.03)\end{array}$ & $\begin{array}{c}0.95 \\
(0.02)\end{array}$ \\
\hline M2 & $\begin{array}{c}1.12 \\
(0.09)\end{array}$ & $\begin{array}{c}0.45 \\
(0.10)\end{array}$ & $\begin{array}{c}3.36 \\
(0.21)\end{array}$ & - & $\begin{array}{c}4.93 \\
(0.17)\end{array}$ & $\begin{array}{c}0.71 \\
(0.02)\end{array}$ & $\begin{array}{c}0.76 \\
(0.02)\end{array}$ & $\begin{array}{c}2.19 \\
(0.04)\end{array}$ & - & $\begin{array}{c}1.72 \\
(0.05)\end{array}$ \\
\hline M3 & - & - & - & $\begin{array}{c}2.07 \\
(0.39)\end{array}$ & $\begin{array}{c}2.07 \\
(0.39)\end{array}$ & - & - & - & $\begin{array}{c}1.09 \\
(0.02)\end{array}$ & $\begin{array}{c}1.09 \\
(0.02)\end{array}$ \\
\hline M4 & - & $\begin{array}{c}6.66 \\
(0.61)\end{array}$ & $\begin{array}{c}0.84 \\
(0.10)\end{array}$ & - & $\begin{array}{c}7.50 \\
(0.57)\end{array}$ & - & $\begin{array}{c}1.08 \\
(0.02)\end{array}$ & $\begin{array}{c}1.79 \\
(0.03)\end{array}$ & - & $\begin{array}{c}1.16 \\
(0.02)\end{array}$ \\
\hline PL & $\begin{array}{c}4.12 \\
(0.15)\end{array}$ & $\begin{array}{c}7.36 \\
(0.46)\end{array}$ & $\begin{array}{l}29.83 \\
(1.92)\end{array}$ & $\begin{array}{c}2.32 \\
(0.37)\end{array}$ & $\begin{array}{l}43.63 \\
(1.32)\end{array}$ & $\begin{array}{c}0.30 \\
(0.01)\end{array}$ & $\begin{array}{c}0.39 \\
(0.01)\end{array}$ & $\begin{array}{c}0.84 \\
(0.01)\end{array}$ & $\begin{array}{c}0.52 \\
(0.01)\end{array}$ & $\begin{array}{c}0.70 \\
(0.01)\end{array}$ \\
\hline
\end{tabular}

Notes: $N=265,998$. "M1", "M2", "M3" and "M4" refer respectively to manufacturers 1, 2, 3, and 4, "PL" corresponds to private label, and "sodas" and "juices" refer respectively to other sodas and fruit juices. Market shares are in number of household purchases. Retail prices in euro per liter are calculated using quantity weights. Standard deviation in parenthesis refer to variation across months. Remark that we are not permitted to reveal names of manufacturers due to confidentiality regarding Kantar WorldPanel data.

we focus on the top selling soft drink brands. These assumptions imply that the choice set of each consumer consists of the 157 differentiated products plus the outside good. Finally, we compute a monthly average (deflated) retail price for each product in the choice set to infer the retail prices of products available to consumers during their shopping trips. ${ }^{33}$

Table 1 reports summary statistics of market shares and retail prices across manufacturers and soft drink categories. There is substantial heterogeneity in the market shares of national brand manufacturers, ranging from $2.07 \%$ to $14.37 \%$. We observe, however, that each national brand manufacturer has a market share advantage over its rivals in each soft drink category. The highest market share advantage is in the cola category where the leading national brand manufacturer has a market share of $12 \%$ (representing $70 \%$ of total cola product sales). Despite the presence of large national brand manufacturers, private labels in the soft drink industry account for $43.63 \%$ of market share. Ranging from $2.32 \%$ of market share in the iced tea category to $29.83 \%$ in the fruit juice category, private labels constitute a substantial part of total sales in each soft drink category. This descriptive evidence suggests that retailers are likely to play an important role in the division of surplus in the vertical chain. For a given national brand manufacturer, there is little variation in retail prices across product categories, except for fruit juices which are substantially more

\footnotetext{
${ }^{33}$ More precisely, we construct the retail price of product $j$ in month $t$ as follows: $p_{j, t}=\frac{\sum_{i} \mathbb{1}_{i, j, t} p_{i, j, t} q_{i, j, t}}{\sum_{i, j, t} q_{i, j, t}}$, where $\mathbb{1}_{i, j, t}$ is an indicator equals to 1 if consumer $i$ has purchased product $j$ in month $t, p_{i, j, t}$ is the retail price paid by the consumer, and $q_{i, j, t}$ is the quantity purchased (in liter). As we average observed retail prices within a month and across outlets of a retail chain, we acknowledge that this might introduce measurement error bias (see Dubois, Griffith and O'Connell, 2020, for a discussion on this issue).
} 
Table 2: Descriptive statistics for retailers

\begin{tabular}{|c|c|c|c|c|c|c|}
\hline \multirow{3}{*}{ Retailer 1} & \multicolumn{3}{|c|}{ Market share } & \multicolumn{3}{|c|}{$\overline{\text { Retail price }}$} \\
\hline & national brand & private label & total & national brand & private label & total \\
\hline & $\begin{array}{c}7.82 \\
(0.25)\end{array}$ & $\begin{array}{c}6.69 \\
(0.34)\end{array}$ & $\begin{array}{l}14.51 \\
(0.53)\end{array}$ & $\begin{array}{c}1.20 \\
(0.02)\end{array}$ & $\begin{array}{c}0.82 \\
(0.02)\end{array}$ & $\begin{array}{c}1.02 \\
(0.02)\end{array}$ \\
\hline Retailer 2 & $\begin{array}{c}3.92 \\
(0.21)\end{array}$ & $\begin{array}{c}5.01 \\
(0.13)\end{array}$ & $\begin{array}{c}8.93 \\
(0.16)\end{array}$ & $\begin{array}{c}1.14 \\
(0.02)\end{array}$ & $\begin{array}{c}0.72 \\
(0.02)\end{array}$ & $\begin{array}{c}0.90 \\
(0.02)\end{array}$ \\
\hline Retailer 3 & $\begin{array}{c}4.56 \\
(0.26)\end{array}$ & $\begin{array}{c}3.14 \\
(0.27)\end{array}$ & $\begin{array}{c}7.71 \\
(0.18)\end{array}$ & $\begin{array}{c}1.13 \\
(0.03)\end{array}$ & $\begin{array}{c}0.76 \\
(0.01)\end{array}$ & $\begin{array}{c}0.98 \\
(0.02)\end{array}$ \\
\hline Retailer 4 & $\begin{array}{c}4.29 \\
(0.18)\end{array}$ & $\begin{array}{c}7.91 \\
(0.40)\end{array}$ & $\begin{array}{l}12.21 \\
(0.44)\end{array}$ & $\begin{array}{c}1.21 \\
(0.02)\end{array}$ & $\begin{array}{c}0.79 \\
(0.02)\end{array}$ & $\begin{array}{c}0.94 \\
(0.01)\end{array}$ \\
\hline Retailer 5 & $\begin{array}{c}1.05 \\
(0.08)\end{array}$ & $\begin{array}{l}10.31 \\
(0.41)\end{array}$ & $\begin{array}{l}11.36 \\
(0.44)\end{array}$ & $\begin{array}{c}0.82 \\
(0.03)\end{array}$ & $\begin{array}{c}0.55 \\
(0.01)\end{array}$ & $\begin{array}{c}0.57 \\
(0.01)\end{array}$ \\
\hline Retailer 6 & $\begin{array}{c}4.94 \\
(0.32)\end{array}$ & $\begin{array}{c}6.98 \\
(0.27)\end{array}$ & $\begin{array}{l}11.91 \\
(0.29)\end{array}$ & $\begin{array}{c}1.10 \\
(0.03)\end{array}$ & $\begin{array}{c}0.68 \\
(0.02)\end{array}$ & $\begin{array}{c}0.85 \\
(0.01)\end{array}$ \\
\hline Retailer 7 & $\begin{array}{c}2.29 \\
(0.20) \\
\end{array}$ & $\begin{array}{c}3.59 \\
(0.25) \\
\end{array}$ & $\begin{array}{c}5.88 \\
(0.25) \\
\end{array}$ & $\begin{array}{c}1.12 \\
(0.03)\end{array}$ & $\begin{array}{c}0.69 \\
(0.03) \\
\end{array}$ & $\begin{array}{c}0.86 \\
(0.02) \\
\end{array}$ \\
\hline
\end{tabular}

Notes: $N=265$, 998. Market shares are in number of household purchases. Retail prices in euro per liter are calculated using quantity weights. Standard deviation in parenthesis refer to variation across months. Remark that we are not permitted to reveal names of retailers due to confidentiality regarding Kantar WorldPanel data.

expensive than other products. The variation in retail prices is more important across manufacturers. For instance, in the cola category, the average retail price of manufacturer 1's products equals 0.92 euro per liter while that of manufacturer 2's products is 0.71 euro per liter. This retail price gap is even higher between national brands and private labels. For instance, the average retail prices of national brands is three times higher than that of private labels in the cola category.

Table 2 displays summary statistics across retailers. There is also a large heterogeneity in the market shares of retailers, ranging from $5.88 \%$ to $14.51 \%$. National brands do not always constitute the largest part of retailers' market shares, especially for retailer 5 where private labels represent more than $90 \%$ of its sales. We also observe variation in the retail prices across retailers. In particular, the retail prices of national brands and private labels distributed by retailer 5 are considerably lower than the retail prices charged by other retailers. Table 10 in Appendix G.1 reports additional summary statistics for each brand of soft drink considered in our empirical analysis (including the brand ownership of each manufacturer).

\subsection{Empirical framework}

To analyze the interaction between manufacturers and retailers in the French soft drink industry, we first specify and estimate a model of consumer demand for soft drinks. Based 
on our demand estimates, we then discuss identification and estimation of our bilateral oligopoly framework.

\subsubsection{Consumer demand for soft drinks}

Demand specification. We consider a discrete choice model of consumer behavior in which each consumer chooses one unit of the product that maximizes his utility (McFadden, 1974). Following the discrete-choice literature (Berry, Levinsohn and Pakes, 1995; Nevo, 2001; Train, 2009), the indirect utility is a function of the product characteristics for which we determine consumer preferences. More precisely, we specify the utility that consumer $i$ derives from purchasing product $j$ in month $t$ as follows:

$$
U_{i j t}=\delta_{b(j)}+\delta_{r(j)}-\alpha_{i j} p_{j t}+\xi_{j t}+\epsilon_{i j t}
$$

where $\delta_{b(j)}$ and $\delta_{r(j)}$ are brand and retail fixed effects which capture respectively the mean utility in the population generated by unobserved time invariant brand and retailer characteristics, $p_{j t}$ denotes the retail price of product $j$ in month $t, \xi_{j t}$ is a scalar that represents unobserved (to the econometrician) characteristics of product $j$ in month $t$, and $\epsilon_{i j t}$ is a mean-zero error term. The parameter $\alpha_{i j}$ captures the disutility of consumer $i$ for the retail price of product $j$. Allowing for heterogeneous consumer price disutilities, we assume that $\alpha_{i j}$ varies across consumers as follows:

$$
\alpha_{i j}=\exp \left(\alpha_{n b(j)}+\alpha_{p l(j)}+\sigma v_{i}\right) \quad \text { where } v_{i} \sim \mathscr{N}(0,1)
$$

where $\alpha_{n b(j)}, \alpha_{p l(j)}$ and $\sigma$ are parameters of the log-normal distribution. We allow for different price sensitivities for national brand and private label products, $\alpha_{n b(j)}$ and $\alpha_{p l(j)}$ respectively, to obtain a more flexible pattern of substitution across products. ${ }^{34}$ We normalize the utility from purchasing the outside good to $U_{i 0 t}=\epsilon_{i 0 t}$. Assuming that $\epsilon_{i j t}$ is independently and identically distributed from the standard Gumbel distribution (also known as type I extreme value distribution), the individual market share of product $j \in \mathscr{J}_{t} \backslash\{0\}$ in month $t$

\footnotetext{
${ }^{34}$ See Bonnet and Réquillart (2013a) for a similar specification which has also been used to allow for heterogeneous price sensitivity across box sizes in the cereal market (Kiser, 1998), movie theaters (Davis, 2002), and brands of food and hygiene products (Erdem, Keane and Sun, 2008).
} 
can be written as follows:

$$
s_{i j t}=\int_{0}^{+\infty} \frac{\exp \left(\delta_{b(j)}+\delta_{r(j)}-\alpha_{i j} p_{j t}+\xi_{j t}\right)}{1+\sum_{k=1}^{J_{t}} \exp \left(\delta_{b(k)}+\delta_{r(k)}-\alpha_{i k} p_{k t}+\xi_{k t}\right)} f\left(\alpha_{i j}\right) \mathrm{d} \alpha_{i j}
$$

where $f(\cdot)$ corresponds to the density function of the log-normal distribution.

Identification. We identify consumer substitution patterns from the variation in retail prices and changes in the number of products offered to consumers in each month. However, the retail price variation may not be exogenous because the pricing behavior of retailers depends on all product characteristics, including $\xi_{j t} \cdot{ }^{35}$ As stressed in Berry (1994), the correlation between retail prices and unobserved demand factors introduces an endogeneity problem which threatens identification of demand parameters. To address this issue and obtain consistent estimates of demand parameters, we use a control function approach (Petrin and Train, 2010) involving two steps. ${ }^{36}$ First, we regress the retail price variable on a set of instruments:

$$
p_{j t}=\delta_{b(j)}+\delta_{r(j)}+\beta \mathbf{Z}_{j t}^{d}+u_{j t}
$$

where $\delta_{b(j)}$ and $\delta_{r(j)}$ are the exogenous brand and retail fixed effects (included instruments), $\mathbf{Z}_{j t}^{d}$ is a vector of excluded instruments, $\boldsymbol{\beta}$ is a vector of parameters, and $u_{j t}$ is an error term capturing all unobserved factors explaining $p_{j t}$. Instrumental variables in $\mathbf{Z}_{j t}^{d}$ should affect retail prices by shifting supply (costs or markups of firms) but not consumer preferences for unobserved product attributes. In practice, we use the number of competing products in each month. Exogeneity of this BLP-type instrument rests on the common assumption that product characteristics are uncorrelated with $\xi_{j t}$ (Berry, Levinsohn and Pakes, 1995). We also use two cost shifters consisting in the input price index of sugar interacted with the quantity of added sugar for each brand of soft drink and the input price index of aluminum interacted with the average canned rate sold for each product in other months. ${ }^{37}$ Exogeneity of these variables rely on the assumption that the soft drink industry represents only a small

\footnotetext{
${ }^{35}$ For instance, we do not observe changes in advertising expenditure for soft drink products or changes in shelf display which are likely to affect consumer behavior and are included in our model through $\xi_{j t}$.

${ }^{36}$ We acknowledge that the control function approach is valid under restrictive functional form restrictions (Blundell and Matzkin, 2014). We use this approach for its simplicity following recent articles in the literature (e.g., Hausman and Newey, 2016; Crawford, Pavanini and Schivardi, 2018; Dubois, Griffith and O'Connell, 2018).

${ }^{37}$ These input price indexes are from the French National Institute for Statistics and Economic Studies.
} 
share of the demand for sugar and aluminum. ${ }^{38}$

The second step of the control function approach uses the OLS residuals of the regression model (13), denoted by $\hat{u}_{j t}$, as a proxy for the unobserved product characteristics that affect both retail prices and consumer behavior (e.g., advertising, shelf display). More specifically, we include $\hat{u}_{j t}$ into (11) to control for the correlation between $p_{j t}$ and $\xi_{j t}$ as follows:

$$
U_{i j t}=\delta_{b(j)}+\delta_{r(j)}-\alpha_{i j} p_{j t}+\rho \hat{u}_{j t}+\tilde{\xi}_{j t}+\epsilon_{i j t}
$$

where $\tilde{\xi}_{j t}=\xi_{j t}-\rho \hat{u}_{j t}$ and $\rho$ is a parameter capturing the mean utility generated by unobserved product attributes that are correlated with retail prices.

Estimation procedure. We estimate the vector of demand parameters, denoted by $\theta^{d} \equiv$ $\left(\alpha_{n b(j)}, \alpha_{p l(j)}, \sigma, \delta_{b(j)}, \delta_{r(j)}, \rho\right)^{\top}$, by maximizing the following simulated log-likelihood function: ${ }^{39}$

$$
\operatorname{SLL}\left(\theta^{d}\right)=\sum_{t} \sum_{i} \sum_{j} \mathbb{1}_{\left\{y_{i j t}=1\right\}} \ln \left(\check{s}_{i j t}\left(\theta^{d}\right)\right)
$$

where $\check{s}_{i j t}\left(\theta^{d}\right)$ represents the simulated counterpart of (12) which is computed using Monte Carlo integration as follows:

$$
\check{s}_{i j t}=\frac{1}{n s} \sum_{h=1}^{n s} \frac{\exp \left(\delta_{b(j)}+\delta_{r(j)}-\exp \left(\alpha_{n b(j)}+\alpha_{p l(j)}+\sigma v_{i h}\right) p_{j t}+\rho \hat{u}_{j t}\right)}{1+\sum_{k=1}^{J_{t}} \exp \left(\delta_{b(k)}+\delta_{r(k)}-\exp \left(\alpha_{n b(k)}+\alpha_{p l(k)}+\sigma v_{i h}\right) p_{k t}+\rho \hat{u}_{k t}\right)}
$$

where $n s$ corresponds to the total number of random draws for each consumer $i$. The use of simulated market shares into the log-likelihood function may generate both noise and bias (Train, 2009, Chap. 10). With large sample size, the simulation noise has the desirable property to vanish without even increasing the number of simulation draws. However, the simulation bias may be magnified which renders the maximum simulated likelihood estimator inconsistent. Fortunately, this bias decreases with the number of draws used in the simulation. ${ }^{40}$ In our application, we use 100 Halton draws for each individual in our

\footnotetext{
${ }^{38}$ In a spirit similar to the Hausman-type instruments (Hausman, 1996), our second cost shifter also relies on the identification assumption that demand for soft drink is independent across months.

${ }^{39}$ The mathematical symbol "T" denotes the transpose operator.

${ }^{40}$ In particular, Lee (1995) has shown that the maximum simulated likelihood estimator is equivalent to its nonsimulated counterpart when the number of draws rises faster than the square root of the number of observations.
} 
sample. $^{41}$

\subsubsection{Identification and estimation of bargaining stage}

Econometric model. As shown in (3), it is possible to recover the marginal cost of retailers for each soft drink product $j \in \mathscr{J}_{t} \backslash\{0\}$ from demand estimates and (2). We have further shown in (10) that one can recover the price-cost margins of manufacturers up to an unknown vector of bargaining weights $\lambda$ to be estimated. To this end, we rely on the variation in marginal costs of retailers across products and markets which can be explained by (i) asymmetries in the bargaining power of firms in the vertical chain, and (ii) differences in marginal costs of production and distribution. We thus proceed by partitioning the marginal cost of retailers for each product $j \in \mathscr{J}_{t} \backslash\{0\}$ as follows:

$$
w_{j t}+c_{j t}=\underbrace{\left(w_{j t}-\mu_{j t}\right)}_{\text {price-cost margins of manufacturers }}+\underbrace{\left(c_{j t}+\mu_{j t}\right)}_{\text {operational costs }}
$$

We leverage our bilateral oligopoly model and make use of the closed-form expression in (10) for the price-cost margins of manufacturers in (14). This markup term is derived from consumer demand for each product $j \in \mathscr{J}_{t}$ given by $q_{j t}=M_{t} s_{j t}$, where $M_{t}$ is the market size and $s_{j t}$ is the market share of product $j$ in market $t$ derived from aggregating consumer-level market shares in (12). ${ }^{42}$ As further detailed in Appendix A.2, this markup term also depends on the out-of-equilibrium demand of each product $k \in \mathscr{J}_{t} \backslash\{0, j\}$ following the removal of product $j \in \mathscr{J}_{t} \backslash\{0\}$, which is given by $\tilde{q}_{k t}^{-j}=M_{t} \tilde{s}_{k t}^{j}$. We derive the out-of-equilibrium market share $\tilde{s}_{k t}^{j}$ from (12) as follows:

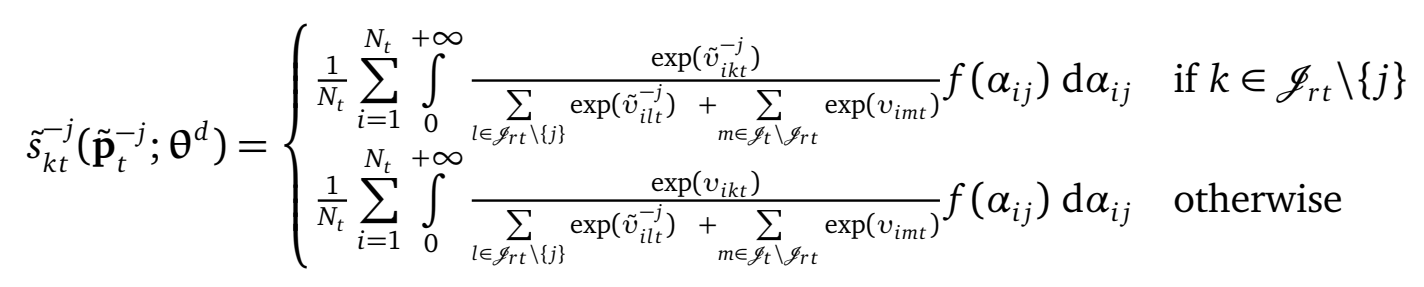

where $v_{i k t} \equiv \delta_{b(k)}+\delta_{r(k)}-\alpha_{i j} p_{k t}+\rho \hat{u}_{k t}$ and $\tilde{v}_{i k t}^{-j} \equiv \delta_{b(k)}+\delta_{r(k)}-\alpha_{i j} \tilde{p}_{k t}^{-j}+\rho \hat{u}_{k t}$.

Absent additional information, we impose further structure on the "operational costs" term in (14) as in Gowrisankaran, Nevo and Town (2015). More specifically, we assume

\footnotetext{
${ }^{41}$ For one-dimensional integration, Bhat (2001) has shown that the simulation error is smaller with 75 Halton draws than with 2000 pseudo-random draws (see also Train, 2000).

${ }^{42}$ That is, $s_{j t}=\frac{1}{N_{t}} \sum_{i=1}^{N_{t}} s_{i j t}$ where $N_{t}$ is the total number of consumers in market $t$.
} 
that the constant marginal cost of product $j \in \mathscr{J}_{t} \backslash\{0\}$ is given by: $c_{j t}+\mu_{j t}=\mathbf{v}_{j t} \mathbf{\kappa}+\omega_{j t}$, where $\mathbf{v}_{j t}$ is a $1 \times K$ vector of cost shifters, $\boldsymbol{\kappa}$ is a $K \times 1$ vector of cost parameters, and $\omega_{j t}$ denotes an additive error term which captures unobserved cost factors (e.g., unobserved productivity of firms). ${ }^{43}$ In our application, $\mathbf{v}_{j t}$ includes category and retailer fixed effects, the (monthly) input price of sugar interacted with the sugar content of each brand of soft drink, and the (monthly) input price of aluminum interacted with the average percentage of cans sold for each product. Hence, the marginal cost function of retailers in the soft drink industry is specified as follows:

$$
w_{j t}+c_{j t}=\Gamma_{j t}\left(\mathbf{q}_{t}, \mathbf{Q}_{\mathbf{p}_{t}}, \mathbf{Q}_{\mathbf{p}_{t} \mathbf{p}_{t}}, \tilde{\mathbf{Q}}_{\Delta t} ; \boldsymbol{\lambda}\right)+\mathbf{v}_{j t} \mathbf{K}+\omega_{j t}
$$

where the vector of supply parameters to be estimated is $\theta^{s} \equiv\left(\lambda^{\top}, \boldsymbol{\kappa}^{\top}\right)^{\top}$.

Identification. Intuitively, identification of the bargaining weights amounts to identifying the slope of the marginal cost function of retailers. For instance, when $\lambda_{f r}=0 \forall f, r$ (retailers make take-it-or-leave-it offers to manufacturers), the price-cost margins of manufacturers equal zero and (15) is flat with respect to quantity as in Berry, Levinsohn and Pakes (1995). In contrast, when manufacturers are able to exert market power, (15) also depends on the price-cost margins of manufacturers $\Gamma_{j t}$ and, in turn, on quantity. In this case, the pricing behavior of retailers differs from the standard oligopoly setting due to the double marginalization, thereby revealing the presence of manufacturers' bargaining power.

However, identification of $\theta^{s}$ can be jeopardized by the fact that the quantity vector $\mathbf{q}_{t}$, which enters non-linearly into (15) through the markup term $\Gamma_{j t}$, is likely to be correlated with unobserved cost factors $\omega_{j t}$. Indeed, under complete information about marginal costs, firms observe the realization of $\omega_{j t}$ before setting wholesale and retail prices which, in turn, affects $\mathbf{q}_{t}$. Moreover, the variation in quantities depends on the unobserved product characteristics $\xi_{j t}$ which is likely to be correlated with $\omega_{j t}$. To address this endogeneity issue, one needs instrumental variables that shift either demand or manufacturer markups but not marginal costs of products. In our application, we rely on the amount of competition that each product faces in characteristics space. ${ }^{44}$ Intuitively, after controlling for differences in

\footnotetext{
${ }^{43}$ Other approaches have been considered in the literature. For instance, Crawford and Yurukoglu (2012) make the assumption that there is no marginal cost of production in the multichannel television industry. Grennan (2013) adopts an alternative specification in which costs are represented only in terms of data and parameters (i.e., without unobservables) which enables to estimate the full distribution of bargaining weights. Our marginal cost specification is instead in line with empirical studies on food industries (e.g., Villas-Boas, 2007; Miller and Weinberg, 2017).

${ }^{44}$ This markup shifter can be related to the so-called BLP instruments and directly builds on the "Differen-
} 
marginal costs, products with distant substitutes in characteristics space should systematically have higher wholesale prices (and hence retail marginal costs) than products with close substitutes when manufacturers are able to exert market power (bargaining weights are close to 0 ). If, however, the location of products in characteristics space does not explain differences in marginal costs of retailers across products, this may reveal that retailers are able to mitigate the market power of manufacturers such that wholesale prices only reflect production costs (bargaining weights are close to 1 ). In practice, we use two sets of instrumental variables: (i) the number of rival products in the same soft drink category, and (ii) the number of rival products sold by the same retailer interacted with manufacturer-category fixed effects. The validity of these instruments hinges on the conditions that they are correlated with quantities and exogenous to the structural error term $\omega_{j t}$. For the first condition, our instruments aims at measuring the competitive pressure exerted on each product which is very likely to explain differences in quantity sold across products and markets. For the exogeneity condition, we rely on the common assumption that observed product characteristics are exogenous.

As the order condition requires at least one instrument for each bargaining weight that interacts with quantities (which grows with the number of manufacturer-retailer pairs), we consider manufacturer-specific bargaining weights in estimation $\left(\lambda_{f r}=\lambda_{f}\right) .{ }^{45}$ For manufacturers 1 and 2 which have the most diverse brand portfolio (see Table 10 in Appendix G.1), we allow bargaining weights to differ between cola/other soda products and fruit juice/iced tea products. Hence, we have six bargaining weights to be estimated.

Estimation procedure. We estimate the vector of supply parameters $\theta^{s}$ by continuous updating GMM (Hansen, Heaton and Yaron, 1996). Note that we concentrate the cost parameters $\kappa$ out of the GMM objective function and search nonlinearly over the vector of bargaining weights. Formally, our GMM estimator is defined as follows:

$$
\hat{\lambda} \equiv \underset{\lambda}{\operatorname{argmin}}\left(\mathbf{Z}^{s} \omega(\lambda, \kappa(\lambda))\right)^{\top} \mathbf{A}^{-1} \mathbf{Z}^{s} \boldsymbol{\omega}(\lambda, \kappa(\lambda))
$$

tiation IVs" suggested by Gandhi and Houde (2020) to identify consumer substitution patterns. See Michel and Weiergraeber (2018) for a related approach to identify firms' conduct in oligopoly markets.

${ }^{45}$ There are 28 manufacturer-retailer pairs in our application, which necessitates the use of at least 28 instruments. We thus employ parameter restrictions for tractability motives as commonly applied in the literature (see e.g. Gowrisankaran, Nevo and Town, 2015; Ho and Lee, 2017; Crawford et al., 2018). We also consider that private label manufacturers are vertically integrated with retailers, implying that wholesale prices of private labels are set to their marginal costs of production $(\lambda=1)$. 
where $\boldsymbol{\omega}(\lambda, \kappa(\lambda))$ is the $\sum_{t} J_{t}$-dimensional vector of unobserved cost factors, $\mathbf{Z}^{s}$ is a $K \times \sum_{t} J_{t}$ matrix of instrumental variables (where $K=6$ ), and $\mathrm{A}$ is a $K \times K$ weighting matrix (see Appendix $E$ for further details on our estimation procedure).

\subsection{Estimation results}

We first estimate the random coefficient logit model using our consumer-level data on soft drink purchases introduced in Section 3.1. Given demand estimates, we compute the pricecost margins and marginal costs of retailers by inverting the system of first-order conditions described in (2). Finally, given demand and retailers' marginal cost estimates, we estimate the marginal cost function of retailers described in (15). In what follows, we present our estimation results.

\subsubsection{Demand estimates}

Table 3 reports parameter estimates of the random coefficient logit model. The estimated coefficient of the first-step residuals of the control function approach is positive and significant at the 5\% level. This suggests that unobserved product attributes are positively correlated with the retail price variable, justifying the need to account for the retail price endogeneity issue. ${ }^{46}$ The retail price has a significant and negative impact on consumer utility. On average, we find that consumers are more sensitive to price variation for private labels than for national brands. This can be explained by the fact that consumers may have more brand loyalty with respect to national brands than private labels. Our estimates also indicate heterogeneity across consumers regarding the marginal price disutility (see Figure 6 in Appendix G).

We use demand estimates to compute the own and cross-price elasticity of demand for each product. Our results are in line with recent empirical work on the soft drink industry. For instance, we find an aggregate own-price elasticity of -1.49 for soft drinks (excluding fruit juices) as in Dubois, Griffith and O'Connell (2020). ${ }^{47}$ In line with Dubé (2004) and Ershov et al. (2021), we also obtain that own-price elasticities for brands in the cola category range from -2.76 to -3.28 on average. Table 4 displays the own and cross-price elasticity

\footnotetext{
${ }^{46}$ Table 11 in Appendix $\mathrm{H}$ displays estimates of the first step of the control function approach. We find a Fstat equals to 22.62 , indicating that our excluded instruments are not weakly correlated with the endogenous retail price variable.

${ }^{47}$ Consistent with Bonnet and Réquillart (2013a), we also obtain an average own-price elasticity of -3.27 for soft drinks (excluding fruit juices).
} 
Table 3: Results of the random coefficient logit model

\begin{tabular}{|c|c|c|c|}
\hline Variable & Coefficient & Variable & Coefficient \\
\hline Retail price $\times$ Private label & $2.24^{*}(0.63)$ & & \\
\hline Retail price $\times$ National brand & $1.05^{*}(0.20)$ & & \\
\hline Retail price $\times v_{i}$ & $0.81^{*}(0.29)$ & & \\
\hline Control function & $3.77^{*}(1.16)$ & & \\
\hline \multicolumn{4}{|l|}{ Retailer fixed effects: } \\
\hline Retailer 1 & $0.99(0.61)$ & Retailer 5 & $0.24(0.59)$ \\
\hline Retailer 2 & $0.49(0.61)$ & Retailer 6 & $0.65(0.61)$ \\
\hline Retailer 3 & $0.32(0.61)$ & Retailer 7 & ref. \\
\hline Retailer 4 & $0.87(0.62)$ & & \\
\hline \multicolumn{4}{|l|}{ Brand fixed effects: } \\
\hline Brand $23(P L)$ & $0.49(1.01)$ & Brand 9 & -1.89 (1.39) \\
\hline Brand 5 & $1.13(1.65)$ & Brand 4 & $-2.83(1.77)$ \\
\hline \multicolumn{4}{|l|}{ Other sodas } \\
\hline Brand $25(P L)$ & $1.93(1.00)$ & Brand 14 & $-0.95(1.60)$ \\
\hline Brand 3 & $-2.71(1.45)$ & Brand 15 & $-0.45(1.77)$ \\
\hline Brand 6 & $-0.93(1.72)$ & Brand 17 & $0.14(1.89)$ \\
\hline Brand 7 & $-0.59(2.20)$ & Brand 19 & $-3.35(1.81)$ \\
\hline Brand 8 & $-4.12 *(1.52)$ & Brand 20 & $1.81(3.20)$ \\
\hline Brand 10 & $-2.95^{*}(1.46)$ & Brand 21 & $-4.84^{*}(1.40)$ \\
\hline \multicolumn{4}{|l|}{ Fruit juices } \\
\hline Brand $22(P L)$ & $6.24^{*}(0.25)$ & Brand 1 & $-0.07(2.42)$ \\
\hline Brand 11 & $2.89(2.64)$ & Brand 18 & $-0.81(1.90)$ \\
\hline Brand 16 & $0.94(2.44)$ & & \\
\hline \multicolumn{4}{|l|}{ Iced tea } \\
\hline Brand $24(P L)$ & $1.70(0.97)$ & Brand 12 & $-0.20(1.82)$ \\
\hline Brand 2 & $-2.58(1.65)$ & Brand 13 & $-2.13(2.09)$ \\
\hline Simulated Log-likelihood & $-922,237$ & & \\
\hline Number of observations & 265,998 & & \\
\hline
\end{tabular}

aggregated by soft drink categories. Results reveal intuitive patterns. For instance, a 1\% increase in the retail prices of iced tea products has a larger effect on the demand for fruit juices $(+1.79 \%)$ than a $1 \%$ increase in the retail prices of other sodas $(+1.61 \%)$ or colas $(+1.36 \%)$. Similarly, we find that colas and other sodas are closer substitutes than cola and iced tea products. The second column of Table 6 reports further results at the manufacturercategory level. Except for iced tea products, we obtain that the (quantity weighted) average own-price elasticities are higher than the aggregate own-price elasticities. This suggests that consumers also substitute between products of the same category (especially for fruit juices). 
Table 4: Category-level price elasticity

\begin{tabular}{lrccc}
\hline \hline \multirow{2}{*}{ Category } & \multicolumn{4}{c}{ Elasticities } \\
\cline { 2 - 5 } & Colas & Other sodas & Fruit juices & Iced tea \\
\hline Colas & -2.30 & 0.84 & 1.36 & 0.25 \\
Other sodas & 0.75 & -2.63 & 1.61 & 0.24 \\
Fruit juices & 0.25 & 0.34 & -1.80 & 0.13 \\
Iced tea & 0.67 & 0.72 & 1.79 & -3.37 \\
\hline \hline
\end{tabular}

Notes: Own and cross-price elasticities aggregated at the category-level. Numbers show the effect of a $1 \%$ increase in the retail prices of all products in the category of row $j$ on the demand for products in the category of column $k$.

\subsubsection{Supply estimates}

Table 5 reports estimates of the retail marginal cost function described in (15). The value of the GMM objective function at estimated parameters is 1.90 and the overidentification test of Hansen (1982) cannot reject our model at the 95\% confidence level. Cost parameters are precisely estimated and have the expected signs. For instance, fruit juice fixed effects contribute positively to the marginal costs of products due to their fruit content. In contrast, the marginal cost of private labels is on average lower than that of national brands. While bargaining weight parameters should theoretically lie in the interval $[0,1]$, we do not impose any parameter constraints in our estimation. Results indicate that there is substantial heterogeneity in the bargaining weights of retailers across manufacturers and soft drink categories. While retailers have a lower bargaining ability than manufacturers 3 and 4, results vis-à-vis manufacturer 1 are more balanced. We do not report standard errors for the bargaining weights of retailers vis-à-vis manufacturer 2 because they are not on the interior of the parameter space. Instead, we use a grid search method and select values of the bargaining weights of retailers vis-à-vis manufacturer 2 that minimize our GMM objective function (we refer to Appendix $\mathrm{E}$ for further details). We find that retailers make take-it-or-leave-it offers to manufacturer 2 for products belonging to the cola/other soda category. This result is particularly consistent with anecdotal evidence suggesting that manufacturer 2's market penetration on the cola/other soda product category in France is very limited. ${ }^{48}$ In contrast, when negotiating wholesale prices of fruit juice products, we find that retailers receive take-it-or-leave-it offers from manufacturer 2 which owns the leading brand in this category.

\footnotetext{
${ }^{48} \mathrm{At}$ the end of the 1990s, the European Commission (EC) received several complaints from manufacturer 2 alleging an abuse of dominant position of manufacturer 1 which raise entry barriers in the cola/other soda product category. In 2005, the EC adopted a commitment decision (Case COMP/A.39.116/B2) requiring manufacturer 1 to stop its anti-competitive business practices including exclusive dealing and bundling. In addition to this anecdotal evidence, Table 1 provides descriptive evidence of the low market shares of manufacturer 2's cola/other soda products.
} 


\section{Table 5: Bargaining and marginal cost parameter estimates}

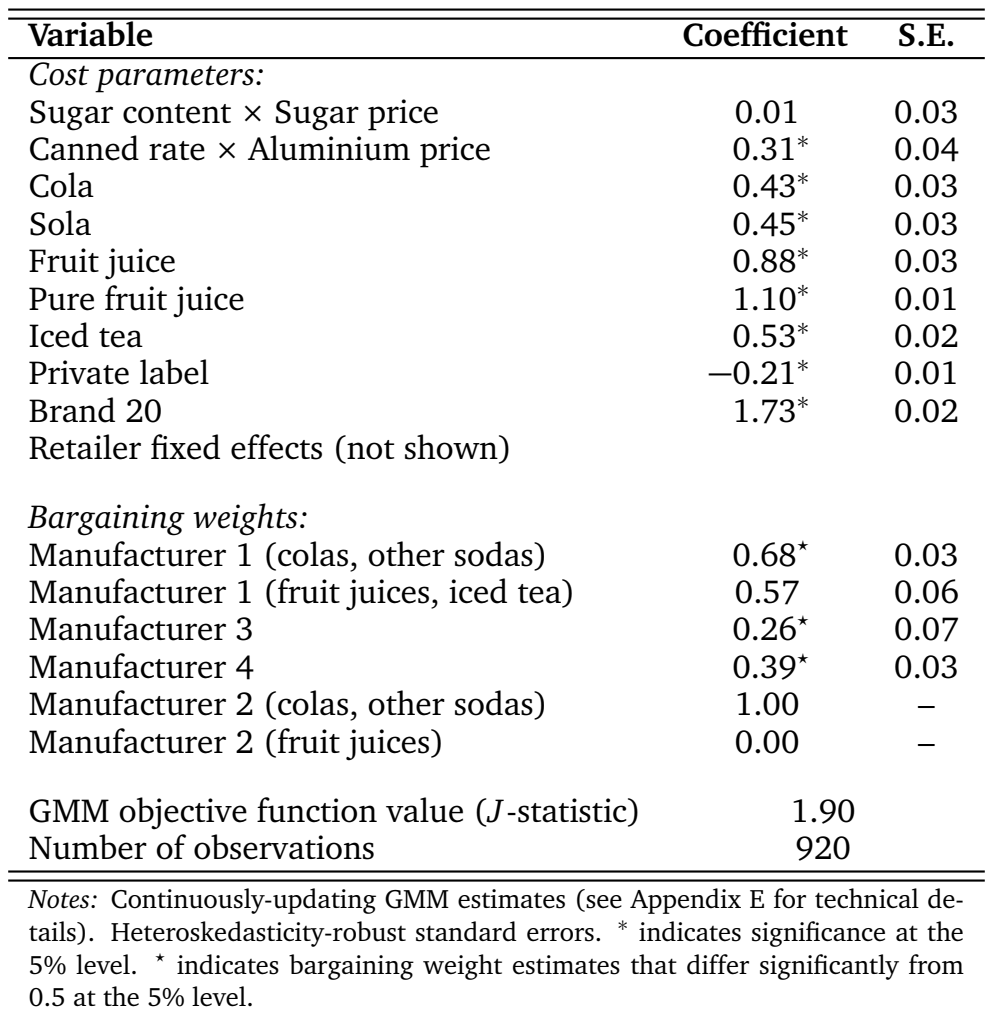

Using bargaining weight and cost parameter estimates, we can compute the price-cost margins of manufacturers, the marginal cost of production and distribution of products, and recover the surplus division in the vertical chain of the French soft drink industry. Table 6 displays the results. Consistent with our cost parameter estimates, we find that the marginal cost of fruit juice products is twice higher than that of cola, other soda, and iced tea products. For each soft drink category, we also find that private labels have much smaller marginal costs than national brands. These results explain part of the (observed) retail price variation which is also driven by differences in price-cost margins. In each soft drink category, we find greater total price-cost margins for national brands than for private labels, which is mainly due to the double-marginalization effects. These margins, however, are not evenly split between manufacturers and retailers. In particular, we obtain that the price-cost margins of manufacturers are systematically lower than the price-cost margins of retailers. This result suggests that the estimated bargaining weights partially explain the surplus division in the soft drink industry, especially for manufacturers 3 and 4 which have a higher bargaining ability than retailers.

In addition to the relative bargaining ability of firms, Section 2.2 highlights that two other sources of bargaining power influence the determination of trading terms between 
Table 6: Price-cost margins and marginal costs estimates

\begin{tabular}{|c|c|c|c|c|c|c|}
\hline \multirow{2}{*}{ Categories } & \multirow{2}{*}{ Retail price } & \multirow{2}{*}{$\begin{array}{l}\text { Own-price } \\
\text { elasticities }\end{array}$} & \multirow{2}{*}{ Marginal Cost } & \multicolumn{3}{|c|}{$\overline{\text { Price-cost margins }}$} \\
\hline & & & & Manufacturers & Retailers & Total \\
\hline \multicolumn{7}{|c|}{ Manufacturer 1: } \\
\hline \multirow[t]{2}{*}{ Colas } & 0.92 & -3.05 & 0.49 & 12.09 & 35.13 & 47.22 \\
\hline & $(0.02)$ & $(0.02)$ & $(0.01)$ & $(0.08)$ & $(0.19)$ & $(0.25)$ \\
\hline \multirow[t]{2}{*}{ Other sodas } & 0.94 & -3.13 & 0.50 & 12.32 & 35.30 & 47.62 \\
\hline & $(0.03)$ & $(0.04)$ & $(0.03)$ & $(0.19)$ & $(0.40)$ & $(0.57)$ \\
\hline \multirow[t]{2}{*}{ Fruit juices } & 1.61 & -3.86 & 0.99 & 11.41 & 28.35 & 39.76 \\
\hline & $(0.08)$ & $(0.06)$ & $(0.07)$ & $(0.26)$ & $(0.45)$ & $(0.70)$ \\
\hline \multirow[t]{2}{*}{ Iced tea } & 0.93 & -3.17 & 0.47 & 15.06 & 35.01 & 50.07 \\
\hline & $(0.03)$ & $(0.04)$ & $(0.02)$ & $(0.17)$ & $(0.41)$ & $(0.57)$ \\
\hline \multicolumn{7}{|c|}{ Manufacturer 2: } \\
\hline \multirow[t]{2}{*}{ Colas } & 0.71 & -2.76 & 0.43 & 1.29 & 39.89 & 41.18 \\
\hline & $(0.02)$ & $(0.05)$ & $(0.02)$ & $(0.06)$ & $(0.59)$ & $(0.60)$ \\
\hline \multirow[t]{2}{*}{ Other sodas } & 0.76 & -2.82 & 0.45 & 1.32 & 39.21 & 40.53 \\
\hline & $(0.02)$ & $(0.05)$ & $(0.02)$ & $(0.06)$ & $(0.89)$ & $(0.86)$ \\
\hline \multirow[t]{2}{*}{ Fruit juices } & 2.19 & -4.07 & 1.15 & 20.52 & 26.28 & 46.80 \\
\hline & $(0.04)$ & $(0.01)$ & $(0.02)$ & $(0.05)$ & $(0.07)$ & $(0.08)$ \\
\hline \multicolumn{7}{|c|}{ Manufacturer 3: } \\
\hline \multirow[t]{2}{*}{ Iced tea } & 1.09 & -3.35 & 0.52 & 19.45 & 32.81 & 52.26 \\
\hline & $(0.02)$ & $(0.02)$ & $(0.01)$ & $(0.10)$ & $(0.19)$ & $(0.29)$ \\
\hline \multicolumn{7}{|c|}{ Manufacturer 4: } \\
\hline \multirow[t]{2}{*}{ Other sodas } & 1.08 & -3.29 & 0.53 & 18.49 & 33.41 & 51.90 \\
\hline & $(0.02)$ & $(0.01)$ & $(0.01)$ & $(0.09)$ & $(0.14)$ & $(0.20)$ \\
\hline \multirow[t]{2}{*}{ Fruit juices } & 1.79 & -3.96 & 1.04 & 14.57 & 27.38 & 41.95 \\
\hline & $(0.03)$ & $(0.02)$ & $(0.01)$ & $(0.11)$ & $(0.12)$ & $(0.23)$ \\
\hline \multicolumn{7}{|l|}{ Private labels: } \\
\hline \multirow[t]{2}{*}{ Colas } & 0.30 & -3.20 & 0.18 & - & 41.89 & 41.89 \\
\hline & $(0.01)$ & $(0.08)$ & $(0.01)$ & & (1.12) & (1.12) \\
\hline \multirow[t]{2}{*}{ Other sodas } & 0.39 & -3.53 & 0.25 & - & 36.53 & 36.53 \\
\hline & $(0.01)$ & $(0.04)$ & $(0.01)$ & & $(0.36)$ & $(0.36)$ \\
\hline \multirow[t]{2}{*}{ Fruit juices } & 0.84 & -3.83 & 0.60 & - & 28.83 & 28.83 \\
\hline & $(0.01)$ & $(0.01)$ & $(0.01)$ & & $(0.12)$ & $(0.12)$ \\
\hline \multirow[t]{2}{*}{ Iced tea } & 0.52 & -3.83 & 0.33 & - & 33.64 & 33.64 \\
\hline & $(0.01)$ & $(0.04)$ & $(0.01)$ & & $(0.38)$ & $(0.38)$ \\
\hline
\end{tabular}

Notes: Retail prices and marginal costs are in euro per liter. Price-cost margins are in percentage of the retail prices. All values are calculated using quantity weights and standard deviation in parenthesis refer to variation across months.

manufacturers and retailers in bilateral oligopolies. Table 7 displays estimates of these two bargaining forces as well as the share of the surplus generated by bilateral agreements which is captured by each retailer. We find that the ratio of the gains from trade of manufacturers to retailers ranges from 0.43 to 0.50 , suggesting that the losses from not reaching an agreement are twice higher for retailers than for manufacturers. While this bargaining force would tilt the distribution of bargaining power towards manufacturers, we also find that the ratio of the concession costs of manufacturers to retailers is close to half. This highlights that costs of making price concessions in negotiations decrease substantially more retailers' profits than manufacturers' profits, implying that the former are less willing to grant wholesale price concessions which reinforces their bargaining power. Overall, we obtain that each 
Table 7: Surplus division estimates

\begin{tabular}{lccc}
\hline \hline & Ratio of gains from trade & Ratio of concession costs & Share of retailers \\
\hline Retailer 1 & 0.49 & -0.48 & 67.60 \\
& $(0.01)$ & $(0.00)$ & $(0.18)$ \\
Retailer 2 & 0.48 & -0.49 & 67.01 \\
& $(0.01)$ & $(0.01)$ & $(0.51)$ \\
Retailer 3 & 0.48 & -0.48 & 66.48 \\
& $(0.01)$ & $(0.01)$ & $(0.25)$ \\
Retailer 4 & 0.50 & -0.48 & 67.11 \\
& $(0.01)$ & $(0.01)$ & $(0.26)$ \\
Retailer 5 & 0.43 & -0.55 & 69.51 \\
& $(0.01)$ & $(0.02)$ & $(0.67)$ \\
Retailer 6 & 0.48 & -0.49 & 67.61 \\
& $(0.01)$ & $(0.01)$ & $(0.50)$ \\
Retailer 7 & 0.47 & -0.49 & 66.60 \\
& $(0.01)$ & $(0.00)$ & $(0.23)$ \\
\hline \hline Notes: The first column displays the average ratio of gains from trade of manufacturers to retailers: $\left(\pi_{f t}-\right.$ \\
$\left.d_{f t}^{-j}\right) /\left(\pi_{r t}-d_{r t}^{-j}\right)$. The second column shows the quantity weighted average ratio of concession costs of manufac- \\
turers to retailers: $\frac{\partial \pi_{f t}}{\partial w_{j t}} / \frac{\partial \pi_{r t}}{\partial w_{j t}}$. The third columns shows the average share of the surplus from bilateral agreements \\
captured by each retailer. Standard deviation in parenthesis refer to variation across months.
\end{tabular}

retailer captures more than $65 \%$ of the surplus generated by its bilateral agreements with manufacturers, indicating that retailers have a higher bargaining power than soft drink manufacturers. This result shows that firms' relative concession costs play a critical role in the distribution of bargaining power in bilateral oligopolies.

\section{The equilibrium effects of retail mergers}

As first formalized by Williamson (1968), the welfare effect of horizontal mergers involves a basic trade-off. On the one hand, the reduction in the number of competing firms is likely to increase market power and raise prices paid by consumers. On the other hand, mergers may create efficiencies that give firms an incentive to decrease their prices. The role of buyer power as an efficiency defense has raised thorny questions in recent merger reviews. Leveraging estimates of our bilateral oligopoly model, this section aims at shedding new light on the effects of retail mergers on the buyer power of retailers and retail prices paid by consumers.

Theoretical insights. We consider a hypothetical merger between two retailers, indexed by $r$ and $r^{\prime}$, which gives rise to a multi-store retailer, indexed by $r r^{\prime}$, distributing the set of products $\mathscr{J}_{r t} \cup \mathscr{J}_{r^{\prime} t}$ as in Rey and Vergé (2020) (see also Grennan, 2013; Sheu and Taragin, 
2021, among others). ${ }^{49}$ Based on (1b), we define the (per-market) profit function of the merged entity as follows:

$$
\pi_{r r^{\prime} t}^{p o s t} \equiv \sum_{j \in \mathscr{F}_{r t} \cup \mathscr{I}_{r^{\prime} t}}\left(p_{j t}-w_{j t}-c_{j t}\right) q_{j t}\left(\mathbf{p}_{t}\right)
$$

In what follows, we examine the (pure) bargaining effect of the merger using insights drawn from Section 2. More specifically, we compare the pre-merger bilateral negotiation between manufacturer $f(j)$ and retailer $r$ over the wholesale price of product $j \in \mathscr{J}_{r t}$ with the postmerger bilateral negotiation between manufacturer $f(j)$ and the merged retailer $r r^{\prime}$ over the same wholesale price and discuss the effects on (i) the gains from trade of firms described in (7a) and (7b), and (ii) firms' concession costs in (8a) and (8b). ${ }^{50}$

As shown in (17), the merged retailer $r r^{\prime}$ distributes both sets of products $\mathscr{J}_{r t}$ and $\mathscr{J}_{r^{\prime} t}$ implying that the downstream market concentration increases. When products are substitutes, the gains from trade of the merged retailer $r r^{\prime}$ in its negotiation for product $j \in \mathscr{J}_{r t}$ are lower than what retailer $r$ obtains in the pre-merger situation. The intuition is that the marginal contribution of product $j$ to retailer $r$ 's profit reduces when it distributes a higher number of substitute products. Based on (6), we obtain that a decrease in the gains from trade of the merging retailers strengthens their bargaining power vis-à-vis manufacturer $f$. This mechanism is in line with the conventional wisdom suggesting that larger retailers are able to get better trading terms (Galbraith, 1952). In what follows, however, we stress that the effects generated by the merger on the relative concession costs of firms may nuance this view.

The post-merger concession costs of manufacturer $f(j)$ and the merged retailer $r r^{\prime}$ in the negotiation over the wholesale price of product $j \in \mathscr{J}_{r t}$ are respectively given by:

$$
\begin{aligned}
& \frac{\partial \pi_{f(j) t}^{\text {post }}}{\partial w_{j t}}=q_{j t}+\sum_{k \in \mathscr{g}_{f(j) t}}\left(w_{k t}-\mu_{k t}\right) \sum_{l \in \mathscr{g}_{r t} \cup \mathscr{J}_{r^{\prime} t}} \frac{\partial q_{k t}}{\partial p_{l t}} \frac{\partial p_{l t}}{\partial w_{j t}}
\end{aligned}
$$

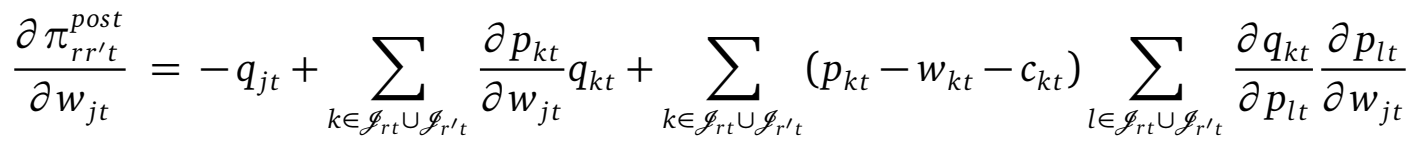

Compared to the pre-merger situation described in (8a) and (8b), the merged retailer fully

\footnotetext{
${ }^{49}$ In other words, the merger can be seen as a collusive behavior between retailers $r$ and $r^{\prime}$ which seek to maximize their joint profits $\left(\pi_{r t}+\pi_{r^{\prime} t}\right)$. This differs from the case where a merger reduces product variety (e.g., Iozzi and Valletti, 2014; Ho and Lee, 2017; Gaudin, 2018).

${ }^{50}$ For the sake of conciseness, we only provide the analysis for product $j \in \mathscr{J}_{r t}$. The effects of the merger on the wholesale price of product $j \in \mathscr{J}_{r^{\prime} t}$ is similar.
} 
internalizes the effects of an increase in $w_{j t}$ on the profit of retailer $r^{\prime}$. This has two implications for firms' concession costs. First, the second term in (18b) indicates that the retail price of each product $k \in \mathscr{J}_{r^{\prime} t}$ is also affected by a change in $w_{j t}$, which increases the retail price effect discussed in Section 2.2. Second, the last terms in (18a) and (18b) describe the impact of this (additional) retail price change on consumer demand. In particular, the portfolio effect in the last term of (18b) is greater than in ( $8 \mathrm{~b})$ because the merged retailer distributes a larger number of products. Using a simple framework of vertical relations with one manufacturer and three (single-product) retailers, we show in Appendix F that the concession costs of the merging retailers decrease (in absolute value) after the merger. This implies that the profits of the merging retailers are less sensitive to a change in wholesale prices which, as described in (6), reduces their bargaining power vis-à-vis manufacturer $f$.

To summarize, we find that the ultimate impact of downstream mergers on the bargaining power of retailers vis-à-vis manufacturers depends on two opposite bargaining forces. Based on this theoretical insight, we analyze the bargaining effect of retail mergers in the French soft drink industry using the notion of "equilibrium of fear" before conducting our counterfactual simulations.

Retail mergers and "equilibrium of fear". As described in (9), the outcome of the bargaining game developed in Section 2 can be interpreted in terms of "equilibrium of fear". Hence, the directional impact of retail mergers on wholesale prices can be understood by analyzing the effects on firms' fear of disagreement. Using estimates of our bilateral oligopoly model, we compute the ratio of firms' fear of disagreement for any (hypothetical) merger of two retailers (holding retail prices fixed). ${ }^{51}$ Figure 1 displays the results. We find that, for any merger, the fear of disagreement of the merging retailers is systematically higher than that of manufacturers in each bilateral negotiation (that is, $\frac{1}{\lambda} \frac{\pi_{r r^{\prime}(j) t}-d_{r r^{\prime}(j) t}^{-j}}{-\partial \pi_{r r^{\prime}(j) t} / \partial w_{j t}}>\frac{1}{(1-\lambda)} \frac{\pi_{f(j) t}-d_{f(j) t}^{-j}}{\partial \pi_{f(j) t} / \partial w_{j t}}$ ). This suggests that the merging retailers have to make price concessions to each of their suppliers, implying that retail mergers always weaken the bargaining power of the merged entity.

To analyze the heterogeneous effect of retail mergers on wholesale prices, we regress the ratio of firms' fear of disagreement on retailer, manufacturer-category, and market fixed effects. We also include fixed effects for mergers involving two small retailers and two large retailers to control for size effects. ${ }^{52}$ Results in Table 8 show that a merger between two large (resp. small) retailers decreases (resp. increases) the ratio of firms' fear of disagree-

\footnotetext{
${ }^{51}$ We consider a total of 21 downstream mergers.

${ }^{52}$ Based on market shares reported in Table 2, we consider that retailers 2, 3 and 7 are small retailers and retailers 1, 4, 5 and 6 are large retailers.
} 


\section{Figure 1: The retail mergers effects on the ratio of firms' fear of disagreement}

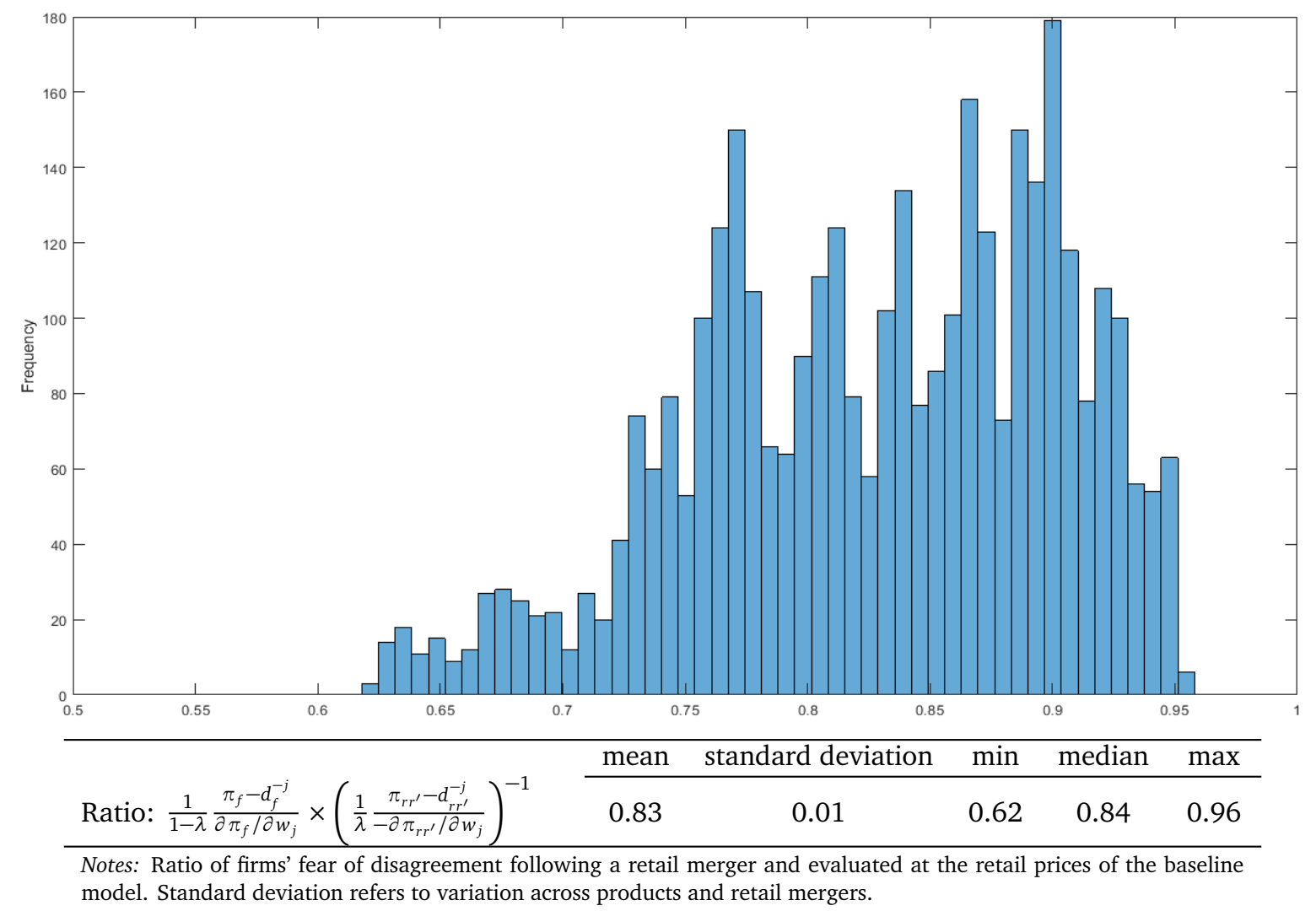

ment. This suggests that the increase in wholesale prices should be higher when the merging retailers are large. We also find that the fixed effects for retailers 1 and 4 are positive, implying that the increase in wholesale prices is smaller when a merger involves one of these two retailers.

These results offer preliminary evidence that the effect of retail mergers on firms' concession costs dominates that on firms' gains from trade, which weakens the bargaining power of the merging retailers vis-à-vis manufacturers. Moreover, the increase in wholesale prices is likely to be greater when a merger involves two large retailers. To further examine these findings while taking into account of changes in retail prices due to lower retail competition, we simulate three different mergers: (i) a merger involving two large retailers (retailers 1 and 4), (ii) a merger involving a small and a large retailer (retailers 2 and 6), and (iii) a merger involving two small retailers (retailers 3 and 7). ${ }^{53}$

\footnotetext{
${ }^{53}$ Based on Table 12 in Appendix H.1, we choose to simulate such mergers as they are likely to generate respectively a large, a medium, and a small wholesale price increase for the merging retailers.
} 
Table 8: The retail merger effects on firms' fear of disagreement

\begin{tabular}{|c|c|c|}
\hline Variable & $\overline{\text { Coefficient }}$ & $\overline{\overline{\text { S.E. }}}$ \\
\hline Intercept & $0.749^{*}$ & 0.003 \\
\hline $\begin{array}{l}\text { Merger size: } \\
\text { Two small retailers } \\
\text { Two large retailers }\end{array}$ & $\begin{array}{r}0.061^{*} \\
-0.064^{*}\end{array}$ & $\begin{array}{l}0.001 \\
0.001\end{array}$ \\
\hline $\begin{array}{l}\text { Retailer fixed effects: } \\
\text { Retailer } 1 \\
\text { Retailer } 2 \\
\text { Retailer } 3 \\
\text { Retailer } 4 \\
\text { Retailer } 5 \\
\text { Retailer } 6 \\
\text { Retailer } 7\end{array}$ & $\begin{array}{c}0.012^{*} \\
-0.041^{*} \\
-0.044^{*} \\
0.012^{*} \\
\text { ref. } \\
0.008^{*} \\
-0.047^{*}\end{array}$ & $\begin{array}{l}0.002 \\
0.002 \\
0.002 \\
0.002 \\
\text { ref. } \\
0.002 \\
0.002\end{array}$ \\
\hline \multicolumn{3}{|c|}{$\begin{array}{l}\text { Manufacturer-category fixed effects (not shown) } \\
\text { Market fixed effects (not shown) }\end{array}$} \\
\hline $\begin{array}{l}R^{2} \text { adjusted } \\
\text { Number of observations }\end{array}$ & \multicolumn{2}{|c|}{0.901} \\
\hline 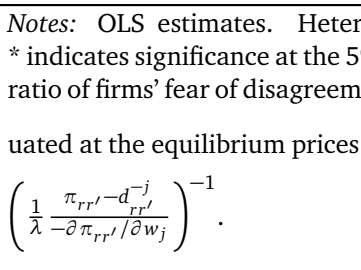 & $\begin{array}{l}\text { edasticity-rob } \\
\text { evel. The dep } \\
\text { following a re } \\
\text { the baseline } m\end{array}$ & $\begin{array}{l}\text { dard errors. } \\
\text { ariable is the } \\
\text { ger and eval- } \\
\frac{\pi_{f}-d_{f}^{-j}}{\partial \pi_{f} / \partial w_{j}} \times\end{array}$ \\
\hline
\end{tabular}

Merger simulations. Using estimates of our bilateral oligopoly model, we simulate the impact of retail mergers on equilibrium outcomes. We use the algorithm described in Appendix $\mathrm{D}$ to recompute a new bargaining and downstream price equilibrium. In particular, we perform our merger simulations holding fixed: (i) consumer preferences, (ii) the marginal cost of production and distribution of each product, (iii) the buyer-seller network structure, and (iv) the Nash bargaining weights of firms. ${ }^{54}$

Simulation results are reported in Table 9. For each merger simulation, we find that the (quantity-weighted) average price-cost margins of manufacturers for products distributed by the merging retailers increase. Retail mergers thus weaken the bargaining power of the merging retailers vis-à-vis manufacturers which is consistent with the insight drawn from our preliminary analysis. More specifically, the change in concession costs of firms which undermines the clout of the merging retailers in negotiations with manufacturers dominates the benefit obtained from the reduction in their gains from trade. As suggested by results

\footnotetext{
${ }^{54}$ The fact that marginal costs are held fixed is a reasonable short-run assumption which allows us to focus on the role of buyer power as an efficiency defense in merger analysis. We also follow prior empirical work by assuming that the Nash bargaining weights remain unaffected by mergers (e.g., Gowrisankaran, Nevo and Town, 2015; Sheu and Taragin, 2021). One may consider ad-hoc changes in these weights as in Grennan (2013). An extension would be to use the approach developed by Molina (2021) which, however, requires post-merger data.
} 
Table 9: Results of the merger simulations

\begin{tabular}{|c|c|c|c|c|c|}
\hline & \multirow{2}{*}{$\Delta$ Retail price } & \multicolumn{2}{|c|}{ 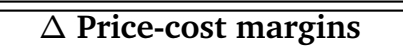 } & \multicolumn{2}{|c|}{$\Delta$ Profit } \\
\hline & & Manufacturer & Retailers & Manufacturer & Retailers \\
\hline \multicolumn{6}{|c|}{ Merger between retailers 1 and 4: } \\
\hline Retailer 1 & $\begin{array}{c}8.08 \\
(0.26)\end{array}$ & $\begin{array}{c}4.65 \\
(0.12)\end{array}$ & $\begin{array}{l}22.49 \\
(0.48)\end{array}$ & $\begin{array}{l}-2.08 \\
(0.21)\end{array}$ & $\begin{array}{c}2.64 \\
(0.12)\end{array}$ \\
\hline Retailer 4 & $\begin{array}{c}9.28 \\
(0.17)\end{array}$ & $\begin{array}{c}4.66 \\
(0.10)\end{array}$ & $\begin{array}{l}27.06 \\
(0.44)\end{array}$ & $\begin{array}{l}-4.37 \\
(0.23)\end{array}$ & $\begin{array}{c}2.03 \\
(0.08)\end{array}$ \\
\hline Other retailers & $\begin{array}{c}0.66 \\
(0.01)\end{array}$ & $\begin{array}{c}1.42 \\
(0.05)\end{array}$ & $\begin{array}{c}1.76 \\
(0.02)\end{array}$ & $\begin{array}{c}9.75 \\
(0.22)\end{array}$ & $\begin{array}{c}9.95 \\
(0.16)\end{array}$ \\
\hline Total & $\begin{array}{c}3.60 \\
(0.08)\end{array}$ & $\begin{array}{c}2.71 \\
(0.06)\end{array}$ & $\begin{array}{l}10.17 \\
(0.16)\end{array}$ & $\begin{array}{c}4.30 \\
(0.14)\end{array}$ & $\begin{array}{c}6.86 \\
(0.07)\end{array}$ \\
\hline \multicolumn{6}{|c|}{ Merger between retailers 2 and 6: } \\
\hline Retailer 2 & $\begin{array}{c}6.54 \\
(0.20)\end{array}$ & $\begin{array}{c}2.73 \\
(0.07)\end{array}$ & $\begin{array}{l}12.40 \\
(0.36)\end{array}$ & $\begin{array}{l}-5.18 \\
(0.29)\end{array}$ & $\begin{array}{c}1.17 \\
(0.09)\end{array}$ \\
\hline Retailer 6 & $\begin{array}{c}5.36 \\
(0.08)\end{array}$ & $\begin{array}{c}3.29 \\
(0.15)\end{array}$ & $\begin{array}{c}9.34 \\
(0.11)\end{array}$ & $\begin{array}{l}-2.46 \\
(0.22)\end{array}$ & $\begin{array}{c}1.50 \\
(0.07)\end{array}$ \\
\hline Other retailers & $\begin{array}{c}0.42 \\
(0.01)\end{array}$ & $\begin{array}{c}0.99 \\
(0.03)\end{array}$ & $\begin{array}{c}1.06 \\
(0.01)\end{array}$ & $\begin{array}{c}5.69 \\
(0.17)\end{array}$ & $\begin{array}{c}5.60 \\
(0.13)\end{array}$ \\
\hline Total & $\begin{array}{c}1.99 \\
(0.05)\end{array}$ & $\begin{array}{c}1.60 \\
(0.05)\end{array}$ & $\begin{array}{c}5.95 \\
(0.13)\end{array}$ & $\begin{array}{c}2.94 \\
(0.10)\end{array}$ & $\begin{array}{c}4.38 \\
(0.08)\end{array}$ \\
\hline \multicolumn{6}{|c|}{ Merger between retailers 3 and 7: } \\
\hline Retailer 3 & $\begin{array}{c}2.99 \\
(0.01)\end{array}$ & $\begin{array}{c}1.40 \\
(0.06)\end{array}$ & $\begin{array}{c}9.66 \\
(0.18)\end{array}$ & $\begin{array}{c}-2.56 \\
(0.06)\end{array}$ & $\begin{array}{c}0.69 \\
(0.02)\end{array}$ \\
\hline Retailer 7 & $\begin{array}{c}4.34 \\
(0.05)\end{array}$ & $\begin{array}{c}2.00 \\
(0.12)\end{array}$ & $\begin{array}{l}14.59 \\
(0.20)\end{array}$ & $\begin{array}{l}-4.48 \\
(0.09)\end{array}$ & $\begin{array}{c}0.13 \\
(0.03)\end{array}$ \\
\hline Other retailers & $\begin{array}{c}0.19 \\
(0.01)\end{array}$ & $\begin{array}{c}0.41 \\
(0.01)\end{array}$ & $\begin{array}{c}0.48 \\
(0.02)\end{array}$ & $\begin{array}{c}2.38 \\
(0.05)\end{array}$ & $\begin{array}{c}2.37 \\
(0.05)\end{array}$ \\
\hline Total & $\begin{array}{c}0.82 \\
(0.02)\end{array}$ & $\begin{array}{c}0.66 \\
(0.02)\end{array}$ & $\begin{array}{c}2.61 \\
(0.05)\end{array}$ & $\begin{array}{c}1.24 \\
(0.04)\end{array}$ & $\begin{array}{c}2.02 \\
(0.04)\end{array}$ \\
\hline
\end{tabular}

Notes: Percentage changes in retail prices and price-cost margins are calculated using quantity weights. Standard deviation in parenthesis refer to variation across markets.

of our preliminary analysis (see Table 12 of Appendix H.1), we can also observe that this wholesale price increase is higher (resp. smaller) for a merger involving two large (resp. small) retailers. Despite this loss of bargaining power vis-à-vis manufacturers, our simulation results highlight that each retail merger remains profitable. This is mainly explained by the reduction of downstream competition which allows the merging retailers to substantially increase their price-cost margins. Note that the other retailers benefit more from the merger than the merging retailers, which is consistent with the free-riding effect highlighted in Deneckere and Davidson (1985).

Our retail merger analysis illustrates well the different bargaining forces at work in our model of bilateral oligopoly. In particular, we highlight that the concession costs of firms during negotiations may have important implications for retail merger analysis. Interest- 
ingly, our results regarding the bargaining effect of retail mergers stand in contrast with Sheu and Taragin (2021) who use a framework of bilateral oligopoly with a simultaneous timing assumption which rules out the role of firms' concession costs in the bargaining outcome. By accounting for this additional bargaining force, we find no support for the countervailing buyer power theory of Galbraith (1952). Instead, we obtain that the sole motive for retail mergers is to increase market power, suggesting that antitrust practitioners should be particularly concerned about these operations.

\section{Concluding remarks}

The concept of buyer power and its implications for market outcomes have become increasingly topical in political and antitrust debates. In this article, we offer a framework for analyzing bilateral oligopolies with upstream and downstream competition. Using the "Nash-in-Nash" solution to determine the surplus division between manufacturers and retailers, we show that bargaining outcomes can be interpreted in terms of "equilibrium of fear" and depend on three different sources of bargaining power. We also show that our framework admits analytical solutions and can be estimated in a tractable way using data on soft drink purchases in France.

Our results suggest that retailers have a higher bargaining power than soft drink manufacturers. Exploring determinants of buyer power, we find evidence that retailers' costs of making price concessions during negotiations play an important role in their bargaining power vis-à-vis manufacturers. Using estimates of our bilateral oligopoly framework, we then analyze the effects of retail mergers on buyer power and retail prices paid by consumers. In contrast to the conventional wisdom, we find that the merging retailers systematically pay higher wholesale prices following the merger. The mechanism underlying this result is that retail mergers lower the concession costs of the merging retailers which, in turn, reduces their bargaining leverage vis-à-vis soft drink manufacturers. Our findings thus suggest that the concession costs of firms during negotiations, which have largely been ignored in empirical work, have critical implications for merger analysis in bilateral oligopolies.

While we focus on retail mergers in the French soft drink industry, our bilateral oligopoly framework can be used to analyze a number of other industries or policy questions such as tax incidence or buyer alliances (Molina, 2021). In addition to its flexibility, our framework can be estimated without data on wholesale contracts or marginal costs of firms, which are rarely available in practice. 
As retailers often distribute multiple product categories, a fruitful area for future research would be to extend our model to multi-category pricing. This would involve a multicategory demand model allowing for possible substitution and complementarity between product categories (see, e.g., Thomassen et al., 2017). The presence of complementary products in the "Nash-in-Nash" bargaining model would also raise a number of interesting theoretical and empirical issues that remain unexplored in the literature (see Collard-Wexler, Gowrisankaran and Lee, 2019; Easterbrook et al., 2019). 


\section{Appendix}

\section{A Derivation of the price-cost margins}

This section presents details on the analytical derivative of the price-cost margins of retailers and manufacturers.

\section{A.1 Price-cost margins of retailers}

Following Berry, Levinsohn and Pakes (1995) and Nevo (2001), we use matrix algebra to re-write the set of first-order conditions characterizing Nash equilibrium in retail prices given by (2) as follows:

$$
\mathbf{q}_{t}+\left(\mathbf{O}_{r t} \circ \mathbf{Q}_{\mathbf{p}_{t}}\right) \gamma_{t}=\mathbf{0}_{J_{t}}
$$

where $\gamma_{t}$ is the $J_{t}$-dimensional vector of price-cost margins of retailers, $\mathbf{q}_{t}$ represents the $J_{t}$-dimensional vector of quantity, $\mathbf{O}_{r t}$ denotes the $J_{t} \times J_{t}$ ownership matrix of retailers with $\mathbf{O}_{r t}[j, k]=1$ if products $j$ and $k$ are distributed by the same retailer in market $t$ and 0 otherwise, $\mathbf{Q}_{\mathbf{p}_{t}}$ is the $J_{t} \times J_{t}$ matrix of first partial derivatives of market shares with respect to retail prices with $\mathbf{Q}_{\mathbf{p}_{t}}[j, k]=\frac{\partial q_{k t}}{\partial p_{j t}}$, and the mathematical symbol "o" represents the Hadamard product operator (element-by-element multiplication). By inverting (19), we can obtain the vector of price-cost margins of retailers as follows:

$$
\gamma_{t}=-\left(\mathbf{O}_{r t} \circ \mathbf{Q}_{\mathbf{p}_{t}}\right)^{-1} \mathbf{q}_{t}
$$

\section{A.2 Price-cost margins of manufacturers}

Nash bargaining problem. Consider the bilateral negotiation between manufacturer $f$ and retailer $r$ over the wholesale price of product $j \in \mathscr{J}_{f t} \cap \mathscr{J}_{r t}$, that is $w_{j t}$. Following Horn and Wolinsky (1988), the equilibrium wholesale price $w_{j t}^{*}$ maximizes the (asymmetric) Nash product of the bilateral negotiation between manufacturer $f$ and retailer $r$ taking other wholesale prices as given, that is:

$$
w_{j t}^{*} \equiv \underset{w_{j t}}{\operatorname{argmax}}\left(\pi_{f t}-d_{f t}^{-j}\right)^{1-\lambda_{f r}}\left(\pi_{r t}-d_{r t}^{-j}\right)^{\lambda_{f r}}
$$

The terms $\pi_{f t}$ and $\pi_{r t}$ in (21) correspond respectively to the profit of manufacturer $f$ and retailer $r$ if they reach an agreement (given that all other bilateral agreements are formed):

$$
\begin{aligned}
& \pi_{f t}=\left(w_{j t}-\mu_{j t}\right) q_{j t}\left(\mathbf{p}_{t}\left(w_{j t}, \mathbf{w}_{-j t}^{*}\right)\right)+\sum_{k \in \mathscr{I}_{f t} \backslash\{j\}}\left(w_{k t}^{*}-\mu_{k t}\right) q_{k t}\left(\mathbf{p}_{t}\left(w_{j t}, \mathbf{w}_{-j t}^{*}\right)\right) \\
& \pi_{r t}=\left(p_{j t}\left(w_{j t}, \mathbf{w}_{-j t}^{*}\right)-w_{j t}-c_{j t}\right) q_{j t}\left(\mathbf{p}_{t}\left(w_{j t}, \mathbf{w}_{-j t}^{*}\right)\right)+\sum_{k \in \mathscr{g}_{r t}\{\{j\}}\left(p_{k t}\left(w_{j t}, \mathbf{w}_{-j t}^{*}\right)-w_{k t}^{*}-c_{k t}\right) q_{k t}\left(\mathbf{p}_{t}\left(w_{j t}, \mathbf{w}_{-j t}^{*}\right)\right)
\end{aligned}
$$


where $w_{k t}^{*}$ is the (anticipated) equilibrium wholesale price of product $k \neq j$ and $\mathbf{w}_{-j t}^{*}$ is the vector of (anticipated) equilibrium wholesale prices determined in other bilateral bargains. The terms $d_{f t}^{-j}$ and $d_{r t}^{-j}$ in (21) correspond respectively to the status quo payoffs of manufacturer $f$ and retailer $r$ in the event of bilateral disagreement and are specified as follows:

$$
\begin{aligned}
& d_{f t}^{-j}=\sum_{k \in \mathscr{g}_{f t} \backslash\{j\}}\left(w_{k t}^{*}-\mu_{k t}\right) \tilde{q}_{k t}^{-j}\left(\tilde{\mathbf{p}}_{t}^{-j}\right) \\
& d_{r t}^{-j}=\sum_{k \in \mathscr{g}_{r t} \backslash\{j\}}\left(\tilde{p}_{k, t}^{-j}\left(\infty, \mathbf{w}_{-j t}^{*}\right)-w_{k t}^{*}-c_{k t}\right) \tilde{q}_{k t}^{-j}\left(\tilde{\mathbf{p}}_{t}^{-j}\right)
\end{aligned}
$$

where $\tilde{p}_{k, t}^{-j}$ is the out-of-equilibrium retail price of product $k \in \mathscr{J}_{r t} \backslash\{j\}$ when product $j$ is not offered on market $t, \tilde{\mathbf{p}}_{t}^{-j}$ is the $J_{t}$-dimensional vector of out-of-equilibrium retail prices set by retailer $r$ when product $j$ is not offered on market $t$ (see Appendix C for further details), and $\tilde{q}_{k t}^{-j}$ is the quantity of product $k$ in market $t$ given that product $j$ is removed from market $t$. As mentioned in Section 2.2, this specification of firms' status quo payoffs builds on two assumptions. First, the "Nash-in-Nash" solution implies that contracts are binding which rules out the possibility for firms to renegotiate wholesale prices following a bargaining breakdown (that is, wholesale prices of each product $k \in \mathscr{J}_{t} \backslash\{0, j\}$ remain fixed). Second, we assume that retailers compete on the downstream market with "interim unobservability", implying that only retailer $r$ is able to observe the bargaining breakdown with manufacturer $f$ for product $j \in \mathscr{J}_{r t}$ and optimally set retail prices of its other products accordingly.

First-order condition of the "Nash-in-Nash". The first-order condition of (21) which characterizes the division of surplus between manufacturer $f$ and retailer $r$ for product $j$ is given as follows:

$$
\begin{aligned}
& \lambda_{f r}\left(\pi_{f t}-d_{f t}^{-j}\right) \frac{\partial \pi_{r t}}{\partial w_{j t}}+\left(1-\lambda_{f r}\right)\left(\pi_{r t}-d_{r t}^{-j}\right) \frac{\partial \pi_{f t}}{\partial w_{j t}}=0 \\
& \Leftrightarrow\left(\Gamma_{j t} q_{j t}-\sum_{k \in \mathscr{q}_{f t} \backslash\{j\}} \Gamma_{k t}\left(\tilde{q}_{k t}^{-j}-q_{k t}\right)\right)\left(-q_{j t}+\sum_{k \in \mathscr{q}_{r t}} \frac{\partial p_{k t}}{\partial w_{j t}} q_{k t}+\sum_{k \in \mathscr{q}_{r t}} \gamma_{k t} \sum_{l \in \mathscr{q}_{r t}} \frac{\partial q_{k t}}{\partial p_{l t}} \frac{\partial p_{l t}}{\partial w_{j t}}\right) \\
& +\frac{1-\lambda_{f r}}{\lambda_{f r}}\left(\gamma_{j t} q_{j t}-\sum_{k \in \mathscr{q}_{r} \backslash\{j\}} \tilde{\gamma}_{k t} \tilde{q}_{k t}^{-j}-\gamma_{k t} q_{k t}\right)\left(q_{j t}+\sum_{k \in \mathscr{q}_{f t}} \Gamma_{k t} \sum_{l \in \mathscr{q}_{r t}} \frac{\partial q_{k t}}{\partial p_{l t}} \frac{\partial p_{l t}}{\partial w_{j t}}\right)=0
\end{aligned}
$$

where $\Gamma_{j t} \equiv w_{j t}-\mu_{j t}, \gamma_{j t} \equiv p_{j t}-w_{j t}-c_{j t}$, and $\tilde{\gamma}_{k t} \equiv \tilde{p}_{k t}^{-j}-w_{k t}^{*}-c_{k t}$.

Price-cost margins of manufacturers. For each market $t$, we have a total of $J_{t}$ price-cost margins of manufacturers, that is $\Gamma_{j t} \forall j \in \mathscr{J}_{t}$. In a spirit similar to the price-cost margins of retailers, we rely on a system of $J_{t}$ equations where (22) is the $j$ th equation. More specifically, it can be shown that the left-hand side of (22) is the $j$ th equation of the following system of "Nash-in-Nash" first order conditions written in matrix form as follows:

$$
\begin{aligned}
& \left(\left(\mathbf{O}_{f, t} \circ \tilde{\mathbf{Q}}_{\Delta t}\right) \boldsymbol{\Gamma}_{t}\right) \circ\left(\left(\mathbf{P}_{\mathbf{w}_{t}}-\mathbf{O}_{r, t} \circ \mathbf{I}_{t}\right) \mathbf{q}_{t}+\mathbf{P}_{\mathbf{w}_{t}}\left(\mathbf{O}_{r, t} \circ \mathbf{Q}_{\mathbf{p}_{t}}\right) \boldsymbol{\gamma}_{t}\right)+\Lambda \circ\left(\mathbf{O}_{r, t} \circ\left(\mathbf{1}_{J_{t}} \mathbf{q}_{t}^{\top}\right) \boldsymbol{\gamma}_{t}\right. \\
& \left.+\left(\mathbf{O}_{r, t} \circ\left(\tilde{\mathbf{Q}}_{\Delta t}-\mathbf{1}_{J_{t}} \mathbf{q}_{t}^{\top}\right) \circ \tilde{\boldsymbol{\gamma}}_{t}^{\top}\right) \mathbf{1}_{J_{t}}\right) \circ\left(\mathbf{q}_{t}+\left(\left(\mathbf{P}_{\mathbf{w}_{t}} \mathbf{Q}_{\mathbf{p}_{t}}\right) \circ \mathbf{O}_{f, t}\right) \boldsymbol{\Gamma}_{t}\right)=\mathbf{0}_{J_{t}}
\end{aligned}
$$


where $\mathbf{O}_{f t}$ is the $J_{t} \times J_{t}$ ownership matrix of manufacturers with $\mathbf{O}_{f t}[j, k]=1$ if products $j$ and $k$ are offered by the same manufacturer in market $t$ and 0 otherwise, $\mathbf{I}_{t}$ is a $J_{t} \times J_{t}$ diagonal matrix, $\mathbf{1}_{J_{t}}$ is a $J_{t}$-dimensional all-ones vector, and $\Lambda$ is a $J_{t}$-dimensional matrix in which the $j$ th element equals $\frac{1-\lambda_{f(j) r(j)}}{\lambda_{f(j) r(j)}}$. In addition, $\tilde{\mathbf{Q}}_{\Delta t}$ is the $J_{t} \times J_{t}$ matrix of differences in quantities upon a bargaining breakdown constructed as follows:

$$
\tilde{\mathbf{Q}}_{\Delta t}=\left(\begin{array}{cccc}
q_{1, t}\left(\mathbf{p}_{t}\right) & -\Delta \tilde{q}_{2, t}^{-1}\left(\tilde{\mathbf{p}}_{t}^{-1}\right) & \cdots & -\Delta \tilde{q}_{J, t}^{-1}\left(\tilde{\mathbf{p}}_{t}^{-1}\right) \\
-\Delta \tilde{q}_{1, t}^{-2}\left(\tilde{\mathbf{p}}_{t}^{-2}\right) & q_{2, t}\left(\mathbf{p}_{t}\right) & \cdots & -\Delta \tilde{q}_{J, t}^{-2}\left(\tilde{\mathbf{p}}_{t}^{-2}\right) \\
\vdots & \vdots & \ddots & \vdots \\
-\Delta \tilde{q}_{1, t}^{-J}\left(\tilde{\mathbf{p}}_{t}^{-J}\right) & -\Delta \tilde{q}_{2, t}^{-J}\left(\tilde{\mathbf{p}}_{t}^{-J}\right) & \cdots & q_{J t}\left(\mathbf{p}_{t}\right)
\end{array}\right)
$$

where $-\Delta \tilde{q}_{k, t}^{-j}\left(\tilde{\mathbf{p}}_{t}^{-j}\right)=q_{k, t}\left(\mathbf{p}_{t}\right)-\tilde{q}_{k, t}^{-j}\left(\tilde{\mathbf{p}}_{t}^{-j}\right), \tilde{\gamma}_{t}$ is the $J_{t} \times J_{t}$ matrix of price-cost margins and out-of-equilibrium price-cost margins of retailers given by:

$$
\tilde{\gamma}_{t}[k, j]= \begin{cases}+\infty & \text { if } k=j \\ \tilde{\gamma}_{k t}^{-j}=\tilde{p}_{k t}^{-j}+\gamma_{k t}-p_{k t} & \text { if } k \neq j \text { and } j, k \in \mathscr{J}_{r t} \\ \gamma_{k t} & \text { otherwise }\end{cases}
$$

and $\mathbf{P}_{\mathbf{w}_{t}}$ is the matrix of retail pass-through which has an analytical expression described in Appendix B.

Let us define: $\quad \mathbf{V}_{t} \equiv\left(\mathbf{P}_{\mathbf{w}_{t}}-\mathbf{O}_{r, t} \circ \mathbf{I}_{t}\right) \mathbf{q}_{t}+\mathbf{P}_{\mathbf{w}_{t}}\left(\mathbf{O}_{r, t} \circ \mathbf{Q}_{\mathbf{p}_{t}}\right) \gamma_{t} ; \mathbf{M}_{f, t} \equiv \mathbf{O}_{f, t} \circ \tilde{\mathbf{Q}}_{\Delta t} ;$

$$
\tilde{\mathbf{V}}_{t} \equiv \mathbf{O}_{r, t} \circ\left(\mathbf{1}_{J_{t}} \mathbf{q}_{t}^{\top}\right) \gamma_{t}+\left(\mathbf{O}_{r, t} \circ\left(\tilde{\mathbf{Q}}_{\Delta t}-\mathbf{1}_{J_{t}} \mathbf{q}_{t}^{\top}\right) \circ \tilde{\gamma}_{t}^{\top}\right) \mathbf{1}_{J_{t}} ; \quad \tilde{\mathbf{M}}_{t} \equiv\left(\mathbf{P}_{\mathbf{w}_{t}} \mathbf{Q}_{\mathbf{p}_{t}}\right) \circ \mathbf{O}_{f, t} ;
$$

and re-write the system of $J_{t}$ equations (23) as follows:

$$
\mathbf{V}_{t} \circ\left(\mathbf{M}_{t} \boldsymbol{\Gamma}_{t}\right)+\Lambda \circ \tilde{\mathbf{V}}_{t} \circ \mathbf{q}_{t}+\Lambda \circ \tilde{\mathbf{V}}_{t} \circ\left(\tilde{\mathbf{M}}_{t} \boldsymbol{\Gamma}_{t}\right)=\mathbf{0}
$$

To derive the vector of price-cost margins of manufacturers from (24), we introduce the following Lemma:

Lemma (Associative property). Let $\mathbf{V}, \Gamma$, and $\mathbf{1}_{J_{t}}$ be three $J_{t}$-dimensional vectors. Consider a $J \times J$ matrix denoted $\mathbf{M}$. If we define $\mathbf{C} \equiv \mathbf{V} \circ(\mathbf{M} \Gamma)$ and $\mathbf{D} \equiv\left(\left(\mathbf{V} \mathbf{J}_{J_{t}}^{\top}\right) \circ \mathbf{M}\right) \Gamma$, then

$$
\mathrm{C} \equiv \mathrm{D} .
$$

Proof. See Appendix A.3.

From (24) and the above Lemma, we can derive the price-cost margins of manufacturers as follows:

$$
\begin{aligned}
& \left(\left(\mathbf{V}_{t} \mathbf{1}_{J_{t}}^{\top}\right) \circ \mathbf{M}_{t}\right) \boldsymbol{\Gamma}_{t}+\Lambda \circ \tilde{\mathbf{V}}_{t} \circ \mathbf{q}_{t}+\left(\left(\left(\Lambda \circ \tilde{\mathbf{V}}_{t}\right) \mathbf{1}_{J_{t}}^{\top}\right) \circ \tilde{\mathbf{M}}_{t}\right) \boldsymbol{\Gamma}_{t}=\mathbf{0} \\
\Leftrightarrow & \boldsymbol{\Gamma}_{t}=-\left(\left(\mathbf{V}_{t} \mathbf{1}_{J_{t}}^{\top}\right) \circ \mathbf{M}_{t}+\left(\left(\Lambda \circ \tilde{\mathbf{V}}_{t}\right) \mathbf{1}_{J_{t}}^{\top}\right) \circ \tilde{\mathbf{M}}_{t}\right)^{-1}\left(\Lambda \circ \tilde{\mathbf{V}}_{t} \circ \mathbf{q}_{t}\right)
\end{aligned}
$$

As a result, we have an analytical expression for the price-cost margins of manufacturers in terms of $\lambda$ (bargain- 
ing weights), $\left(\mathbf{q}_{t}, \tilde{\mathbf{q}}_{t}^{-1}, \ldots, \tilde{\mathbf{q}}_{t}^{-J_{t}}\right.$ ) (demand and out-of-equilibrium demands), $\mathbf{Q}_{\Delta, t}$ (changes in demand upon bargaining breakdowns), $\left(\mathbf{Q}_{\mathbf{p}_{t}}, \tilde{\mathbf{Q}}_{\tilde{\mathbf{p}}_{t}^{-1}}, \ldots, \tilde{\mathbf{Q}}_{\tilde{\mathbf{p}}_{t}^{-t_{t}}}\right)$ (jacobian and out-of-equilibrium jacobians of demand), and $\mathbf{Q}_{\mathbf{p}_{t} \mathbf{p}_{t}}$ (hessian of demand which is an array of $J_{t}$ matrices of second partial derivatives) via the matrix $\mathbf{P}_{\mathbf{w}_{t}}$.

\section{A.3 Proof of Lemma}

We present the proof of the Lemma used in Appendix A.2 to derive an analytical expression for the price-cost margins of manufacturers. For the sake of exposition, we remove the subscript $t$ in our notations.

Lemma (Associative property). Let $\mathbf{V}, \Gamma$, and $\mathbf{1}_{J}$ be three $J$-dimensional vectors where every element of $\mathbf{1}_{J}$ is equal to 1 . Consider a $J \times J$ matrix denoted $\mathbf{M}$. If we define $\mathbf{C} \equiv \mathbf{V} \circ(\mathbf{M} \Gamma)$ and $\mathbf{D} \equiv\left(\left(\mathbf{V} \mathbf{1}_{J}^{\top}\right) \circ \mathbf{M}\right) \mathbf{\Gamma}$, then

$$
\mathbf{C}=\mathbf{D} .
$$

Proof. The $i$ th element of the vector $\mathbf{C}$ can be computed as follows:

$\begin{aligned} {[\mathbf{C}]_{i} } & =[\mathbf{V} \circ(\mathbf{M} \mathbf{\Gamma})]_{i} \\ \Leftrightarrow \quad[\mathbf{C}]_{i} & =[\mathbf{V}]_{i} \sum_{j=1}^{J}[\mathbf{M}]_{i j}[\mathbf{\Gamma}]_{j} \quad \text { where }[\mathbf{M}]_{i j} \text { denotes the element at the } i \text { th row and } j \text { th column of } \mathbf{M} .\end{aligned}$

Similarly, the $i$ th element of the vector $\mathbf{D}$ is derived as follows:

$$
\begin{aligned}
\quad[\mathbf{D}]_{i} & =\left[\left(\left(\mathbf{V} \mathbf{1}_{J}^{\top}\right) \circ \mathbf{M}\right) \mathbf{\Gamma}\right]_{i} \\
\Leftrightarrow \quad[\mathbf{D}]_{i} & =\sum_{j=1}^{J}[\mathbf{V}]_{i}[\mathbf{M}]_{i j}[\mathbf{\Gamma}]_{j} \\
\Leftrightarrow \quad[\mathbf{D}]_{i} & =[\mathbf{V}]_{i} \sum_{j=1}^{J}[\mathbf{M}]_{i j}[\mathbf{\Gamma}]_{j}
\end{aligned}
$$

Then, we have shown that $\forall i,[D]_{i}=[\mathbf{C}]_{i} \quad \Rightarrow \quad \mathbf{C}=\mathbf{D}$.

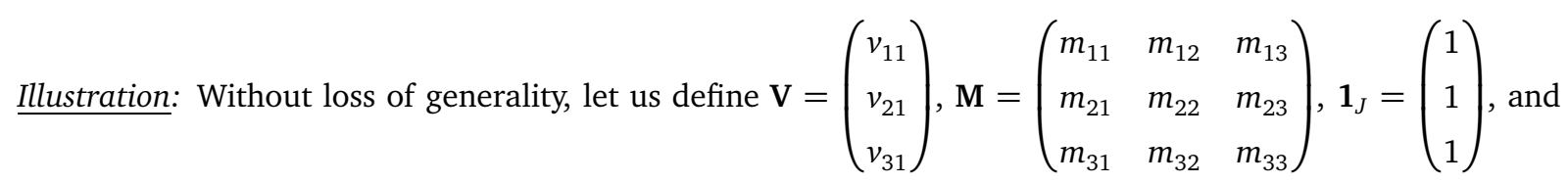
$\Gamma=\left(\begin{array}{c}\Gamma_{11} \\ \Gamma_{21} \\ \Gamma_{31}\end{array}\right)$. The second element of each vector $\mathbf{C}$ and $\mathbf{D}$ can be respectively derived as follows:

$$
[\mathbf{C}]_{2}=v_{21}\left(m_{21} \Gamma_{11}+m_{22} \Gamma_{21}+m_{23} \Gamma_{31}\right) \quad \text { and } \quad[\mathbf{D}]_{2}=v_{21} m_{21} \Gamma_{11}+v_{21} m_{22} \Gamma_{21}+v_{21} m_{23} \Gamma_{31}
$$

As a result, we have $[\mathrm{C}]_{2}=[\mathrm{D}]_{2}$. 


\section{B Derivation of the retail pass-through}

In this section, we derive an analytical expression for the matrix of pass-through of wholesale prices to retail prices. The first-order condition (2) which characterizes the pricing behavior of retailer $r$ for product $j \in \mathscr{J}_{r, t}$ is given by:

$$
q_{j t}\left(\mathbf{p}_{t}\right)+\sum_{k \in \mathscr{g}_{r t}}\left(p_{k t}-w_{k t}-c_{k t}\right) \frac{\partial q_{k t}}{\partial p_{j t}}=0
$$

Taking into account that retailers compete on the downstream market with "interim unobservability", we can differentiate (26) with respect to the wholesale price of product $l \in \mathscr{J}_{r t}$ as follows:

$$
\begin{gathered}
\frac{\partial}{\partial w_{l t}}\left(q_{j t}\right)+\sum_{k \in \mathscr{\not}_{r t}} \frac{\partial}{\partial w_{l t}}\left(p_{k t}-w_{k t}-c_{k t}\right) \frac{\partial q_{k t}}{\partial p_{j t}}+\sum_{k \in \mathscr{I}_{r t}}\left(p_{k t}-w_{k t}-c_{k t}\right) \frac{\partial}{\partial w_{l t}}\left(\frac{\partial q_{k t}}{\partial p_{j t}}\right)=0 \\
\Leftrightarrow \sum_{k \in \mathscr{g}_{r t}} \frac{\partial q_{j t}}{\partial p_{k t}} \frac{\partial p_{k t}}{\partial w_{l t}}+\sum_{k \in \mathscr{I}_{r t}} \frac{\partial p_{k t}}{\partial w_{l t}} \frac{\partial q_{k t}}{\partial p_{j t}}-\frac{\partial q_{l t}}{\partial p_{j t}}+\sum_{k \in \mathscr{I}_{r t}} \sum_{h \in \mathscr{I}_{r t}}\left(p_{k t}-w_{k t}-c_{k t}\right) \frac{\partial^{2} q_{k t}}{\partial p_{j t} \partial p_{h t}} \frac{\partial p_{h t}}{\partial w_{l t}}=0
\end{gathered}
$$

It can be shown that the left-hand side of equation (27) corresponds to the $l \times j$ element of the following $J_{t} \times J_{t}$ matrix:

$$
\mathbf{P}_{\mathbf{w}_{t}}\left(\mathbf{O}_{r, t} \circ \mathbf{Q}_{\mathbf{p}_{t}}\right)+\mathbf{P}_{\mathbf{w}_{t}}\left(\mathbf{O}_{r, t} \circ \mathbf{Q}_{\mathbf{p}_{t}}^{\top}\right)-\mathbf{O}_{r, t} \circ \mathbf{Q}_{\mathbf{p}_{t}}^{\top}+\mathbf{P}_{\mathbf{w}_{t}}\left(\mathbf{O}_{r, t} \circ \ddot{\mathbf{Q}}_{\mathbf{p}_{t} \mathbf{p}_{t}}\right)
$$

where $\mathbf{P}_{\mathbf{w}_{t}}$ is the $J_{t} \times J_{t}$ matrix of first partial derivatives of retail prices with respect to wholesale prices:

$$
\mathbf{P}_{\mathbf{w}_{t}}[j, k]= \begin{cases}\frac{\partial p_{k t}}{\partial w_{j t}} & \text { if } j, k \in \mathscr{J}_{r t} \\ 0 & \text { otherwise }\end{cases}
$$

and $\ddot{\mathbf{Q}}_{\mathbf{p}_{t} \mathbf{p}_{t}}$ represents a $J_{t} \times J_{t}$ matrix with the $k$ th column being equals to $\ddot{\mathbf{Q}}_{\mathbf{p}_{t} \mathbf{p}_{t}}[\cdot, k]=\left(\mathbf{O}_{r t} \circ \mathbf{Q}_{\mathbf{p}_{k t} \mathbf{p}_{t}}\right) \gamma_{t}$ where $\mathbf{Q}_{\mathbf{p}_{k t} \mathbf{p}_{t}}$ denotes the following $J_{t} \times J_{t}$ matrix of second partial derivatives:

$$
\mathbf{Q}_{\mathbf{p}_{k t} \mathbf{p}_{t}}=\left(\begin{array}{ccc}
\frac{\partial^{2} q_{1 t}}{\partial p_{k t} \partial p_{1 t}} & \cdots & \frac{\partial^{2} q_{J t}}{\partial p_{k t} \partial p_{1 t}} \\
\vdots & \ddots & \vdots \\
\frac{\partial^{2} q_{1 t}}{\partial p_{k t} \partial p_{J t}} & \cdots & \frac{\partial^{2} q_{J t}}{\partial p_{k t} \partial p_{J t}}
\end{array}\right)
$$

Given (27) and (28), $\mathbf{P}_{\mathbf{w}_{t}}$ can be obtained as follows:

$$
\begin{aligned}
& \mathbf{P}_{\mathbf{w}_{t}}\left(\mathbf{O}_{r t} \circ\left(\mathbf{Q}_{\mathbf{p}_{t}}+\mathbf{Q}_{\mathbf{p}_{t}}^{\top}+\ddot{\mathbf{Q}}_{\mathbf{p}_{t} \mathbf{p}_{t}}\right)\right)-\mathbf{O}_{r t} \circ \mathbf{Q}_{\mathbf{p}_{t}}^{\top}=\mathbf{0}_{J_{t} \times J_{t}} \\
\Leftrightarrow & \mathbf{P}_{\mathbf{w}_{t}}=\left(\mathbf{O}_{r t} \circ \mathbf{Q}_{\mathbf{p}_{t}}^{\top}\right)\left(\mathbf{O}_{r t} \circ\left(\mathbf{Q}_{\mathbf{p}_{t}}+\mathbf{Q}_{\mathbf{p}_{t}}^{\top}+\ddot{\mathbf{Q}}_{\mathbf{p}_{t} \mathbf{p}_{t}}\right)\right)^{-1}
\end{aligned}
$$


As we assume in our application (Section 3) that manufacturers of private labels are vertically integrated with retailers, we derive $\mathbf{P}_{\mathbf{w}_{t}}$ as follows:

$$
\mathbf{P}_{\mathbf{w}_{t}}=\left(\mathbf{O}_{r t}^{*} \circ \mathbf{Q}_{\mathbf{p}_{t}}^{\top}\right)\left(\mathbf{O}_{r t} \circ\left(\mathbf{Q}_{\mathbf{p}_{t}}+\mathbf{Q}_{\mathbf{p}_{t}}^{\top}+\ddot{\mathbf{Q}}_{\mathbf{p}_{t} \mathbf{p}_{t}}\right)\right)^{-1}
$$

where $\mathbf{O}_{r t}^{*}$ is the ownership matrix of retailers in which rows for private labels are set to 0 , that is: $\mathbf{O}_{r t}^{*}[j, \cdot]=$ $\mathbf{0}_{J_{t}}^{\top}$ if product $j$ is a private label.

\section{Computation of the out-of-equilibrium retail prices}

In this section, we derive the out-of-equilibrium retail prices following bilateral disagreements between manufacturers and retailers. Let us assume that, for a given market $t$, product $j \in \mathscr{J}_{r t}$ is no longer offered on the market. Under the assumptions that wholesale prices and distribution costs of other products remain unchanged, ${ }^{55}$ the equilibrium margins $\left(\gamma_{k t}\right)$ and out-of-equilibrium margins $\left(\tilde{\gamma}_{k t}^{-j}\right)$ of product $k \in \mathscr{J}_{r t} \backslash\{j\}$ are written as follows: $\gamma_{k t}=p_{k t}-w_{k t}-c_{k t}$ and $\tilde{\gamma}_{k t}^{-j}=\tilde{p}_{k t}^{-j}-w_{k t}-c_{k t}$, implying the following equality:

$$
\tilde{p}_{k t}^{-j}-\tilde{\gamma}_{k t}^{-j}-\left(p_{k t}-\gamma_{k t}\right)=0 \quad \forall k \in \mathscr{J}_{r t} \backslash\{j\}
$$

Based on the above equality, we have the following system of $J_{t}$ nonlinear equations:

$$
\tilde{\mathbf{p}}_{t}^{-j}-\tilde{\gamma}_{t}^{-j}-\left(\mathbf{p}_{t}-\gamma_{t}\right)=\mathbf{0}_{J_{t}}
$$

where $\mathbf{0}_{J_{t}}$ is a $J_{t}$-dimensional vector with all entries being equal to $0, \tilde{\mathbf{p}}_{t}^{-j}$ is a $J_{t}$-dimensional vector of out-ofequilibrium retail prices upon the removal of product $j$ for which the $k$ th element equals:

$$
\tilde{\mathbf{p}}_{t}^{-j}[k, 1]= \begin{cases}+\infty & \text { if } j=k \\ \tilde{p}_{k t}^{-j} & \text { if } k \in \mathscr{J}_{r t} \\ p_{k t} & \text { if } k \notin \mathscr{J}_{r t}\end{cases}
$$

and $\tilde{\gamma}_{t}^{-j}$ s a $J_{t}$-dimensional vector of out-of-equilibrium price-cost margins of retailers upon the removal of product $j$ for which the $k$ th element equals:

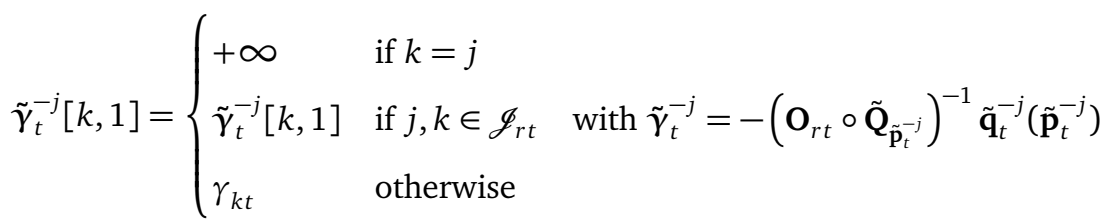

To solve the system (31) and recover the out-of-equilibrium retail prices $\tilde{p}_{k t}^{-j} \forall k \in \mathscr{J}_{r t}$, we employ a trustregion dogleg method. ${ }^{56}$ Equilibrium retail prices are used as an initial guess for the out-of-equilibrium retail

\footnotetext{
${ }^{55}$ We leverage a feature of the "Nash-in-Nash" bargaining protocol which implies that a breakdown in a bilateral negotiation has no effect on wholesale prices determined in the other negotiations.

${ }^{56}$ The search for a numerical root is performed with the MATLAB fsolve function.
} 
prices, that is $\tilde{\mathbf{p}}_{t}^{-j,(0)}=\mathbf{p}_{t}$.

\section{Counterfactual algorithm}

This section describes the algorithm used to conduct our retail merger simulations in Section 4. To estimate the vector of equilibrium retail prices following a retail merger, we have to solve a new bargaining and downstream price equilibrium for each market $t$. In the resolution of the new bargaining equilibrium, new status quo payoffs of firms involved in bilateral negotiations have to be constructed. In particular, we have to recover every vector of out-of-equilibrium retail prices in case of a bargaining breakdown. Hence, the problem can be seen as a large system of nonlinear equations for which $\theta^{\text {post }} \equiv\left(\left(\mathbf{p}_{t}^{\text {post }}\right)^{\top},\left(\tilde{\mathbf{p}}_{t}^{-1, \text { post }}\right)^{\top}, \ldots\left(\tilde{\mathbf{p}}_{t}^{-J \text {,post }}\right)^{\top}\right)^{\top}$ is a vector of dimension $J_{t}+\sum_{j}\left|\mathscr{I}_{r(j) t} \backslash\{j\}\right|$ that solves the following system:

$$
\mathbf{F}\left(\theta^{\text {post }}\right)=\left\{\begin{array}{cc}
\mathbf{f}\left(\tilde{\mathbf{p}}_{t}^{-1, \text { post }}, \mathbf{p}_{t}^{\text {post }}\right) & =\mathbf{0}_{J_{t}} \\
\vdots & \vdots \\
\mathbf{f}\left(\tilde{\mathbf{p}}_{t}^{-J, \text { post }}, \mathbf{p}_{t}^{\text {post }}\right) & =\mathbf{0}_{J_{t}} \\
\mathbf{g}\left(\mathbf{p}_{t}^{\text {post }}, \tilde{\mathbf{p}}_{t}^{-1, \text { post }}, \ldots, \tilde{\mathbf{p}}_{t}^{-J, \text { post }}\right) & =\mathbf{0}_{J_{t}}
\end{array}\right.
$$

In (32), each $\mathbf{f}\left(\tilde{\mathbf{p}}_{t}^{-j \text {,post }}, \mathbf{p}_{t}^{\text {post }}\right)=\mathbf{0}_{J_{t}}$ with $j \in \mathscr{J}_{r t}$ represents a sub-system of $J_{t}$ nonlinear equations characterizing the out-of-equilibrium behavior of retailers in the event of a bargaining breakdown (see Appendix $\mathrm{C}$ ). The last sub-sytem $\mathbf{g}\left(\mathbf{p}_{t}^{\text {post }}, \tilde{\mathbf{p}}_{t}^{-1, \text { post }}, \ldots, \tilde{\mathbf{p}}_{t}^{-J, \text { post }}\right)=\mathbf{0}_{J_{t}}$ consists of $J_{t}$ nonlinear equations which characterize the equilibrium behavior of firms in market $t$ (that is, the bargaining between manufacturers and retailers and the downstream price competition). As it is computationally cumbersome to solve for the whole nonlinear system (32), we decompose the problem in sub-systems and employ a Gauss-Seidel-type algorithm.

Iterative Estimation Algorithm. The iterative algorithm used to perform our merger simulations is described as follows. For each market $t$, we assume that the marginal production and distribution costs (that is, $c_{j t}+$ $\left.\mu_{j t} \forall j \in \mathscr{J}_{t} \backslash\{0\}\right)$ remain unchanged.

1. Initialization: For each market $t$, parameters to be estimated are the $J_{t}$-dimensional vector of counterfactual equilibrium retail prices $\mathbf{p}_{t}^{\text {post }}$ and the $\left|\mathscr{J}_{r t} \backslash\{j\}\right|$ retail prices in each vector of counterfactual out-of-equilibrium retail prices when product $j \in \mathscr{J}_{r t}$ is removed from the market (that is, $\tilde{\mathbf{p}}_{t}^{-j, \text { post }}$ ). For every vector of counterfactual retail prices and out-of-equilibrium retail prices, we use as an initial guess the vector of retail prices which solves the new downstream price equilibrium following the retail merger (holding wholesale prices fixed), that is:

$$
\hat{\mathbf{p}}_{t}^{\text {post }}=-\left(\mathbf{O}_{r t}^{\text {post }} \circ \hat{\mathbf{Q}}_{\hat{\mathbf{p}}_{t}^{\text {post }}}\right)^{-1} \hat{\mathbf{q}}_{t}\left(\hat{\mathbf{p}}_{t}^{\text {post }}\right)+\mathbf{w}_{t}+\mathbf{c}_{t}
$$

where $\mathbf{O}_{r t}^{\text {post }}$ is the ownership matrix of retailers following the retail merger.

2. At the $i$ th iteration, we recover each vector of counterfactual out-of-equilibrium retail prices $\tilde{\mathbf{p}}_{t}^{-j,(i)}$ upon the removal of product $j \in \mathscr{J}_{t} \backslash\{0\}$ by solving the following system of nonlinear equations (we drop 
the label "post" for expositional convenience):

$$
\underbrace{\tilde{\tilde{p}}_{t}^{-j,(i)}-\tilde{\gamma}_{t}^{-j,(i)}}_{\mathbf{w}_{t}^{(i)}+\mathbf{c}_{t}}-(\underbrace{\mathbf{p}_{t}^{(i-1)}-\gamma_{t}^{(i-1)}}_{\mathbf{w}_{t}^{(i-1)}+\mathbf{c}_{t}})=\mathbf{0}
$$

where $\boldsymbol{\gamma}_{t}^{(i-1)}=-\left(\mathbf{O}_{r t} \circ \mathbf{Q}_{\mathbf{p}}\left(\mathbf{p}_{t}^{(i-1)}\right)\right)^{-1} \mathbf{q}_{t}\left(\mathbf{p}_{t}^{(i-1)}\right), \tilde{\gamma}_{t}^{-j,(i)}$ is a $J_{t}$-dimensional vector with $k$ th element equals to:

$$
\tilde{\gamma}_{t}^{-j,(i)}[k, 1]= \begin{cases}\infty & \text { if } j=k \\ \tilde{\gamma}_{t}^{-j,(i)}[k, 1] & \text { if } j, k \in \mathscr{J}_{r t} \text { with } \tilde{\boldsymbol{\gamma}}_{t}^{-j,(i)}=-\left(\mathbf{O}_{r t} \circ \tilde{\mathbf{Q}}_{\tilde{\mathbf{p}}_{t}^{-j,(i)}}\left(\tilde{\mathbf{p}}_{t}^{-j,(i)}\right)\right)^{-1} \tilde{\mathbf{q}}_{t}^{-j}\left(\tilde{\mathbf{p}}_{t}^{-j,(i)}\right) \\ \boldsymbol{\gamma}_{t}^{(i-1)}[k, 1] & \text { otherwise }\end{cases}
$$

Note that before each iteration we update the vector $\tilde{\mathbf{p}}_{t}^{-j,(i)}$ using $\tilde{\mathbf{p}}_{t}^{-j,(i-1)}$ as starting point.

3. Given the guess of $\mathbf{p}_{t}^{(i-1)}$ and each out-of-equilibrium retail prices (and, in turn, retail margins) from step 2, we construct the $J_{t} \times J_{t}$ matrices $\mathbf{P}_{\mathbf{w}_{t}}^{(i)}$ and $\tilde{\mathbf{Q}}_{\Delta t}^{(i)}$ using derivatives from Appendix B and Appendix A.2 respectively.

4. The vector of counterfactual equilibrium retail prices $\mathbf{p}_{t}^{(i)}$ is the solution to the following system of nonlinear equations:

$$
\underbrace{\mathbf{p}_{t}^{(i)}-\left(\gamma_{t}^{(i)}+\Gamma_{t}^{(i)}\right)}_{\mathbf{c}_{t}+\mu_{t}}-\underbrace{\mathbf{p}_{t}-\left(\gamma_{t}-\Gamma_{t}\right)}_{\mathbf{c}_{t}+\mu_{t}}=0_{J_{t}}
$$

where $\boldsymbol{\Gamma}_{t}^{(i)}$ is derived as in Appendix A.2. Note that before each iteration we update the vector $\mathbf{p}_{t}^{(i)}$ using $\mathbf{p}_{t}^{(i-1)}$ as starting point.

5. We iteratively apply steps 2 . to 4 . until convergence, that is $\left\|\mathbf{p}_{t}^{(i)}-\mathbf{p}_{t}^{(i-1)}\right\|<\epsilon$ (where in practice we use $\epsilon=10^{-06}$ ).

\section{E Estimation procedure of the bargaining model}

Estimation procedure. As mentioned in Section 3.2.2, we estimate the bargaining weights and cost parameters by continuous updating GMM (Hansen, Heaton and Yaron, 1996). Because cost parameters enter linearly into (15), we concentrate these parameters out of the objective function. Concretely, for any guess of the vector of bargaining weights $\lambda$, we compute the $\sum_{t} J_{t}$-dimensional vector of price-cost margins of manufacturers $\Gamma(\lambda)$ using (25) and recover the vector of cost parameters as follows: $\mathbf{k}=\left(\mathbf{v}^{\top} \mathbf{v}\right)^{-1} \mathbf{v}^{\top}(\mathbf{w}+\mathbf{c}-\Gamma(\lambda))$, where $\mathbf{v}$ is a $\sum_{t} J_{t} \times K$ matrix of cost shifters and $\mathbf{w}+\mathbf{c}$ is the $J_{t}$-dimensional vector of retail marginal costs. As described in (16), this approach allows us to search only over $\lambda$ which considerably increases the speed of convergence.

Grid search method. To obtain estimation results in Table 5, we proceed as follows. First, we run our GMM procedure using an exponential transformation to bound each bargaining weight between 0 and 1 , that is $\lambda=\frac{\exp \left(\lambda_{e}\right)}{1+\exp \left(\lambda_{e}\right)}$ where the nonlinear search is over $\lambda_{e}$. We find results that are qualitatively similar to those 


\section{Figure 2: Grid search method (3D plot)}

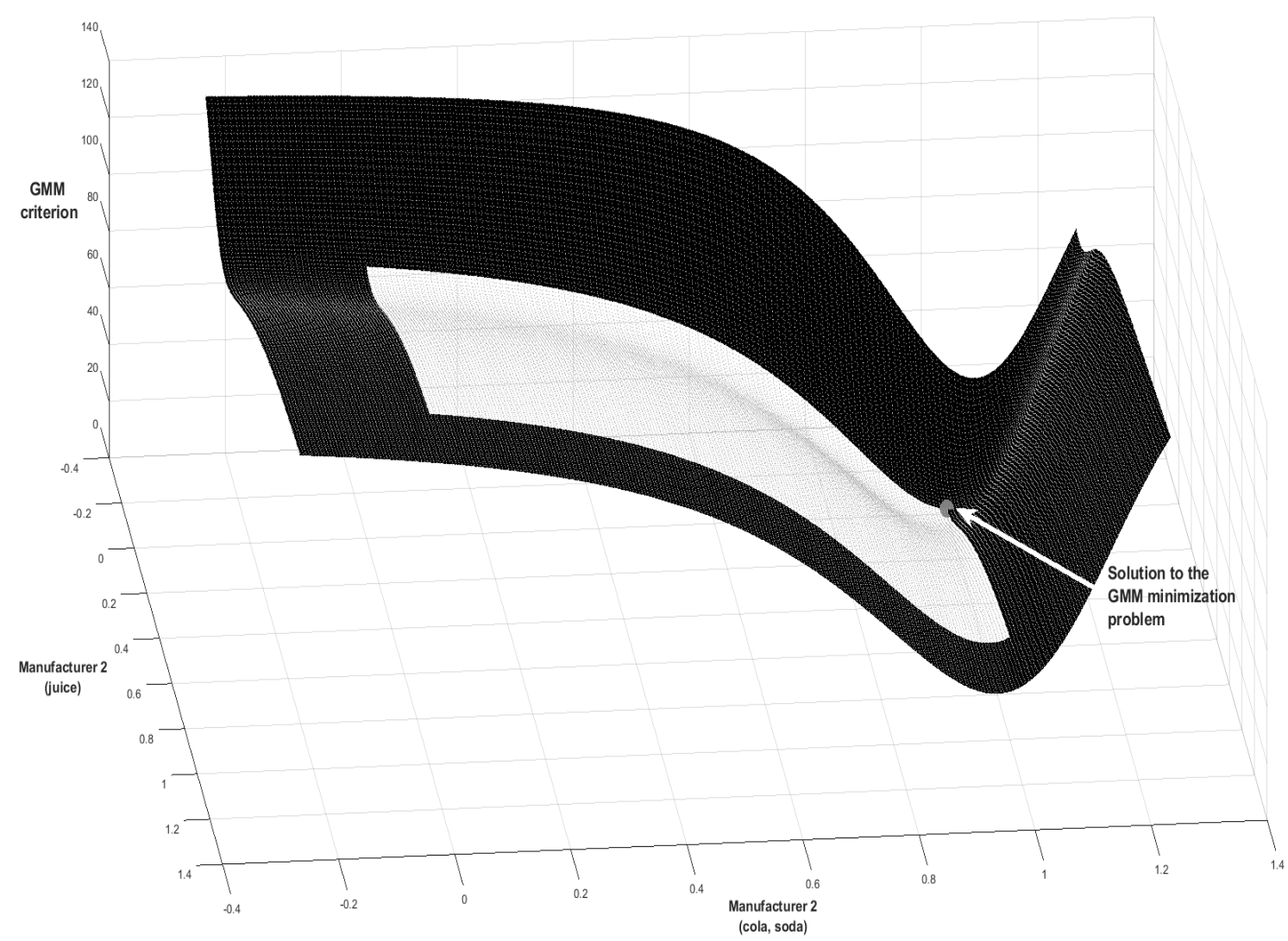

Notes: The $x$-axis displays the bargaining weight of retailers vis-à-vis manufacturer 2 for colas and other sodas products. The $z$-axis displays the bargaining weight of retailers vis-à-vis manufacturer 2 for fruit juices. The grid runs over each of these two bargaining weights from -0.4 to 1.4 with step-size 0.01 . The $y$-axis depicts values of the GMM criterion. The black area represents the set of all parameter values for which bargaining weights have no economic meaning: $\lambda \notin[0,1]$. The grey dot locates the solution to our GMM minimization problem in (16). This figure is drawn by keeping all other bargaining weights and cost parameters fixed to their estimated values (see Table 5).

reported in Table 5 where the bargaining weights of retailers vis-à-vis manufacturer 2 are on the boundary of the parameter space (that is, bargaining weights equal 0 for fruit juices and 1 for the colas/other sodas products). As the asymptotic distribution of estimators at the boundary is complex (e.g., it is generally not normal), we re-run our GMM procedure without any constraint on the bargaining weights of retailers but keeping those vis-à-vis manufacturer 2 fixed to 0 and 1 . We then use a two-dimensional grid search method to test the robustness of our estimation procedure. We consider a grid of values for each bargaining weight of retailers vis-à-vis manufacturer 2 from 0 to 1 with a step-size of 0.01 (holding the other bargaining weights and cost parameters at their estimated values). Figure 2 displays the results. The $x$-axis and the $z$-axis represent respectively the bargaining weight of retailers vis-à-vis manufacturer 2 for colas/other sodas and fruit juices. The $y$-axis shows values of the GMM criterion. The black area represents the set of parameter values for which bargaining weights have no economic meaning. We find that values of the bargaining weights that minimize the GMM criterion are around 0 for fruit juices and 1 for colas/other sodas. Moreover, the curvature of the GMM objective function suggests that alternative parameter values are not likely to be candidate for (local) minima. To further explore this issue, Figure 3 displays a one-dimensional grid search for each bargaining weight of retailers vis-à-vis manufacturer 2. Again, we find that the GMM objective function exhibits a great 


\section{Figure 3: Grid search method (2D plot)}

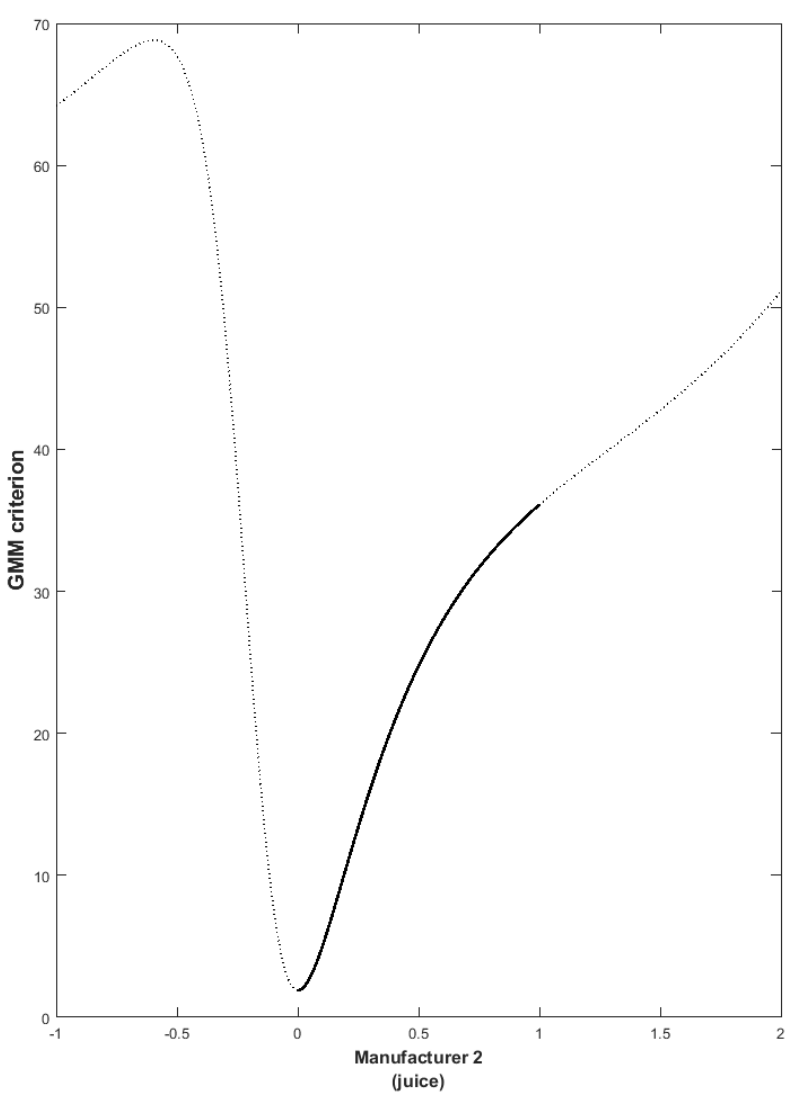

(a) Bargaining weight: Fruit juices

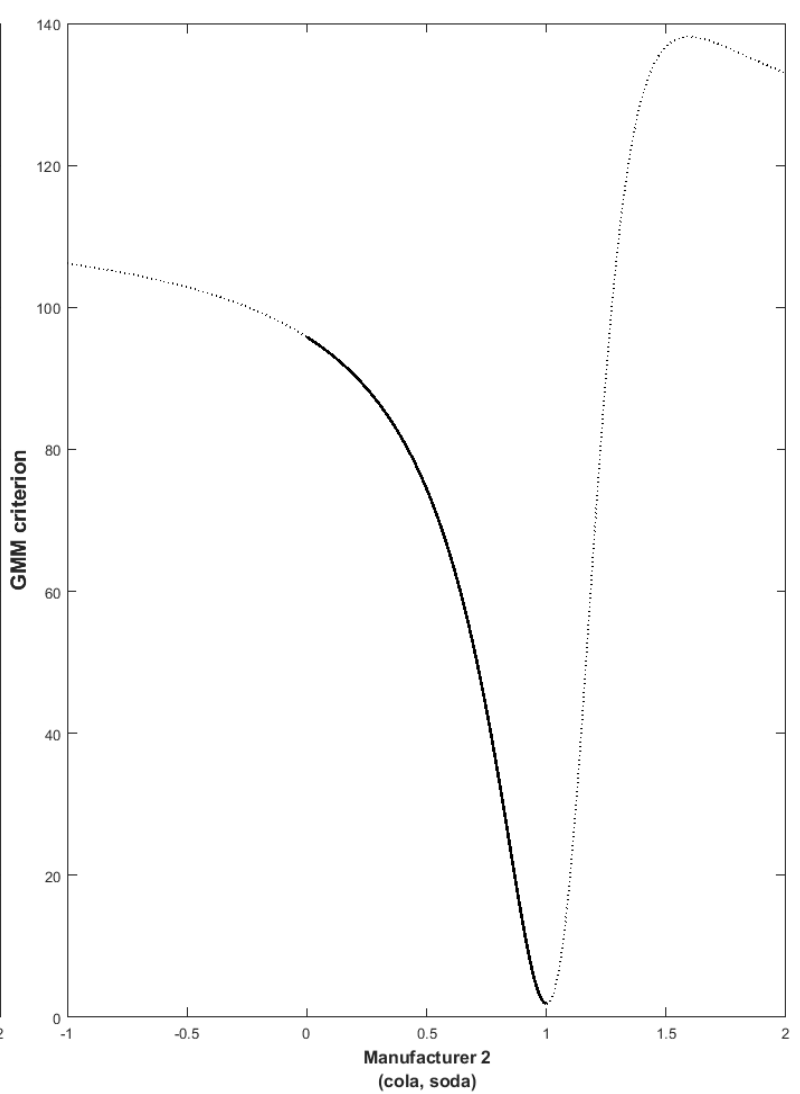

(b) Bargaining weight: Colas and other sodas

Notes: The $x$-axis displays the bargaining weight of retailers vis-à-vis manufacturer 2 for fruit juices or colas/other sodas products. The grid runs over each of these two bargaining weights from -1 to 2 with step-size 0.01 . The $y$-axis depicts values of the GMM criterion. The dotted lines represent the set of all parameter values for which bargaining weights have no economic meaning: $\lambda \notin[0,1]$. Each figure is drawn by keeping all other bargaining weights and cost parameters fixed to their estimated values (see Table 5).

curvature around 0 (Figure 3a) and 1 (Figure 3b) and that alternative values for each bargaining weight yield a higher GMM criterion. These figures thus provide graphical evidence that values other than 0 and 1 for the bargaining weights of retailers vis-à-vis manufacturer 2 would be rejected by the data.

\section{F Equilibrium effects of retail mergers: Theoretical insights}

In this section, we consider a stylized setting of vertical relations in which a monopoly manufacturer, $F$, distributes its product through three retailers labelled by $R_{j}$ with $j=1, \ldots, 3$. Firms operate under constant returns to scale with a unit cost of production and distribution normalized to zero for the sake of exposition. The timing of play follows the two-stage game described in Section 2 . In the first stage, $F$ bargains simultaneously and secretly over wholesale prices with each retailer and, in the second stage, retailers compete in prices on the downstream market. The surplus division between the manufacturer and retailers is determined by the "Nash-in-Nash" bargaining solution and retailers compete on the downstream market with "interim unobservability". To simplify our retail merger analysis, we fix the bargaining weights to 0.5 in each bilateral 


\section{Figure 4: Linear demand specification}

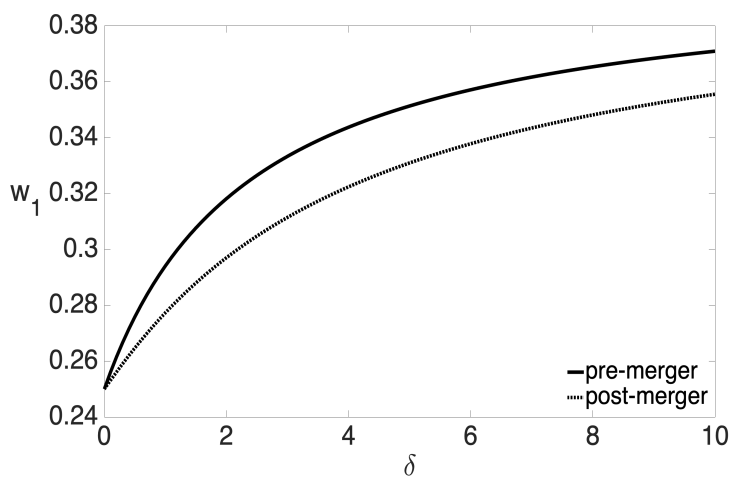

(a) Equilibrium wholesale price
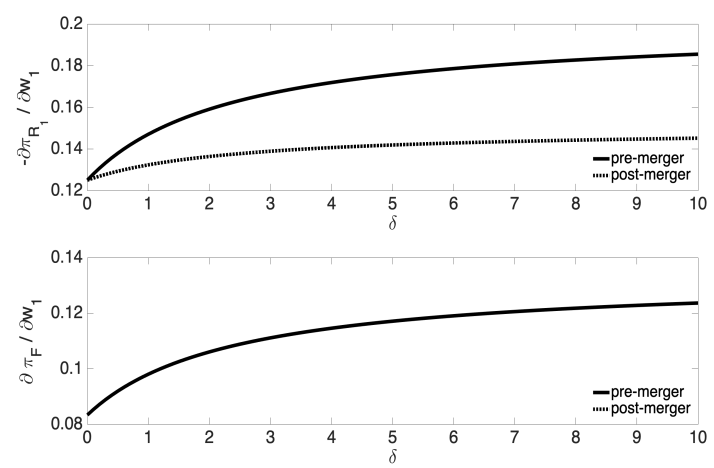

(b) $R_{1}$ 's and F's concession cost

Notes: Figures 4a and 4b are drawn under a linear demand system à la Shubik and Levitan (1980) and a bargaining weight $\lambda$ equals to 0.5 in every bilateral negotiation. The $x$-axis in each figure corresponds to different values of $\delta$ which captures the degree of substitution between retailers. The $y$-axis in Figure 4 a represents the wholesale price paid by $R_{1}$. The $y$-axes in Figure $4 \mathrm{~b}$ represent the concession cost of $R_{1}$ and $F$ evaluated at the pre-merger equilibrium prices: $-\left.\frac{\partial \pi_{R_{1}}}{\partial w_{1}}\right|_{\mathbf{w}=\mathbf{w}^{p r e}}$ and $\left.\frac{\partial \pi_{F}}{\partial w_{1}}\right|_{\substack{\mathbf{w}=\mathbf{w}^{\text {pre }} \\ \mathbf{p}=\mathbf{p}^{\text {pre }}}}$ where $\mathbf{w}=\left(w_{1}, w_{2}, w_{3}\right)^{\top}$ and $\mathbf{p}=\left(p_{1}, p_{2}, p_{3}\right)^{\top}$.

negotiation. Moreover, we consider two possible demand specifications: a linear demand system and a logit demand system.

Linear demand specification. We first consider the effect of a downstream merger between $R_{1}$ and $R_{2}$ on their bargaining power vis-à-vis $F$ under a linear demand system à la Shubik and Levitan (1980). ${ }^{57}$ The demand for retailer $j$ is given by $q_{j}=\frac{3-3(1+\delta) p_{j}+\delta \sum_{k=1}^{3} p_{k}}{9}$ with $\delta \geq 0$ reflecting the degree of substitution between retailers. Figure 4a depicts the pre- and post-merger equilibrium wholesale price $w_{1}$ for different values of $\delta$. It is shown that the merger between $R_{1}$ and $R_{2}$ generates a decrease in $w_{1}$ for any $\delta>0$. This merger effect is in line with Horn and Wolinsky (1988) who instead consider a linear demand à la Singh and Vives (1984). In Figure 4b, we plot the concession cost of $R_{1}$ and $F$ in the pre- and post-merger situation (both evaluated at the pre-merger equilibrium prices) for different values of $\delta$ to gain insight on the mechanism behind this decline in $w_{1}$. While the merger does not affect $F$ 's concession cost, it reduces the concession cost of $R_{1}$ which, in turn, decreases its bargaining power vis-à-vis $F$. As pointed out in the theoretical insights of Section 4, the merger also reduces the gains from trade of $R_{1}$ which reinforces its bargaining power vis-à-vis $F$. Under a linear demand system, Figure 4a thus shows that the latter effect dominates the former which explains why a merger strengthens the bargaining power of the merging retailers. However, the linear demand system implies that $\frac{\partial p_{j}}{\partial w_{k}}=0$ for $\forall j \neq k$ which, in turn, rules out some effects generated by the merger on firms' concession costs. ${ }^{58}$

\footnotetext{
${ }^{57}$ As described in Section 4, we focus on a downstream merger that gives rise to a multi-store retailer (i.e., there is no reduction in product variety). In this illustration, the merged entity thus distributes two products.

${ }^{58}$ For instance, $F$ 's concession cost described in (8a) or the second term of retailer $r$ 's concession cost described in (8b) are never affected by a downstream merger under a linear demand system.
} 


\section{Figure 5: Logit demand specification}

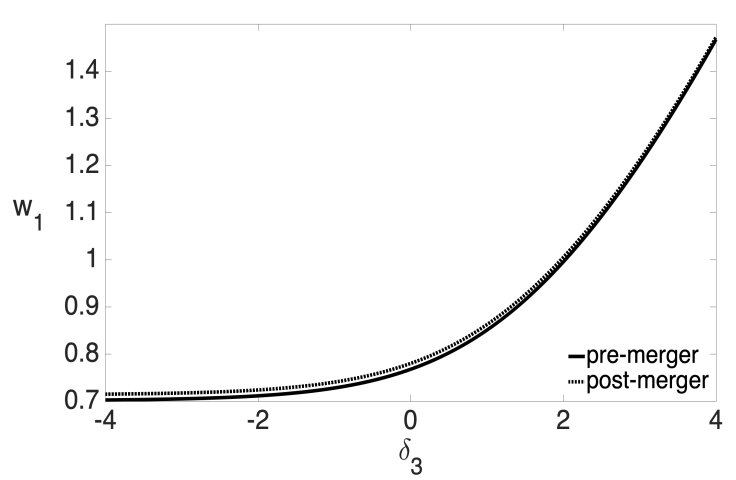

(a) Equilibrium wholesale price
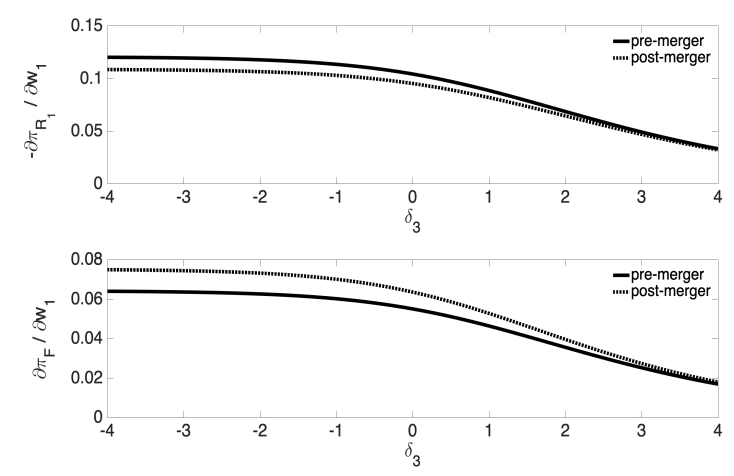

(b) $R_{1}$ 's and F's concession cost

Notes: Figures $5 \mathrm{a}$ and $5 \mathrm{~b}$ are drawn under a logit demand system and a bargaining weight $\lambda$ equals to 0.5 in every bilateral negotiation. The $x$-axis in each figure corresponds to different values of $\delta_{3}$ which captures the consumers' valuation for $R_{3}$. The $y$-axis in Figure 5 a represents the wholesale price paid by $R_{1}$. The $y$-axes in Figure $5 \mathrm{~b}$ represent the concession cost of $R_{1}$ and $F$ evaluated at the pre-merger equilibrium prices: $-\left.\frac{\partial \pi_{R_{1}}}{\partial w_{1}}\right|_{\substack{\mathbf{w}=\mathbf{w}_{\mathbf{p}} \text { pre } \\ \text { pre }}}$ and $\left.\frac{\partial \pi_{F}}{\partial w_{1}}\right|_{\substack{\mathbf{w}=\mathbf{w}^{\text {pre }} \mathbf{p}=\mathbf{p}^{\text {pre }} \\ \text { pre }}}$ where $\mathbf{w}=\left(w_{1}, w_{2}, w_{3}\right)^{\top}$ and $\mathbf{p}=\left(p_{1}, p_{2}, p_{3}\right)^{\top}$.

Logit demand specification. We now consider a logit demand system which does not impose that $\frac{\partial p_{j}}{\partial w_{k}}=0$ for $\forall j \neq k$. The demand for retailer $j$ is given by $q_{j}=\frac{\exp \left(\delta_{3}-p_{j}\right)}{\sum_{k=1}^{3} \exp \left(\delta_{3}-p_{k}\right)} M$ where the market size $M$ is normalized to 1 and $\delta_{3}$ represents a fixed effect for retailer $R_{3}$. In contrast to the linear demand specification, Figure $5 \mathrm{a}$ shows that a merger between $R_{1}$ and $R_{2}$ increases $w_{1}$. This increase is even higher when consumers have a lower valuation for the non-merging retailer $R_{3}\left(\delta_{3}<0\right)$. Hence, the larger are the merging retailers in the pre-merger situation the higher is the wholesale price increase in the post-merger situation. To understand this result, Figure $5 \mathrm{~b}$ depicts the concession cost of $R_{1}$ and $F$ in the pre- and post-merger situation (both evaluated at the pre-merger equilibrium prices) for different values of $\delta_{3}$. As in Figure $4 \mathrm{~b}$, the concession cost of $R_{1}$ decreases with the merger which weakens its bargaining power vis-à-vis $F$. Moreover, the merger increases $F$ 's concession cost to the detriment of $R_{1}$ 's bargaining power. Hence, while the merger reduces $R_{1}$ 's gains from trade with $F$, Figure 5 a shows that the decrease in $R_{1}$ 's concession costs relative to $F$ is the dominant effect. As a result, this illustrative example highlights the importance of accounting for changes in firms' relative concession costs in merger analysis. 


\section{G Additional tables and figures}

\section{G.1 Descriptive statistics}

Table 10: Descriptive statistics for brands

\begin{tabular}{|c|c|c|c|c|c|c|c|c|c|}
\hline & \multicolumn{5}{|c|}{ Brand ownership } & \multicolumn{2}{|c|}{ Market share } & \multicolumn{2}{|c|}{ Retail price } \\
\hline & M1 & M2 & M3 & M4 & $\mathrm{PL}$ & mean & s.d. & mean & s.d. \\
\hline \multicolumn{10}{|l|}{ Colas } \\
\hline Brand 4 & $\bullet$ & $\circ$ & $\circ$ & $\circ$ & $\circ$ & 0.14 & 0.03 & 1.02 & 0.11 \\
\hline Brand 5 & $\bullet$ & $\circ$ & $\circ$ & $\circ$ & $\circ$ & 11.86 & 0.55 & 0.92 & 0.02 \\
\hline Brand 9 & $\circ$ & $\bullet$ & $\circ$ & $\circ$ & $\circ$ & 1.12 & 0.09 & 0.72 & 0.02 \\
\hline PL & $\circ$ & $\circ$ & $\circ$ & $\circ$ & $\bullet$ & 4.12 & 0.15 & 0.30 & 0.01 \\
\hline Total & & & & & & 17.25 & 0.64 & 0.76 & 0.01 \\
\hline \multicolumn{10}{|l|}{ Other sodas } \\
\hline Brand 3 & $\bullet$ & $\circ$ & $\circ$ & $\circ$ & $\circ$ & 0.39 & 0.02 & 0.78 & 0.01 \\
\hline Brand 6 & $\bullet$ & ○ & $\circ$ & $\circ$ & $\circ$ & 1.20 & 0.10 & 0.95 & 0.05 \\
\hline Brand 8 & $\circ$ & $\bullet$ & $\circ$ & $\circ$ & $\circ$ & 0.08 & 0.03 & 0.80 & 0.03 \\
\hline Brand 10 & $\circ$ & $\bullet$ & $\circ$ & $\circ$ & $\circ$ & 0.37 & 0.08 & 0.75 & 0.02 \\
\hline Brand 14 & $\circ$ & $\circ$ & $\circ$ & $\bullet$ & $\circ$ & 1.71 & 0.11 & 0.89 & 0.05 \\
\hline Brand 15 & $\circ$ & $\circ$ & $\circ$ & $\bullet$ & $\circ$ & 1.75 & 0.20 & 1.03 & 0.02 \\
\hline Brand 17 & $\circ$ & $\circ$ & $\circ$ & $\bullet$ & $\circ$ & 2.21 & 0.41 & 1.11 & 0.02 \\
\hline Brand 18 & $\circ$ & ० & $\circ$ & $\bullet$ & $\circ$ & 0.77 & 0.07 & 1.14 & 0.02 \\
\hline Brand 19 & $\circ$ & $\circ$ & $\circ$ & $\bullet$ & $\circ$ & 0.09 & 0.01 & 1.00 & 0.02 \\
\hline Brand 20 & $\circ$ & $\circ$ & $\circ$ & $\bullet$ & $\circ$ & 0.13 & 0.02 & 3.50 & 0.03 \\
\hline Brand 21 & $\circ$ & ० & $\circ$ & $\bullet$ & $\circ$ & 0.02 & 0.01 & 0.75 & 0.01 \\
\hline PL & $\circ$ & $\circ$ & $\circ$ & $\circ$ & $\bullet$ & 7.36 & 0.46 & 0.39 & 0.01 \\
\hline Total & & & & & & 16.05 & 1.17 & 0.74 & 0.01 \\
\hline \multicolumn{10}{|l|}{ Fruit juices } \\
\hline Brand 1 & $\bullet$ & $\circ$ & $\circ$ & $\circ$ & $\circ$ & 0.26 & 0.07 & 1.78 & 0.11 \\
\hline Brand 7 & $\bullet$ & $\circ$ & $\circ$ & $\circ$ & $\circ$ & 0.31 & 0.16 & 1.48 & 0.07 \\
\hline Brand 11 & $\circ$ & $\bullet$ & $\circ$ & $\circ$ & $\circ$ & 3.36 & 0.21 & 2.19 & 0.04 \\
\hline Brand 16 & $\circ$ & $\circ$ & ० & $\bullet$ & $\circ$ & 0.84 & 0.10 & 1.79 & 0.03 \\
\hline PL & ० & ० & ० & ० & $\bullet$ & 29.83 & 1.92 & 0.84 & 0.01 \\
\hline Total & & & & & & 34.60 & 2.10 & 1.01 & 0.02 \\
\hline \multicolumn{10}{|l|}{ Iced tea } \\
\hline Brand 2 & $\bullet$ & $\circ$ & $\circ$ & $\circ$ & $\circ$ & 0.22 & 0.06 & 0.93 & 0.03 \\
\hline Brand 12 & $\circ$ & $\circ$ & $\bullet$ & $\circ$ & $\circ$ & 1.95 & 0.35 & 1.08 & 0.02 \\
\hline Brand 13 & $\circ$ & $\circ$ & $\bullet$ & $\circ$ & $\circ$ & 0.12 & 0.05 & 1.32 & 0.08 \\
\hline PL & $\circ$ & $\circ$ & $\circ$ & $\circ$ & $\bullet$ & 2.32 & 0.37 & 0.52 & 0.01 \\
\hline Total & & & & & & 4.61 & 0.79 & 0.79 & 0.02 \\
\hline Outside good & & & & & & 27.49 & 0.81 & & \\
\hline
\end{tabular}

Notes: $N=265,998$. "M1", "M2", "M3" and "M4" refer respectively to manufacturers 1, 2, 3, and 4 and "PL" stands for private label. Filled circles represent the brand ownership of each manufacturer. Market shares are in number of household purchases and standard deviation refer to variation across months. Retail prices in euro per liter are calculated using quantity weights and standard deviation refer to variation across months. Remark that we are not permitted to reveal names of the brands, manufacturers and retailers due to confidentiality regarding Kantar WorldPanel data. 


\section{H Demand results}

Table 11: First-stage of the control function approach

\begin{tabular}{lrc}
\hline \hline Variable & Coefficient & SE \\
\hline Sugar content $\times$ Sugar price & 0.0005 & 0.0012 \\
Canned rate $\times$ Aluminium price & $0.0037^{*}$ & 0.0004 \\
Number of competing products & $-0.9334^{*}$ & 0.0016 \\
Retailer fixed effects (not shown) & & \\
Brand fixed effects (not shown) & \\
F-statistic & \\
$\quad$ Excluded instruments & 22.62 \\
& \\
$R^{2}$ adjusted & 0.99 \\
Number of observations & \multicolumn{2}{c}{919} \\
\hline \hline * indicates significance at the 5\% level. & Heteroskedasticity-robust \\
standard errors. &
\end{tabular}

Figure 6: Distribution of the retail price sensitivity across consumers
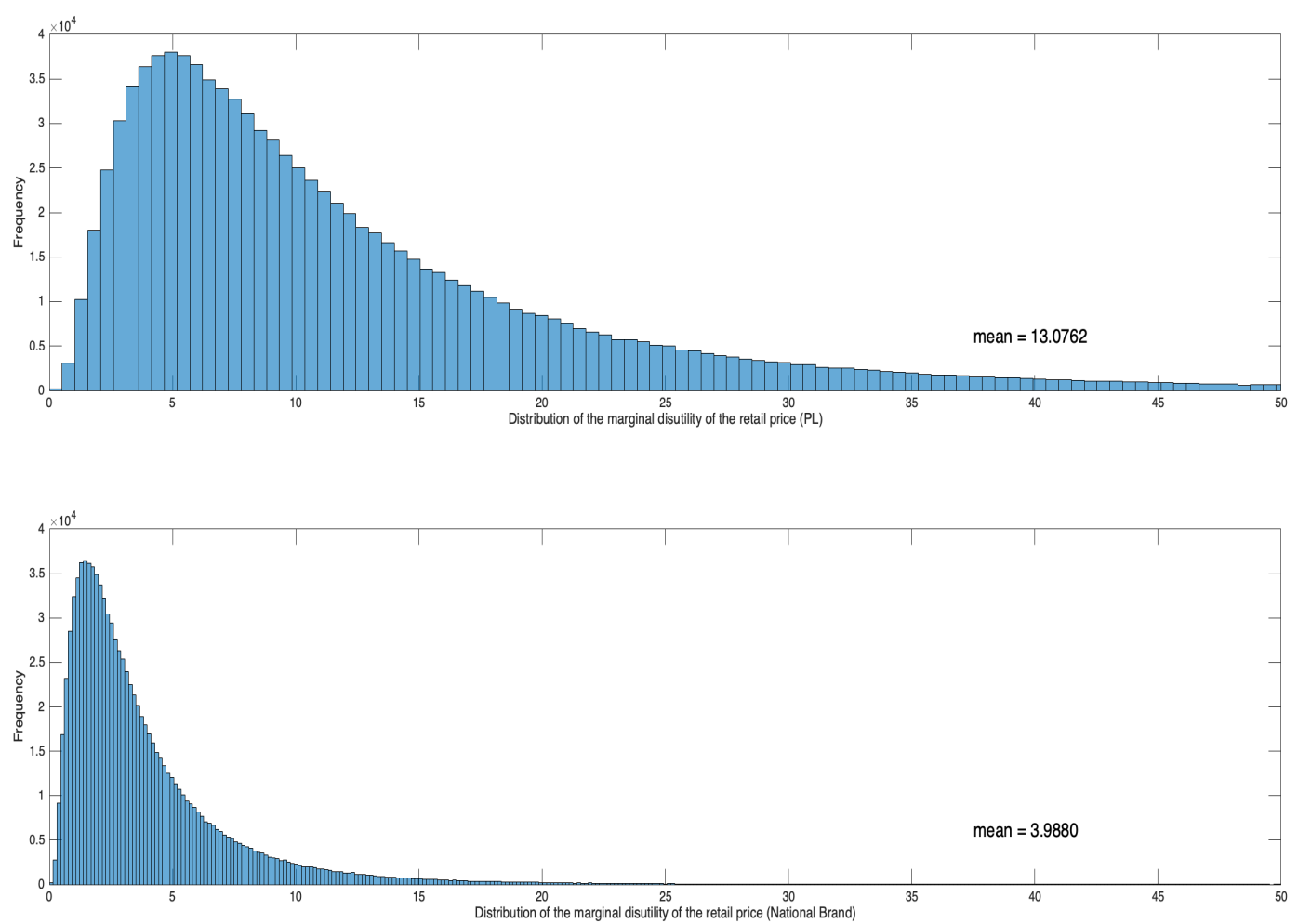


\section{H.1 Retail mergers analysis}

Table 12: The retail merger effects on firms' fear of disagreement

\begin{tabular}{|c|c|c|}
\hline Variable & Coefficient & S.E. \\
\hline Intercept & $0.673^{*}$ & 0.003 \\
\hline \multicolumn{3}{|l|}{ Retail merger fixed effects: } \\
\hline Merger between retailers 1 and 2 & $0.025^{*}$ & 0.003 \\
\hline Merger between retailers 1 and 3 & $0.036^{*}$ & 0.003 \\
\hline Merger between retailers 1 and 4 & -0.001 & 0.002 \\
\hline Merger between retailers 1 and 5 & $0.017^{*}$ & 0.003 \\
\hline Merger between retailers 1 and 6 & ref. & ref. \\
\hline Merger between retailers 1 and 7 & $0.053^{*}$ & 0.004 \\
\hline Merger between retailers 2 and 3 & $0.070^{*}$ & 0.002 \\
\hline Merger between retailers 2 and 4 & $0.039^{*}$ & 0.002 \\
\hline Merger between retailers 2 and 5 & $0.044^{*}$ & 0.002 \\
\hline Merger between retailers 2 and 6 & $0.040^{*}$ & 0.002 \\
\hline Merger between retailers 2 and 7 & $0.086^{*}$ & 0.003 \\
\hline Merger between retailers 3 and 4 & $0.049^{*}$ & 0.003 \\
\hline Merger between retailers 3 and 5 & $0.049^{*}$ & 0.002 \\
\hline Merger between retailers 3 and 6 & $0.050^{*}$ & 0.003 \\
\hline Merger between retailers 3 and 7 & $0.094^{*}$ & 0.002 \\
\hline Merger between retailers 4 and 5 & $0.028^{*}$ & 0.002 \\
\hline Merger between retailers 4 and 6 & $0.016^{*}$ & 0.002 \\
\hline Merger between retailers 4 and 7 & $0.066^{*}$ & 0.004 \\
\hline Merger between retailers 5 and 6 & $0.027^{*}$ & 0.002 \\
\hline Merger between retailers 5 and 7 & $0.060^{*}$ & 0.003 \\
\hline Merger between retailers 6 and 7 & $0.067^{*}$ & 0.004 \\
\hline \multicolumn{3}{|c|}{$\begin{array}{l}\text { Manufacturer-category fixed effects (not shown) } \\
\text { Market fixed effects (not shown) }\end{array}$} \\
\hline$R^{2}$ adjusted & \multicolumn{2}{|l|}{0.848} \\
\hline Number of observations & \multicolumn{2}{|l|}{3,546} \\
\hline \multicolumn{3}{|c|}{$\begin{array}{l}\text { Notes: OLS estimates. Heteroskedasticity-robust standard errors. * indi } \\
\text { cates significance at the } 5 \% \text { level. Boldfaced rows indicate mergers that we } \\
\text { simulate (see Table 9). As in Table } 8 \text {, the dependent variable corresponds } \\
\text { to the ratio of firms' fear of disagreement following a downstream merger } \\
\text { and evaluated at the equilibrium prices of the baseline model. }\end{array}$} \\
\hline
\end{tabular}




\section{References}

Aumann, Robert J., and Mordecai Kurz. 1977. "Power and Taxes." Econometrica, 45(5): 1137-1161.

Berry, Steven T. 1994. "Estimating Discrete-Choice Models of Product Differentiation." RAND Journal of Economics, 25(2): 242-262.

Berry, Steven T., and Philip Haile. 2014. "Identification in Differentiated Products Markets Using Market Level Data.” Econometrica, 82(5): 1749-1797.

Berry, Steven T., James Levinsohn, and Ariel Pakes. 1995. "Automobile Prices in Market Equilibrium." Econometrica, 63(4): 841-890.

Bhat, Chandra R. 2001. "Quasi-random maximum simulated likelihood estimation of the mixed multinomial logit model." Transportation Research Part B, 35(7): 677-693.

Binmore, Kenneth George, Ariel Rubinstein, and Asher Wolinsky. 1986. "The Nash Bargaining Solution in Economic Modelling." RAND Journal of Economics, 17(2): 176-188.

Blundell, Richard, and Rosa L. Matzkin. 2014. "Control functions in nonseparable simultaneous equations models." Quantitative Economics, 5(2): 271-295.

Bonnet, Céline, and Vincent Réquillart. 2013a. "Impact of Cost Shocks on Consumer Prices in Vertically-Related Markets: The Case of The French Soft Drink Market." American Journal of Agricultural Economics, 95(5): 1088-1108.

Bonnet, Céline, and Vincent Réquillart. 2013b. "Tax incidence with strategic firms in the soft drink market." Journal of Public Economics, 106: 77-88.

Carlton, Dennis W., and Mark Israel. 2011. "Proper Treatment of Buyer Power in Merger Review." Review of Industrial Organization, 39(1/2): 127-136.

Chipty, Tasneem, and Christopher M. Snyder. 1999. "The Role of Firm Size in Bilateral Bargaining: A Study of the Cable Television Industry." Review of Economics and Statistics, 81(2): 326-340.

Chorniy, Anna, Daniel Miller, and Tilan Tang. 2020. "Mergers in Medicare Part D: Assessing market power, cost efficiencies, and bargaining power." International Journal of Industrial Organization, 68: 102548.

Colen, Liesbeth, Zohra Bouamra-Mechemache, Victoria Daskalova, and Kjersti Nes. 2020. "Retail alliances in the agricultural and food supply chain." EUR 30206 EN, European Commission, ISBN 978-92-76-18585-7, doi:10.2760/33720, JRC120271.

Collard-Wexler, Allan, Gautam Gowrisankaran, and Robin S. Lee. 2019. "'Nash-inNash" Bargaining: A Microfoundation for Applied Work." Journal of Political Economy, 127(1): 163-195. 
Craig, Stuart V., Matthew Grennan, and Ashley Swanson. 2021. "Mergers and Marginal Costs: New Evidence on Hospital Buyer Power." RAND Journal of Economics, 52(1): 151178.

Crawford, Gregory S., and Ali Yurukoglu. 2012. "The Welfare Effects of Bundling in Multichannel Television Markets." American Economic Review, 102: 643-685.

Crawford, Gregory S., Nicola Pavanini, and Fabiano Schivardi. 2018. "Asymmetric Information and Imperfect Competition in Lending Markets." American Economics Review, 108(7): 1659-1701.

Crawford, Gregory S., Robin S. Lee, Michael D. Whinston, and Ali Yurukoglu. 2018. "The Welfare Effects of Vertical Integration in Multichannel Television Markets." Econometrica, 86(3): 891-954.

Crémer, Jacques, and Michael H. Riordan. 1987. "On Governing Multilateral Transactions with Bilateral Contracts." RAND Journal of Economics, 18(3): 436-451.

Dana, James D. 2012. "Buyer groups as strategic commitments." Games and Economic Behavior, 74(2): 470-485.

Davis, Peter. 2002. "Estimating multi-way error components models with unbalanced data structures." Journal of Econometrics, 106(1): 67-95.

de Fontenay, Catherine C., and Joshua S. Gans. 2014. "Bilateral Bargaining with Externalities." Journal of Industrial Economics, 62(4): 756-788.

Deneckere, Raymond, and Carl Davidson. 1985. "Incentives to Form Coalitations with Bertrand Competition." RAND Journal of Economics, 16(4): 473-486.

Dobson, Paul W., and Michael Waterson. 1997. "Countervalling Power and Consumer Prices." Economic Journal, 107(441): 418-430.

Draganska, Michaela, Daniel Klapper, and Sofia Berto Villas-Boas. 2010. "A Larger Slice or a Larger Pie? An Empirical Investigation of Bargaining Power in the Distribution Channel." Marketing Science, 29(1): 57-74.

Dubé, Jean-Pierre. 2004. "Multiple Discreteness and Product Differentiation: Demand for Carbonated Soft Drinks." Marketing Science, 23(1): 66-81.

Dubois, Pierre, Rachel Griffith, and Martin O'Connell. 2018. "The Effects of Banning Advertising in Junk Food Markets." Review of Economic Studies, 85(1): 396-436.

Dubois, Pierre, Rachel Griffith, and Martin O'Connell. 2020. "How Well Targeted Are Soda Taxes?" American Economic Review, 110(10): 3661-3704.

Easterbrook, Kathleen F., Gautam Gowrisankaran, Dina Older Aguilar, and Yufei Wu. 2019. "Accounting For Complementarities in Hospital Mergers: Is a Substitute Needed For Current Approaches?" Antitrust Law Journal, 89(2): 497-531. 
Erdem, Tülin, Michael P. Keane, and Baohong Sun. 2008. "The impact of advertising on consumer price sensitivity in experience goods markets." Quantitative Marketing and Economics, 6(2): 139-176.

Ershov, Daniel, Jean-William Laliberté, Mathieu Marcoux, and Scott Orr. 2021. "Estimating Complementarity With Large Choice Sets: An Application to Mergers." Unpublished. Available at: https://papers.ssrn.com/sol3/papers.cfm?abstract_ $i d=3802097$.

European Commission. 2007. "Competitiveness of the European Food Industry - An economic and legal assessment."

European Commission. 2014. "The economic impact of modern retail on choice and innovation in the EU food sector."

Galbraith, John Kenneth. 1952. American Capitalism: The Concept of Countervailing Power. Houghton Mifflin.

Galbraith, John Kenneth. 1954. "Countervailing Power." American Economic Review: Papers and Proceedings, 44(2): 1-6.

Gandhi, Amit, and Jean-François Houde. 2020. "Measuring Substitution Patterns in Differentiated Products Industries." Unpublished. Available at: https://www.dropbox. com/s/98h94s7rasvnnnr/GH_submission_ecma.pdf?dl=0.

Gaudin, Germain. 2018. "Vertical Bargaining and Retail Competition: What Drives Countervailing Power?" Economic Journal, 128(614): 2380-2413.

Gaudin, Germain. 2019. "Vertical relations, opportunism, and welfare." RAND Journal of Economics, 50(2): 342-358.

Gaynor, Martin, Katherine Ho, and Robert J. Town. 2015. "The Industrial Organization of Health-Care Markets." Journal of Economic Literature, 53(2): 235-284.

Gowrisankaran, Gautam, Aviv Nevo, and Robert J. Town. 2015. "Mergers When Prices Are Negotiated: Evidence from the Hospital Industry." American Economic Review, 105(1): 172-203.

Grennan, Matthew. 2013. "Price Discrimination and Bargaining: Empirical Evidence from Medical Devices." American Economic Review, 103(1): 145-177.

Hansen, Lars Peter. 1982. "Large Sample Properties of Generalized Method of Moments Estimators." Econometrica, 50(4): 1029-1054.

Hansen, Lars Peter, John Heaton, and Amir Yaron. 1996. "Finite-Sample Properties of Some Alternative GMM Estimators." Journal of Business \& Economic Statistics, 14(3): 262280.

Harsanyi, John C. 1956. "Approaches to the Bargaining Problem Before and After the Theory of Games: A Critical Discussion of Zeuthen's, Hicks', and Nash's Theories." Econometrica, 24(2): 144-157. 
Harsanyi, John C. 1977. Rational Behaviour and Bargaining Equilibrium in Games and Social Situations. Cambridge University Press.

Hausman, Jerry A. 1996. "Valuation of New Goods under Perfect and Imperfect Competition." In The Economics of New Goods. Vol. 58, , ed. Timothy Bresnahan and R. Gordon, 207-248. National Bureau of Economic Research, Inc.

Hausman, Jerry A., and Whitney K. Newey. 2016. "Individual Heterogeneity and Average Welfare." Econometrica, 84(3): 1225-1248.

Hemphill, C. Scott, and Nancy L. Rose. 2018. "Mergers that Harm Sellers." Yale Law Journal, 127(7): 2078-2109.

Ho, Katherine, and Robin S. Lee. 2017. "Insurer Competition in Health Care Markets." Econometrica, 85(2): 379-417.

Horn, Henrik, and Asher Wolinsky. 1988. "Bilateral Monopolies and Incentives for Merger." RAND Journal of Economics, 19(3): 408-419.

Inderst, Roman, and Christian Wey. 2003. "Bargaining, Mergers, and Technology Choice in Bilaterally Oligopolistic Industries." RAND Journal of Economics, 34(1): 1-19.

Inderst, Roman, and Greg Shaffer. 2007. "Retail Mergers, Buyer Power and Product Variety." Economic Journal, 117(516): 45-67.

Iozzi, Alberto, and Tommaso Valletti. 2014. "Vertical Bargaining and Countervailing Power." American Economic Journal: Microeconomics, 6(3): 106-135.

Karaca-Mandic, Pinar, and Kenneth Train. 2003. "Standard error correction in two-stage estimation with nested samples." Econometrics Journal, 6(2): 401-407.

Kiser, Elizabeth K. 1998. "Heterogeneity in Price Sensitivity and Retail Price Discrimination." American Journal of Agricultural Economics, 80(5): 1150-1153.

Lee, Lung-fei. 1995. "Asymptotic Bias in Simulated Maximum Likelihood Estimation of Discrete Choice Models." Econometric Theory, 11(3): 437-483.

Luco, Fernando, and Guillermo Marshall. 2020. "The Competitive Impact of Vertical Integration by Multiproduct Firms." American Economic Review, 110(7): 2041-2064.

McAfee, R. Preston, and Marius Schwartz. 1994. "Opportunism in Multilateral Vertical Contracting: Nondiscrimination, Exclusivity, and Uniformity." American Economic Review, 84(1): 210-230.

McFadden, Daniel. 1974. "Conditional logit analysis of qualitative choice behavior." Frontiers in Econometrics, Chapter 4, 105-142. Academic Press: New York.

Michel, Christian, and Stefan Weiergraeber. 2018. "Estimating Industry Conduct in Differentiated Products Markets." Unpublished. Available at: http://christianmichel. net/wp-content/uploads/2018/11/conduct_cereal .pdf. 
Miller, Nathan H., and Matthew C. Weinberg. 2017. "Understanding the Price Effects of the MillerCoors Joint Venture." Econometrica, 85(6): 1763-1791.

Molina, Hugo. 2021. "Buyer Alliances in Vertical Related Markets." Unpublished. Available at: https://papers.ssrn.com/sol3/papers.cfm?abstract_id=3452497.

Mortimer, Julie Holland. 2008. "Vertical Contracts in the Video Rental Industry." Review of Economic Studies, 75(1): 165-199.

Nash, John F. 1950. “The Bargaining Problem.” Econometrica, 18(2): 155-162.

Nevo, Aviv. 2001. "Measuring Market Power in the Ready-to-Eat Cereal Industry." Econometrica, 69(2): 307-342.

Noton, Carlos, and Andrés Elberg. 2018. "Are Supermarket Squeezing Small Suppliers? Evidence from Negotiated Wholesale Prices." Economic Journal, 128(610): 1304-1330.

O’Brien, Daniel P., and Greg Shaffer. 1992. "Vertical Control with Bilateral Contracts." RAND Journal of Economics, 23(3): 299-308.

Petrin, Amil, and Kenneth Train. 2010. "A Control Function Approach to Endogeneity in Consumer Choice Models." Journal of Marketing Research, 47(1): 3-13.

Rey, Patrick, and Jean Tirole. 1986. "The Logic of Vertical Restraints." American Economic Review, 76(5): 921-939.

Rey, Patrick, and Thibaud Vergé. 2004. "Bilateral control with vertical contracts." RAND Journal of Economics, 35(4): 728-746.

Rey, Patrick, and Thibaud Vergé. 2020. "Secret contracting in multilateral relations." Unpublished. Available at: https://www.tse-fr.eu/sites/default/files/TSE/ documents/doc/by/rey/744_version2020.pdf.

Roth, Alvin E. 1979. Axiomatic Models of Bargaining. Vol. 170 of Lecture Notes in Economics and Mathematical Systems, Springer-Verlag Berlin Heidelberg.

Sheu, Gloria, and Charles Taragin. 2021. "Simulating Mergers in a Vertical Supply Chain with Bargaining." RAND Journal of Economics, 52(3): 596-632.

Shubik, Martin, and Richard Levitan. 1980. Market Structure and Behavior. Harvard University Press.

Singh, Nirvikar, and Xavier Vives. 1984. "Price and Quantity Competition in a Differentiated Duopoly." RAND Journal of Economics, 15(4): 546-554.

Smith, Howard. 2016. "The Economic of Retailer-Supplier Pricing Relationships: Theory and Evidence." In Handbook on the Economics of Retailing and Distribution. Edward Elgar Publishing Limited.

Smith, Howard, and John Thanassoulis. 2015. "Prices, Profits, and Pass-Through of Costs Along A Supermarket Supply Chain: Bargaining and Competition." Oxford Review of Economic Policy, 31(1): 64-89. 
Snyder, Christopher M. 2008. "Countervailing Power." In The New Palgrave Dictionary of Economics. 1-3. Palgrave Macmillan UK.

Stole, Lars A., and Jeffrey Zwiebel. 1996. "Intra-firm Bargaining under Non-binding Contracts." Review of Economic Studies, 63(3): 375-410.

Svejnar, Jan. 1986. "Bargaining Power, Fear of Disagreement, and Wage Settlements: Theory and Evidence from U.S. Industry." Econometrica, 54(5): 1055-1078.

Thomassen, Øyvind, Howard Smith, Stephan Seiler, and Pascale Schiraldi. 2017. "Multi-Category Competition and Market Power: A Model of Supermarket Pricing." American Economic Review, 107(8): 2308-2351.

Train, Kenneth. 2000. "Halton Sequences for Mixed Logit." Department of Economics, UCB.

Train, Kenneth. 2009. Discrete Choice Methods with Simulation. . Second ed., Cambridge University Press.

Villas-Boas, Sofia Berto. 2007. "Vertical Relationships between Manufacturers and Retailers: Inference with Limited Data." Review of Economic Studies, 74(2): 625-652.

Williamson, Oliver E. 1968. "Economies as an Antitrust Defense: The Welfare Tradeoffs." American Economic Review, 58(1): 18-36.

Yang, Chenyu. 2020. "Vertical structure and innovation: A study of the SoC and smartphone industries." RAND Journal of Economics, 51(3): 739-785. 